This dissertation has been microtilmed exactly as received

$67-6306$

DAHM, Donald Bruce, 1938-

AN INVESTIGATION OF THE GAS-PHASE REACTION OF n-PENTANE WITH OXYGEN IN THE LOW-TEMPERATURE REGION USING A CHEMICAL SHOCK TUBE.

The Ohio State University, Ph.D., 1966

Chemistry, physical

University Microfilms, Inc., Ann Arbor, Michigan 


\title{
AN INVESTIGATION OF THE GAS-PHASE REACTION \\ OF n-PENTANE WITH OXYGEN IN THE LOW- \\ TEMPERATURE REGION USING A \\ CHEMICAL SHOCK TUBE
}

\author{
DISSERTATION \\ Presented in Partial Fulfillment of the Requirements \\ for the Degree Doctor of Philosophy in the \\ Graduate School of The Ohio State \\ University
}

By

Donald Bruce Dahm, B. S., M. S.

$* * * * * * * * *$

The OhIo State UnIversity

1966

Approved by:

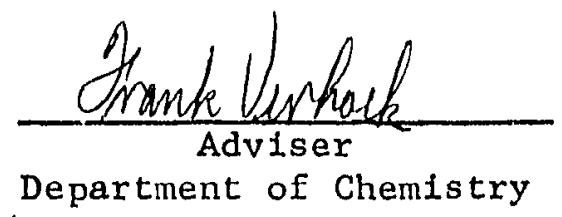




\section{Acknowledgements}

I wish to express my deep appreciation to Professor Frank Verhoek for suggesting this research problem and for his invaluable help, patience and encouragement throughout this work.

I would also like to acknowledge the assistance of the many technicians in the Department of Chemistry who gave so unselfishly of their time, advice and services on various aspects of this research problem.

To my wife, my sincere thanks is expressed for her encouragement, patience and understanding during my stay at the university. Appreciation is also expressed to the National Science Foundation for supporting Mr. Phillip Borer as an Undergraduate Research participant during the summer of 1966. His technical assistance was invaluable during the final portion of this work.

The financial aid of The Petroleum Research Fund of the American Chemical Society for a research assistantship and other support through The Ohio State University Research Foundation Project No. 1130 during a portion of the work is also gratefully acknowledged. 
August 15, $1938 \ldots \ldots$ Born-Fargo, North Dakota

1959 ................ S., Chemistry, North Dakota State University, Fargo, North Dakota

1961 ................... S., Physical Chemistry, South Dakota State University, Brookings, South Dakota

196I-1966

Sept. 1961-June 1962 .. Teaching Assistant, The Ohio State University, Columbus, Ohio

June 1962-April 1963 .. American Chemical Society Petroleum Research Fund Fellow, The Ohio State University, Columbus, Ohio

April 1963-Sept. 1963 . Senior Research Engineer, Martins Company, Baltimore, Maryland

Sept. 1963-Dec. 1964 .. American Chemical Society Petroleum Research Fund Fellow, The Ohio State University, Columbus, Ohio

Dec. 1964-June 1965 ... Teaching Assistant, The Ohio State University, Columbus, Ohio

June 1965-Sept. 1965 .. American Chemical Society Petroleum Research Fund Fellow, The Ohio State University, Columbus, Ohio

Sept. 1965- Dec. 1966 . Teaching Assistant, The Ohio State University, Columbus, Ohio

FIELDS OF STUDY

Major Field: Physical Chemistry

Studies in Chemical Kinetics. Professors Frank H. Verhoek and Jack G. Calvert

Studies in Quantum Mechanics. Professor Edwin N. Lassettre

Studies in Thermodynamics. Professors George E. MacWood and David White 
TABLE OF CONTENTS

INTRODUCTION $\ldots \ldots \ldots \ldots \ldots \ldots \ldots \ldots \ldots \ldots \ldots \ldots \ldots \ldots \ldots \ldots \ldots$

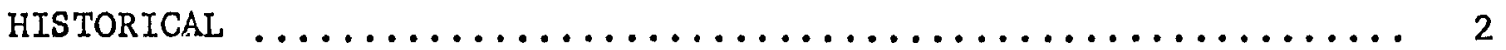

SHOCK TUBE THEORY $\ldots \ldots \ldots \ldots \ldots \ldots \ldots \ldots \ldots \ldots \ldots \ldots \ldots \ldots$

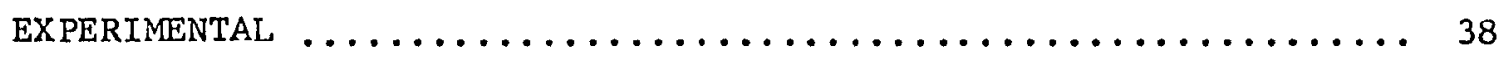

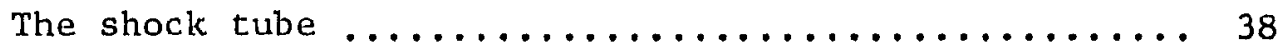

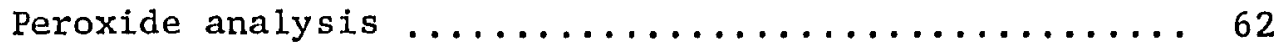

Stability of 3-pentane hydroperoxide in the reaction section of the shock tube ....... 70

Materials .............................. 71

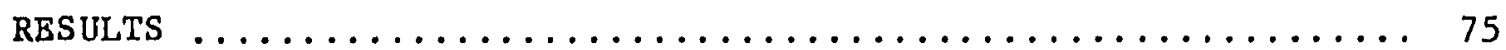

Acetaldehyde addition experiments ............. 105

Tertiary butylhydroperoxide addition experiments .... 112

Analysis of products other than peroxides ........ 113

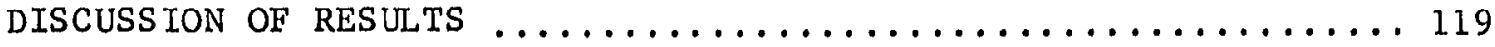

SUGGESTIONS FOR FURTHER WORK .................... 154

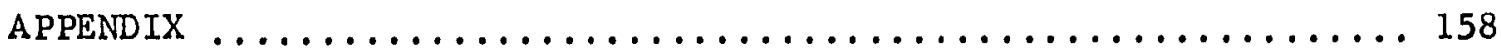

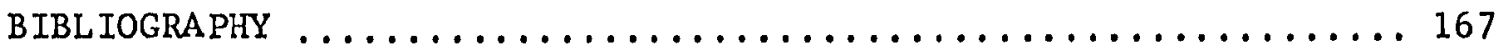


Figure 1. A comparison of some working parameters of common methods for studying fast chemical reactions ............. 15

Figure 2. The simple shock tube $\ldots \ldots \ldots \ldots \ldots \ldots \ldots \ldots \ldots \ldots$

Figure 3. A distance-time diagram showing the waves and states when the diaphragm is ruptured in a shock tube ................ 18

Figure 4 . The chemical shock tube .................. 20

Figure 5. Relationship of $\mathrm{P}_{41}$ and $\mathrm{P}_{21}$ for HeliumArgon mixtures and pure Helium............. 24

Figure 6. Relationship of $P_{41}$ and $P_{21}$ for HeliumArgon mixtures and pure Helium............. 25

Figure 7. Oscilloscope trace of shock wave at

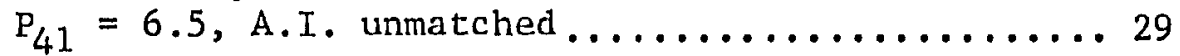

Figure 8. Oscilloscope trace of shock wave at $\mathrm{P}_{41}=6.5$, "Tailored-Interface"........... 29

Figure 9. Relationship of $\mathrm{P}_{21}$ and weight percent

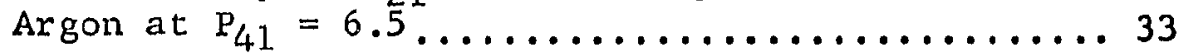

Figure 10. Acoustic impedance calculation for

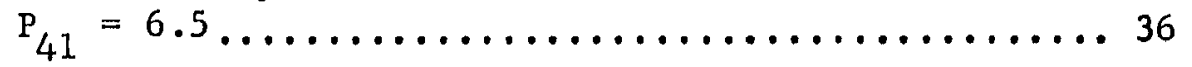

Figure 11. Modified apparatus for scoring diaphragms ........................ 41

Figure 12. DC power supply and trigger circuit.......... 44

Figure 13. Block diagram of electronic circuitry ..........46

Figure 14. Vacuum system for transferring gases to and from reaction and buffer sections of

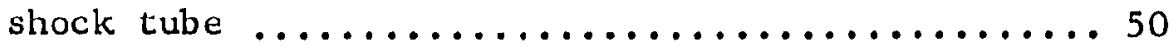

Figure 15. Calibrated septum sample bulb and mercury-leveling device 
Figure 16. Peroxide formation at $298^{\circ} \mathrm{C} \ldots \ldots \ldots \ldots \ldots \ldots$

Figure 17. Peroxide formation at $327^{\circ} \mathrm{C}$ and a

reaction time of 1.6 msec $\ldots \ldots \ldots \ldots \ldots \ldots \ldots \ldots . \ldots 4$

Figure 18. Peroxide formation at $327^{\circ} \mathrm{C}$ and a

reaction time of $1.9 \mathrm{msec} \ldots \ldots \ldots \ldots \ldots \ldots \ldots \ldots . \ldots 5$

Figure 19. Peroxide formation at $327^{\circ} \mathrm{C}$ and a

reaction time of $2.3 \mathrm{msec} \ldots \ldots \ldots \ldots \ldots \ldots \ldots . \ldots 86$

Figure 20. Peroxide formation at $327^{\circ} \mathrm{C}$ and a

reaction time of $2.4 \mathrm{msec} \ldots \ldots \ldots \ldots \ldots \ldots \ldots . \ldots 7$

Figure 21. Peroxide formation at $327^{\circ} \mathrm{C}$ and a

reaction time of $2.5 \mathrm{msec} \ldots \ldots \ldots \ldots \ldots \ldots \ldots 8$

Figure 22. Peroxide formation at $403^{\circ} \mathrm{C}$ and a

reaction time of $1.3 \mathrm{msec} \ldots \ldots \ldots \ldots \ldots \ldots . \ldots 90$

Figure 23. Peroxide formation at $403^{\circ} \mathrm{C}$ and a

reaction time of $1.5 \mathrm{msec} \ldots \ldots \ldots \ldots \ldots \ldots \ldots . \ldots 1$

Figure 24. Peroxide formation at $403^{\circ} \mathrm{C}$ and $a$

reaction time of $1.7 \mathrm{msec} \ldots \ldots \ldots \ldots \ldots \ldots \ldots . \ldots 92$

Figure 25. Peroxide formation at $435^{\circ} \mathrm{C}$ and a

reaction time of $1.4 \mathrm{msec} \ldots \ldots \ldots \ldots \ldots \ldots . \ldots 94$

Figure 26. Peroxide formation at $435^{\circ} \mathrm{C}$ and a

reaction time of $1.6 \mathrm{msec} \ldots \ldots \ldots \ldots \ldots \ldots \ldots$

Figure 27. Peroxide formation at $435^{\circ} \mathrm{C}$ and a

reaction time of $1.8 \mathrm{msec} \ldots \ldots \ldots \ldots \ldots \ldots \ldots . \ldots 6$

Figure 28, Peroxide formation at $298^{\circ} \mathrm{C} \ldots \ldots \ldots \ldots \ldots . \ldots 9$

Figure 29. Peroxide formation at $327^{\circ}$ c .............. 99

Figure 30. Peroxide formation at $403^{\circ}$ C .............. 100

Figure 31. Peroxide formation at $435^{\circ}$ c $\ldots \ldots \ldots \ldots \ldots 101$

Figure 32. Peroxide formation as a function of time

at various temperatures ................ 102

Figure 33. Peroxide formation as a function of

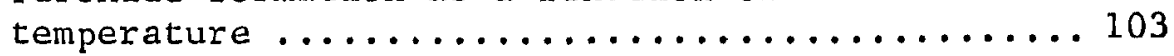

Figure 34. Maximum pexoxide concentration/reaction

time at which the maximum occurs as a

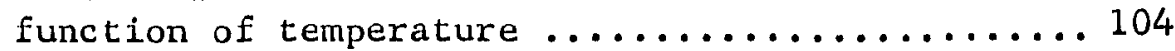


Figure 35. An Arrhenius plot of time to maximum peroxide concentration as a function of reciprocal temperature in degrees

Figure 36. Effect of added acetaldehyde on peroxide formation at $327^{\circ} \mathrm{C}$ and a reaction time of $1.6 \mathrm{msec}$..................... 109

Figure 37. Effect of added acetaldehyde on peroxide formation at $327^{\circ} \mathrm{C}$ and a reaction time of $1.9 \mathrm{msec} \ldots \ldots \ldots \ldots \ldots \ldots \ldots \ldots$

Figure 38. Effect of added acetaldehyde on peroxide formation at $327^{\circ} \mathrm{C}$ and a reaction time of 2.5 msec...................111

Figure 39. Representative oxidation product chroma togram 
Table 1. Evaluation of $\mathrm{P}_{41}$ from $\mathrm{P}_{21}$ values for a Helium driver and a 90:10 (Wt. \%) HeliumArgon mixture in the low-pressure section..........31

Table 2. Acoustic impedance of Helium-Argon mixtures in state 2 for $P_{41}=6.5$ with pure Helium driver................................ 34

Table 3. Acoustic impedance of Helium-Argon mixtures in state 3 for $\mathrm{P}_{41}=6.5$ with

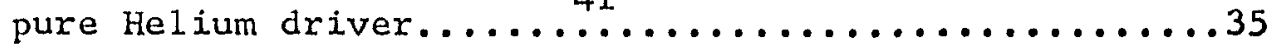

Table 4. Peroxide formation as a function of Oxygen: Pentane molar ratios at $\mathrm{P}_{41}=6.5$ and a reaction temperature of $298^{\circ} \mathrm{C} \ldots \ldots \ldots \ldots \ldots 77$

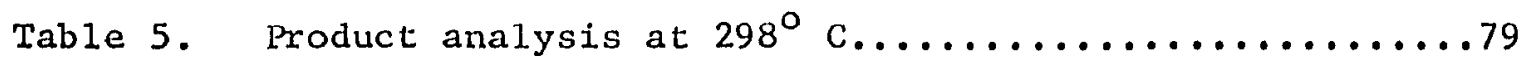

Table 6. Peroxide formation as a function of Oxygen: Pentane molar ratios at $\mathrm{P}_{41}=7.4$ and a reaction temperature of 3270 c............82

Table 7. Peroxide formation as a function of

Oxygen: Pentane molar ratios at $\mathrm{P}_{41}=9.0$

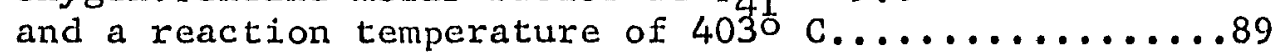

Table 8. Peroxide formation as a function of

Oxygen: Pentane molar ratios at $P_{41}=8.0$

and a reaction temperature of 4350 c............93

Table 9. Effect of added acetaldehyde on peroxide

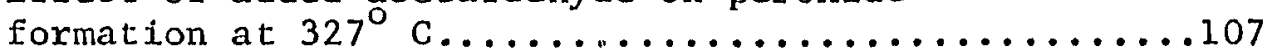

Table 10. Products of the oxidation reaction..............115

Table 11. Retention times of known compounds and products in order of elution ........................

Table 12. Peroxide formation in tertiary butylhydroperoxide addition experiments at $327^{\circ} \mathrm{C}$. and a reaction time of $1.9 \mathrm{msec} . \ldots \ldots \ldots \ldots \ldots \ldots \ldots 6 \ldots \ldots \ldots$ 


\section{INTRODUCTION}

The kinetics of low-temperature hydrocarbon oxidation has been extensively studied and various mechanisms have been proposed. The present research was undertaken to obtain more information about the mechanism, particularly the role of the peroxides and hydroperoxides formed during the reaction, and to determine which chemical intermediates formed during the oxidation reaction are responsible for chain branching.

The chemical shock tube, which is used throughout this study, eliminates many of the experimental difficulties encountered in the more conventional experimental systems. The shock tube has the ability to heat a gas mixture almost instantaneously to a given reaction temperature without wall effects. The mixture is kept at this temperature for a very short time(ca. 1.0-4.0 milliseconds) and then rapidly cooled to room temperature. This allows the fundamental processes undex consideration to be studied without interference from surface reactions or processes occurring at intermediate temperatures. The formation of peroxides and hydroperoxides was followed using iodometric methods. The non-peroxidic compounds were analyzed using conventional gas-chromtographic techniques. The effects of reaction mixture composition, reaction time, reaction temperature and the addition of certain products were studied, with a view to obtaining more information about the mechanism. 


\section{HISTORICAL}

Many workers regard the development of research on the gas-phase oxidation of hydrocarbons as occurring in three stages. The first stretches from the end of the $1890^{\prime} \mathrm{s}$ to the end of the 1920's; the second from the end of the twenties to the middle of the thirties which is a short but very significant period; and finally the third period from the middle thirties to the present day.

The first period comprised mainly purely chemical researches on hydrocarbon oxidation with the identification of stable intermediateand end-products. Based on this, four schemes were set up for the oxidation mechanism, namely hydroxylation, peroxidation, aldehyde formation and dehydrogenation.

The second period is characterized primarily by the examination of the kinetic mechanism of the reaction in terms of the ideas of the chain theory which was then rapidly developing. In this period, the works of several people, but in particulax of Semenov and his school, established that the oxidation could be represented extremely well by a chain reaction which proceeds with degenerate branching. The establishment of the chain character of the oxidation indicated recognition that not only stable molecules but unstable forms present as radicals or atoms determine the course of an oxidation reaction.

In the third period, which is still being continued, the central theme is that of determining the precise chemical description of the 
kinetic mechanisms of the processes taking place. This involves establishing the nature of all substances taking part in the course of the investigated transformation, not only the stable substances, but also the unstable ones, the free radicals and atoms.

In general, interest has centered around the low-temperature or slow combustion of hydrocarbons: in a temperature range from 200$300^{\circ}$ to $500-600^{\circ} \mathrm{C}$. The general results of many studies have been summarized by many people in recent books and review articles. 1-6

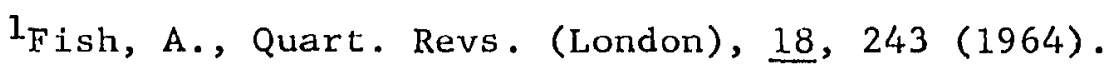

${ }^{2}$ Medley, H. D. and Cooley, S. D., "Hydrocarbon Oxidation," in J. J. McKetta, Jr., Ed., Advances in Petroleum Chemistry and Refining, Vol. III, Interscience Publishers, Inc., New York, 1960, pp. 309-376.

${ }^{3}$ Minkoff, G. J. and Tipper, C. F. H., Chemistry of Combustion Reactions, Butterworths, London, (1960). 121 (1956).

${ }^{4}$ Ridge, M. J., Revs. Pure and Appl. Chem. (Australia), $\underline{6}$,

${ }^{5}$ Shtern, V. Ya., The Gas-Phase Oxidation of Hydrocarbons, The Macmillan Company, New York, (1964).

${ }^{6}$ Tipper, C. F. H., Quart. Revs. (London), 11, 313 (1957).

At the present time there are two accepted mechanisms for chain oxidation and a third recently proposed. Ubbelohde, 7 and later Hinshelwood ${ }^{8}$ and Walsh ${ }^{9}$ proposed that after generation of a free

7Ubbelohde, A. R., Proc. Roy. Soc. (London), A152, 354 (1935).

8 Hinshelwood, C. N., Disc. Faraday Soc., 2, 117 (1947).

${ }^{9}$ Walsh, A. D., Trans. Faraday Soc., 42, 269 (1946). 
radical $\mathrm{R}$. from the parent alkane $\mathrm{RH}$, the next step in the oxidation was the formation of a peroxy radical $\mathrm{RO}_{2}$. which then abstracted, from a suitable source, but usually from the parent alkane, a hydrogen atom to form a hydroperoxide ROOH. This peroxide theory was essentially a development of Backstrom's 10 scheme of aldehyde oxidation.

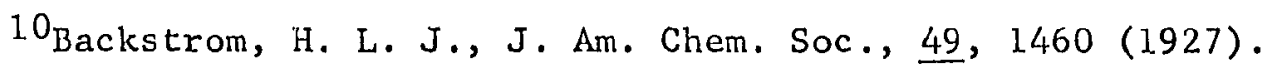

The aldehyde theory is essentially a development by Norrish of Bone's ${ }^{11}$ old hydroxylation theory. Norrish ${ }^{12,13}$ supposed that the

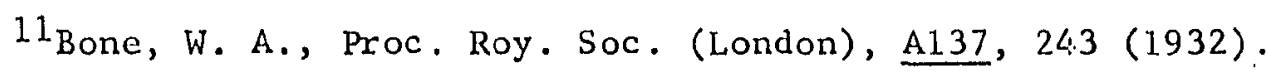

12 Norrish, R. G. W., Proc. Roy. Soc. (London), A150, 36 (1935).

13 Norrish, R. G. W., Proc. Roy. Soc. (London), A221, 151 (1954).

peroxy radical $\mathrm{RO}_{2}$ - was no more than a transition state complex which decomposed into a carbonyl compound and an $\mathrm{OH}$ radical. This aldehyde scheme was originally set forth in a somewhat less detailed form by Pope, Dykstra and Edgar. 14

14 Pope, J. C., Dykstra, E. J. and Edgar, G., J. Am. Chem. Soc., 51, 1875,2203 (1929).

The third mechanism was recently proposed by knox, ${ }^{15}$ who, in his

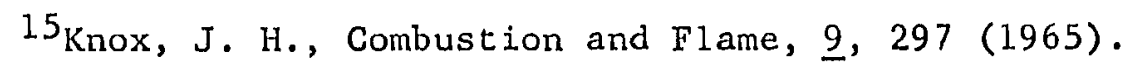

competitive oxidation studies, has demonstrated that the major product initially formed is the olefin with the same number of carbon 
atoms as the parent alkane. This olefin, assumed to be formed by the following reaction,

$$
\mathrm{R} \cdot+\mathrm{O}_{2} \longrightarrow \mathrm{A}=\mathrm{B}+\mathrm{HO}_{2} \cdot
$$

is then subjected to further oxidation in preference to oxidation of the parent alkane, since it reacts seven to ten times as rapidly.

All three mechanisms recognize the presence of $\mathrm{RO}_{2} \cdot$ as an intermediate, and it is worthwhile to examine the data from which inferences may be drawn concerning the reactions of this radical.

In the early 1950's Fok and Nalbandyan ${ }^{16,17,18}$ during an

16 Fok, N. V. and Nalbandyan, A. B., Dok1, Akad, Nauk SSSR, 89, 125 (1953).

17Fok, N. V., Bereslavskii, B. B., Nalbandyan, A. B. and Shtern, V. Ya., Dok1. Akad, Nauk SSSR, 67, 499 (1949).

${ }^{18}$ Fok, N. V. and Nalio andyan, A. B., Dok1. Akad, Nauk SSSR, 85, 1093 (1952).

investigation of the mercury vapor photo-sensitized oxidation of propane under flow conditions, and in the temperature range $25^{\circ}$ to $300^{\circ}$ C., found that the main reaction product at the low temperatures is isopropylhydroperoxide. Beginning at $100^{\circ}$, aldehydes also appear and the quantity formed increases with temperature. At $300^{\circ}$, there are only traces of peroxides and the main products are aldehydes. These data indicate that the $\mathrm{RO}_{2}$. formed can suffer'two simultaneous fates: 1) decomposition to an aldehyde and methoxy radical and 2) hydrogen abstraction from the parent alkane to give the hydroperoxide and an alkyl radical. The data also indicate, since the peroxide concentration decreases as the temperature increases, that 
the activation energy of the peroxy radical decomposition is greater than the activation energy for the hydrogen abstraction reaction which forms the hydroperoxide.

Other Russian workers have found this type of phenomenon. Porikova et a1. 19 found that during the oxidation of a propane-oxygen-

19 Porikova, A. I., Voyevodskii, V. V. and Nalbandyan, A. B., Zh. fiz. Khim., 33, 1336 (1959).

ammonia mixture $(7: 1: 2)$ at $120^{\circ}$ and $220^{\circ} \mathrm{C}$, and exposed to a quartz mercury vapor lamp, the peroxides accumulate linearily. They concluded from the data that this indicated the two simultaneous reactions mentioned, reasoning that if the aldehydes were formed from the peroxides, the curves representing their accumulation should possess an S-shaped form. Further they noticed at the higher temperature that there was a considerable decrease in the amount of peroxide found. The higher temperature, they surmised, furthered the importance of the decomposition reaction of the $\mathrm{RO}_{2}$. radical.

Blyumberg and Norikov ${ }^{20}$ while investigating the oxidation of

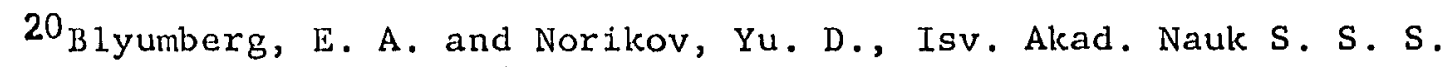
R., O. Kh. N. no. 8,1357 (1962).

butane at $250^{\circ} \mathrm{C}$. and $700 \mathrm{~mm}$ pressure also found that peroxides and aldehydes were formed in a parallel manner. Using labeled atoms they were able to show that $50 \%$ of the aldehydes and acids are not formed from the butylhydroperoxide. 
In another study of interest, kalbandyan and Kleimenov ${ }^{21}$ dem-

21 Nalbandyan, A. B. and Kleimenov, N. A., Dokl. Akad, Nauk SSSR, 124, 119 (1959).

onstrated the actual decomposition of the $\mathrm{RO}_{2}$ radical during hydrocarbon oxidation. Studying the mercury photosensitized oxidation of a mixture of $9 \mathrm{CH}_{4}+\mathrm{O}_{2}$ at one atmosphere pressure and $360^{\circ} \mathrm{C}$. with the addition of $0.05 \%$ labeled methylhydroperoxide $\mathrm{C}^{14} \mathrm{H}_{3} \mathrm{OOH}$ and analyzing for both normal and labeled formaldehyde, they found that $90 \%$ of the formaldehyde found came from the peroxy radical.

Until recently, peroxides and hydroperoxides could only be analyzed by the classical methods of wet chemistry which usually involved the titration of liberated iodine. The method is excellent but 1 imited to determining total peroxides. Various individual peroxides cannot be identified by this method. In 1960, Cartilidge and Tipper 22 demonstrated that a great variety of peroxides could be

${ }^{22}$ Cartilidge, J. and Tipper, C. F. H., Anal. Chem. Acta., 22, 106 (1960).

separated and identified using paper chromatography. Another method, also only recently developed has received very little attention. Cullis and Fersht have analyzed for organic peroxides using the tool

${ }^{23}$ Cullis, C. F. and Fersht, E., Combustion and Flame, I, 185 (1963).

of gas-liquid chromatography. Their method does not have the ease 
and simplicity as does the method of Cartlidge and Tipper. Further information on almost every aspect of peroxides has recently appeared in two monographs on the subject. 24,25

24Davies, A. G., Organic Peroxides, Butterworths, London, 1961.

25 Hawkins, E. G. E., Organic Peroxides, E. and F. F. Spon Ltd., London, 1961.

Despite the advent of these recent methods of positive identification of peroxides, only one interesting study has appeared to date. Cartlidge and Tipper ${ }^{26}$ have studied the slow combustion of five

26 Cartiddge, J. and Tipper, C. F. H., Proc. Roy. Soc. (London), A261, 388 (1961).

hydrocarbons in a flow system at $290^{\circ}$ to $385^{\circ} \mathrm{C}$. Of the three compounds of interest here, two, n-butane and n-heptane, formed peroxides which accounted for approximately $10-20 \%$ of the hydrocarbon oxidized. With propane, only a trace of peroxides was found, mainly hydrogen peroxide and a trace of peracetic acid. In n-butane, hydrogen peroxide, butylhydroperoxide, n- and/or sec-, perpropionic acid and some aldehydeperoxide addition compounds were found. With n-heptane, hydrogen peroxide, diheptylperoxide, heptylhydroperoxide, dihydroperoxyheptane and various aldehyde-peroxide addition compounds were found. It might be stated here at this time that the possibility exists that the aldehyde addition compounds may have been formed in the condensate at liquid air temperatures.

of the studies on peroxide formation which utilized the more 
classical methods of analysis, several should be mentioned. Salooja 27 demonstrated with his study of the isomeric hexanes in a

${ }^{27}$ Salooja, K. C., Combustion and Flame, 9, 219 (1965).

flow system in a temperature range of $250^{\circ}$ to $800^{\circ} \mathrm{C}$. that, at the low temperatures, mainly hydroperoxides are formed. With increasing temperature the concentrations of both the hydroperoxides and hydrogen peroxide increase, but that of the hydrogen peroxide increases at a greater rate. At $600^{\circ} \mathrm{C}$, , only a trace of hydroperoxides is found. At all temperatures investigated he found that increasing the ratio of oxygen to fuel towards stoichiometry had little effect on the amount of peroxide formed. Also of interest in this study is the fact that carbonyl compounds are formed from almost the lowest temperature. In the early stages of the reaction, the organic hydroperoxides are in greater concentration than formaldehyde, but with increasing temperature, the formaldehyde concentration increases at a much greater rate than that of the hydroperoxides.

In a further study, Salooja ${ }^{28}$ investigated the effect of potassium

${ }^{28}$ Salooja, K. C., Combustion and Flame, 10, 45 (1966).

chloride wall coatings on combustion processes. Two of the compounds, pentane and hexane, were studied from $300^{\circ} \mathrm{C}$. to their ignition temperature. Of significance was the fact that no hydrogen peroxide and only very small amounts of hydroperoxides were detected. This seemed to indicate that the inhibition of the hydrogen peroxide formation 
resulted from the fact that the potassium chloride coated surface was a much more effective scavenger of the $\mathrm{HO}_{2}$ radicals formed than was an uncoated surface.

Seakins 29 found that during the oxidation of $\mathrm{n}$-propane at $280^{\circ} \mathrm{C}$.

${ }^{29}$ Seakins, M., Proc. Roy. Soc. (London), A261, 281 (1961).

a linear relationship between the reaction rate and the peroxide concentration existed through the entire course of the reaction. Peroxide formation was found to be proportional to the propane pressure and independent of the oxygen pressure.

Blosser ${ }^{30}$ during the low-temperature oxidation of $\mathrm{n}$-pentane

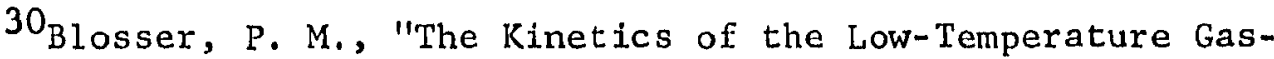
Phase Oxidation of $\mathrm{n}$-Pentane in a Static System," Ph. D. dissertation, The Ohio State University. (1955).

demonstrated that at $230^{\circ} \mathrm{C}$. the hydroperoxides formed were in much greater quantity than hydrogen peroxide. The hydroperoxide was also found initially in greater concentration than formaldehyde. At $275^{\circ} \mathrm{C}$, the hydroperoxides were found but in much lower concentration than at the lower temperature; hydrogen peroxide was barely observed; and formaldehyde was always found in greater concentration than the hydroperoxides.

The gas-phase oxidation of $n$-pentane has been the subject of many writers. The early work has been described by Blosser ${ }^{30}$ and will not be further discussed. With the advent of more sophisticated analytical techniques, some very interesting products from the gas-phase oxidation 
of $n$-pentane have been obtained. Blosser ${ }^{30}$ observed the following oxidation products at $230^{\circ} \mathrm{C}$. : acetaldehyde, acetone, carbon dioxide, carbon monoxide, diethyl ketone, ethylene, formaldehyde, methane, methyl-n-propyl ketone and propionaldehyde.

Sandler ${ }^{31-33}$ and co-workers investlgated the oxidation of $n$ -

${ }^{31}$ Sandler, S. and Beech, J. A., Can. J. Chem., 38, 1455 (1960).

${ }^{32}$ Chung, Y. H. and Sandler, S., Combustion and Flame, 6, 295 (1962).

${ }^{33}$ Chung, Y. H. and Sandler, S., Combustion and Flame, I, 339 (1963).

pentane in both flow and static systems from $250^{\circ}$ to $800^{\circ} \mathrm{C}$. and isolated over thirty products. The ones they were able to identify are: acetaldehyde, acetone, acrolein, 1-butene, cis- and trans-2-butene, butyraldehyde, carbon dioxide, carbon monoxide, cyclopentane, ethylene, formaldehyde, hydrogen, methane, methanol, 2-methyltetrahydrofuran, 1,3- and 1,4-pentadiene, 1-pentene, cis- and trans-2-pentene, propionaldehyde, propylene and unidentified acids. Ethylene and propylene oxides may have been present but could not be detected on the analytical column in use since the acetaldehyde peak was too large.

A mechanism with some kinetic data was postulated in the final paper. ${ }^{33}$ The apparent activation energy was determined on the basis of the consumption of the pentane and found to be $51.9 \mathrm{kcal} . / \mathrm{mole}$. The apparent order with respect to pentane was 1.3 , while that with respect to oxygen was 0.9 . These apparent orders were determined at the maximum rate of oxidation. 
Salooja $a^{34}$ studied the oxidation of $n$-pentane in a flow system be-

34Salooja, K. C., Combustion and Flame, 9 , 33 (1965).

tween $300^{\circ}$ and $500^{\circ} \mathrm{C}$. and found the following products: acetaldehyde, acetone, acrolein, 1-butene, butyraldehyde, ethane, hydrogen, methane, methyl-ethyl ketone, 2-methyltetrahydrofuran, 1-pentene, cisand trans-2-pentene, propionaldehyde and propylene. The results, as can be seen, are very similar to those reported by Sandler.

Some high-temperature oxidation studies of n-pentane have also been reported. Malmberg and workers ${ }^{35}$ obtained formaldehyde, acetaldehyde, propionaldehyde, acrolein and crotonaldehyde in motor

35 Malmberg, E.W., Smith, M. L., Bigler, J. E., and Bobbit, J.A., Fifth International Symposium on Combustion, Reinhold, New York, 1958, p. 385 .

studies of air-pentane mixtures. The carbonyl products were analyzed by column separation of their 2,4-dinitrophenylhydrazone derivatives. Lee, ${ }^{36}$ in a shock tube study of $\mathrm{n}$-pentane from $630^{\circ}$ to $1200^{\circ} \mathrm{C}$. found

36 Lee, W. E., "A Study of Free Radical Processes in the Chemical Shock Tube," Ph.D. dissertation, The Ohio State University (1959).

butane, 1-butene, cis-and trans-2-butene, carbon dioxide, carbon monoxide, ethane, ethylene, hydrogen, methane, pentene, propane and propylene. 
Analysis for carbonyl products was not attempted. Wellman ${ }^{37}$ in a simi-

37 Wellman, W. E., "High Temperature Oxiaation of Hydrocarbons in the Chemical Shock Tube," Ph.D. dissertation, The Ohio State University (1960).

lar shock tube oxidation of $n$-pentane in the temperature range $638^{\circ}$ to $697^{\circ} \mathrm{C}$. found ethane, ethylene, carbon dioxide, carbon monoxide, methane and propylene. Again, no carbonyl compounds were analyzed for.

The shock tube, in the form that it is now known, seems first to have been used by vie11 $\mathrm{e}^{38}$ in 1899 , but both experimental and theoretical

${ }^{38}$ Vielle, P., Comp. Rend., 129, 1228 (1899).

work on shock waves go back much earlier than this. Payman and Shepherd ${ }^{39}$ have an excellent article with many historical references.

39 Payman, W. and Shepherd, W. C. F., Proc. Roy. Soc. (London), A186, 293 (1946).

The earliex shock tube studies were primarily engineering oriented and it was not until 1953 that the first study of a chemical reaction occurred. 40 Since this initial study, the field has expanded tremen-

${ }^{40}$ Carrington, T., and Davidson, N., J. Phys. Chem., 57, 418 (1953).

dously and in recent years the shock tube and its applications in chemistry has been the subject of many monographs and review articles. ${ }^{41-49}$ 
${ }^{41}$ Bradley, J. N., Shock Waves in Chemistry and Physics, John Wiley \& Sons, Inc., New York, 1962.

42 Bradley, J. N., The Roycl Institute of Chemistry (London), Lecture Series 1963, No. 6, "Chemical Applications of the Shock Tube".

${ }^{43}$ Ferri, A., Ed., Fundamcintal Daca Obtainca from Shock Tube Experiments, Agardograph No. 4.1, Pergamon Press, New York, 1961.

${ }^{44}$ Gaydon, A. G. ani Hurle, I. T., The Shock Tube in High Tempera.ure Chemical Physics, Reinhold Publ. Corp., New York, 1963.

45 Glass, T. I. and Hall, - G., Navord Report 1488 (Vol. 6), Haudbook of Supersonic Aerodynatics, ection 10, Shock Tubes, U. S. Govt. Printino office, Washington, 1959.

${ }^{46}$ Greene, L. T. and Toennies, T. P., Chemical Reactions in Shock Waves, E. Arnuld Lta., London $1 \cup 64$.

47 Palmer, H. B., J. Inst. Fuel (Lonirn), 34, 359 (1.961).

48 richard, H. O., Quari. Revs. (London), 24,46 (1960). 1961.

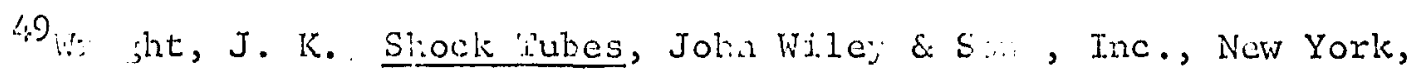

Despit. tha large "nount of literasure on rate studies utilizing the chemical shock tube, tiere have been very few studies on hydrocarbon oxidation. Of the systems studied, the ones given the most attention are those of wetiar:vetlane, ethyleme and acetylene. The highur hydrocarbons have not as yet been subjected to intensive examination. Only two studies have been reported to date, 36,37 and they were both on pentane. In addition, all of the ryorted studies of hydrocarbon oxidation have been at very high temperatures.

As can be seen from Figure 1,50 the temperature range of the

50 Yodified from a urawing which appeared in an article by R. M. Iristrom, Chum. \& Ling. News, Oct. 14, 1963, pp 150.;60. 


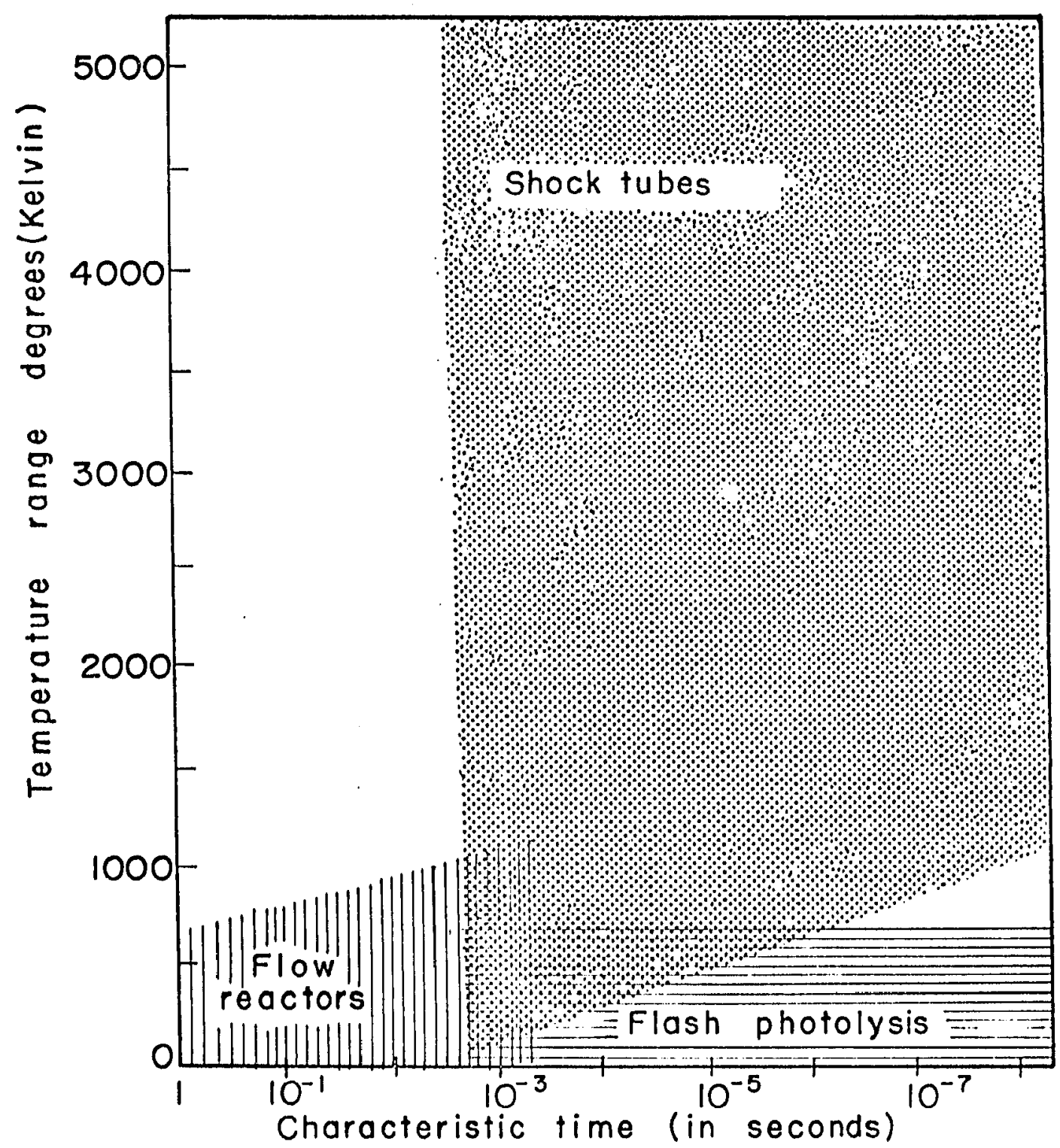

Figure l. A comparison of some working parameters of common methods for studying fast chemical reactions. 
shock tube extends from temperatures as low as $250^{\circ} \mathrm{K}$. to as high as $5000^{\circ} \mathrm{K}$. It would seem that this instrument could be well utilized in obtaining data in the low-temperature region of hydrocarbon oxidation. Since very short reaction times are easily obtained, with exacting product analysis, it should be possible to suggest a detailed mechanism for the first few steps of the hydrocarbon oxidation reaction. 
SHOCK TUBE THEORY

The simple shock tube, as illustrated in Figure 2, consists of two sections separated by a diaphragm. The low-pressure side is shown on the right side of the diagram; this contains the experimental gas which is subjected to the shock wave. The high-pressure side, containing the driver gas, is shown on the left.

After the bursting of the diaphragm, compression waves which steepen rapidly into a shock wave move into the low-pressure side. Simultaneously, an expansion or rarefaction wave moves back into the high-pressure driver gas, but the pressure fall is smooth and not discontinuous as in the shock front. The experimental gas and the driver gas make contact at the "contact surface" which moves along the tube behind the shock front. The movements of the shock front, the contact surface and the rarefaction wave are shown in Figure 3.

The standard nomenclature used in shock tube research denotes the conditions in the undisturbed low-pressure experimental gas by the subscript 1 , so that the initial pressure and temperature in this region are denoted by $\mathrm{P}_{1}$ and $\mathrm{T}_{1}$. The region between the shock front and the contact surface is designated 2, the region between the contact surface and the rarefaction fan as 3 , and the initial conditions on the high-pressure side as $4 . \mathrm{P}_{4}$ is always greater than $\mathrm{P}_{1}$, but usually $\mathrm{T}_{4}=\mathrm{T}_{1}$. If the shock wave is allowed to reflect off the end of the tube, as in the chemical shock tube, there is a further rise in temperature and pressure, and this region is labeled 5 , with $\mathrm{T}_{5}$ 


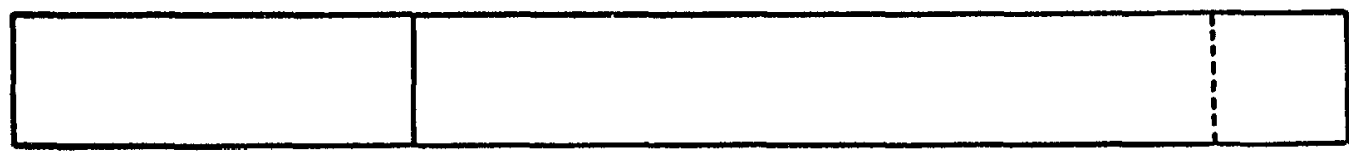

High pressure

Low pressure

Figure 2. The simple shock tube.

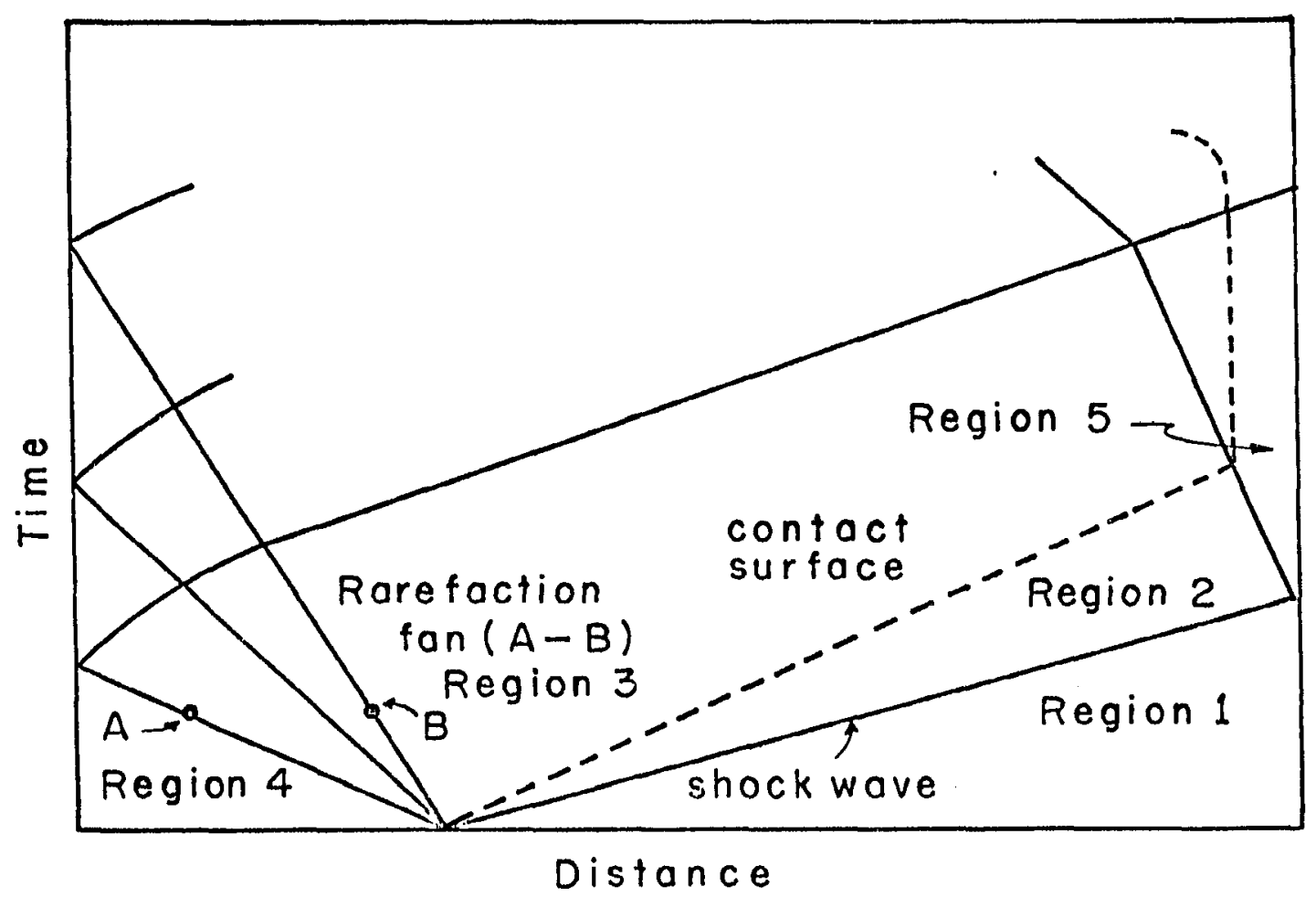

Figure 3. A distance-time diagram showing the waves and states when the diaphragm is ruptured in a shock tube. 
in simple cases being about twice as large as $\mathbf{T}_{2}$.

The chemical shock tube employed in this study is a single-pulse, non-optical shock tube similar to the one developed at The Cornell Aeronautical Laboratory, 51 and originally assembled in this laboratory

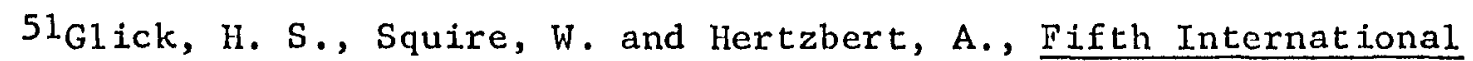
Symposium on Combustion, Reinhold, New York, 1955, p. 393.

by Lee and Malmberg. ${ }^{36}$ It consists of a high-pressure or driver section, a low-pressure section consisting of a buffer and a reaction section, and an expansion tank (Figure 4). The expansion tank is 10cated upstream of the driver section for the purpose of eliminating multiple shock reflections from the ends of the shock tube. The shock tube is assembled for reaction by placing a diaphragm (A) between the driver and the buffer section and a similar diaphragm (B) between the driver and the expansion tank. To initiate the reaction to be studied, diaphragm (A) is broken. This generates a shock wave in the direction of the low-pressure section. The reactant gas is compressed by this adiabatic expansion of the driver gas and heated to a temperature $\mathrm{T}_{2}$. This incident wave reflects off the closed end of the shock tube and further compresses and heats the reactants to $\mathrm{T}_{5}$, which is the temperature of the reaction. The time at which the reactants stay at this temperature is the reaction time, which is in the millisecond region. The reaction mixture is rapldly cooled by expansion or rarefaction waves which are formed when diaphragm (B) is broken. This expansion wave originates from the partially evacuated expansion tank and usually results in a very rapid cooling of the reaction mixture when the 


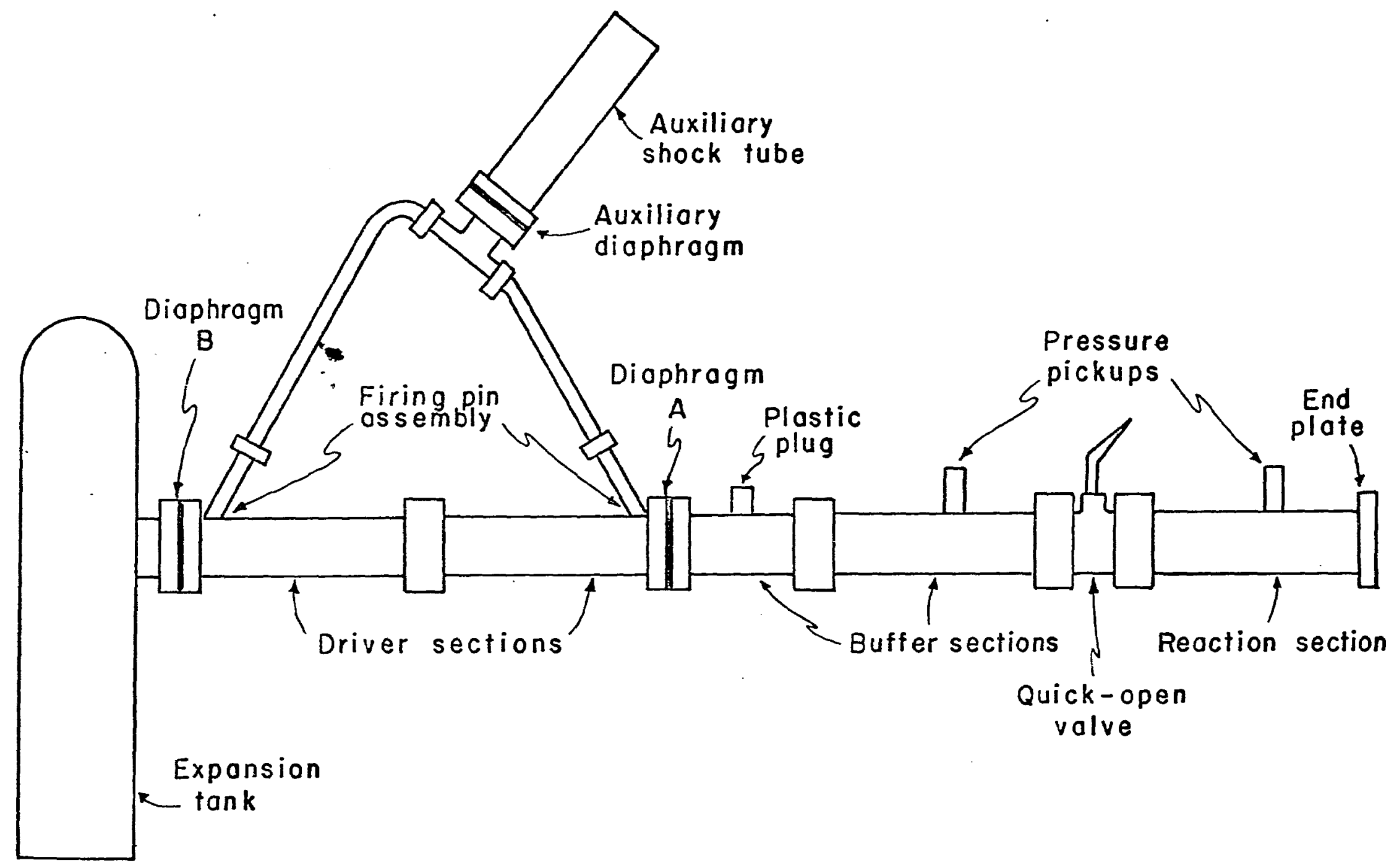

Figure 4. The chemical shock tube. No 
rarefaction wave intersects with the contact surface. This rapid cooling quenches the reaction so quickly that some reaction intermediates may be isolated. After the rapid quenching is completed, the products are removed from the tube and analyzed. During the passage of the reflected shock, the gas particles behind it are at rest relative to the shock tube. This is useful, since it enables observations to be made on a fixed group of molecules throughout their additional heating and compression.

In its ideal form the shock wave is regarded as a very thin plane, a few mean free paths thick. The shock front is assumed to lie in a plane perpendicular to the direction of the gas flow. The theoretical treatment of shock waves is based on the theory of one-dimensional steady flow for an ideal gas.

In the one-dimensional theory of shock waves, the gases are assumed to be ideal and to have constant specific heats. These gases are also at constant pressure in any particular region at any particular time. At any instant during the experiment, there are five distinct regions in which the local conditions differ markedly (Figure 3 ). There is the unexpanded driver gas in state 4 and the uncompressed gas in the low-pressure section, state 1 . These two regions may be characterized thermodynamically by their pressure, density and temperature, so that we have $\mathrm{P}_{4}, P_{4}, \mathrm{~T}_{4}$ and $\mathrm{P}_{1}, P_{1}, \mathrm{~T}_{1}$, respectively. There is also a region behind the contact surface called the rarefaction wave which consists of the expanded driver gas, characterized by $P_{3}, \rho_{3}, T_{3}$. Finally, there are two regions in which the gas has been compressed. One is state 2 , characterized by $\rho_{2}, \mathrm{~T}_{2}$, with $\mathrm{P}_{2}=\mathrm{P}_{3}$; the other is state 5 , which is 
the region through which the reflected shock passes. States 2 and 5 are of particular interest. In these states the gas has been compressed and the temperature, pressure and density of the gas increased. The magnitude of these variables can be calculated since mass, momentum and energy must be conserved along the shock front.

The pressure ratio across the diaphragm $\left(\mathrm{P}_{41}\right)$, the chemical composition of the gases, and the temperatures $\mathrm{T}_{4}$ and $\mathrm{T}_{1}$ determine the properties of the rarefaction and shock waves.

The equations that describe the wave systems and the pressure, temperature and density functions in a simple shock tube have been derived and summarized by Glass and Hall. 45

The equations and symbols used in the calculations are listed below:

$\begin{array}{ll}\text { a } & \text { velocity of sound } \\ \text { A.I. } & \text { acoustic impedance } \\ \mathrm{C}_{\mathrm{p}} & \text { molar heat capacity at constant pressure } \\ \mathrm{C}_{\mathrm{V}} & \text { molar heat capacity at constant volume } \\ \mathrm{c}_{\mathrm{v}} & \text { specific heat capacity at constant volume } \\ \mathrm{e} & \text { internal energy per unit mass } \\ \mathrm{M} & \text { molecular weight } \\ \mathrm{P} & \text { pressure } \\ t & \text { time } \\ T & \text { temperature, degrees Kelvin } \\ w & \text { velocity of the shock wave } \\ P & \text { density }\end{array}$


The following quantities are used to denote certain dimensionless quantities as indicated; $i$ and $j$ represent two of the five regions mentioned above:

$$
\begin{gathered}
E_{i j}=\frac{e_{i}}{e_{j}}=\frac{\left(\frac{e}{T}\right)_{i}}{\left(\frac{e}{T}\right)_{j}}=\frac{\left(c_{v}\right)_{i}}{\left(c_{v}\right)_{j}} \quad T_{i j}=\frac{T_{i}}{T_{j}} \\
P_{i j}=\frac{P_{i}}{P_{j}}=\frac{1}{P_{j i}} ; \Gamma_{i j}=\frac{\rho_{i}}{P_{j}} \\
w_{i j}=\frac{w_{i}}{a_{j}} ; \gamma_{i}=\left(\frac{c_{P}}{c_{v}}\right)_{i} \\
\alpha_{i}=\frac{\gamma_{i}+1}{\gamma_{i}-1} ; \beta_{i}=\frac{\gamma_{i}-1}{2 \gamma_{i}}
\end{gathered}
$$

Equation (1) gives implicitly the relationship between the strength of the shock wave $P_{21}$ produced in the shock tube as a function of the pressure ratio across the diaphragm $P_{14}$, the specific heat ratios $\gamma_{4}, \gamma_{1}$, and the internal energy ratio of the gases in the high-and low-pressure sections. The shock strength $\mathrm{P}_{21}$ for a given $\mathrm{P}_{14}$ value can be determined by plotting the $\log$ of different $\mathrm{P}_{41}$ values calculated from Equation (1) against the $P_{21}$ values used in the calculations.

$$
P_{14}=\frac{1}{P_{41}}=\frac{1}{P_{21}}\left[1-\left(P_{21}-1\right) \sqrt{\frac{\beta_{4} E_{14}}{\alpha_{1} P_{21}+1}}\right] \frac{1}{\beta_{4}}
$$

As soon as the shock strength for a certain initial experimental $\mathrm{P}_{41}$ has been read from the graphs (Figures 5,6), all other 


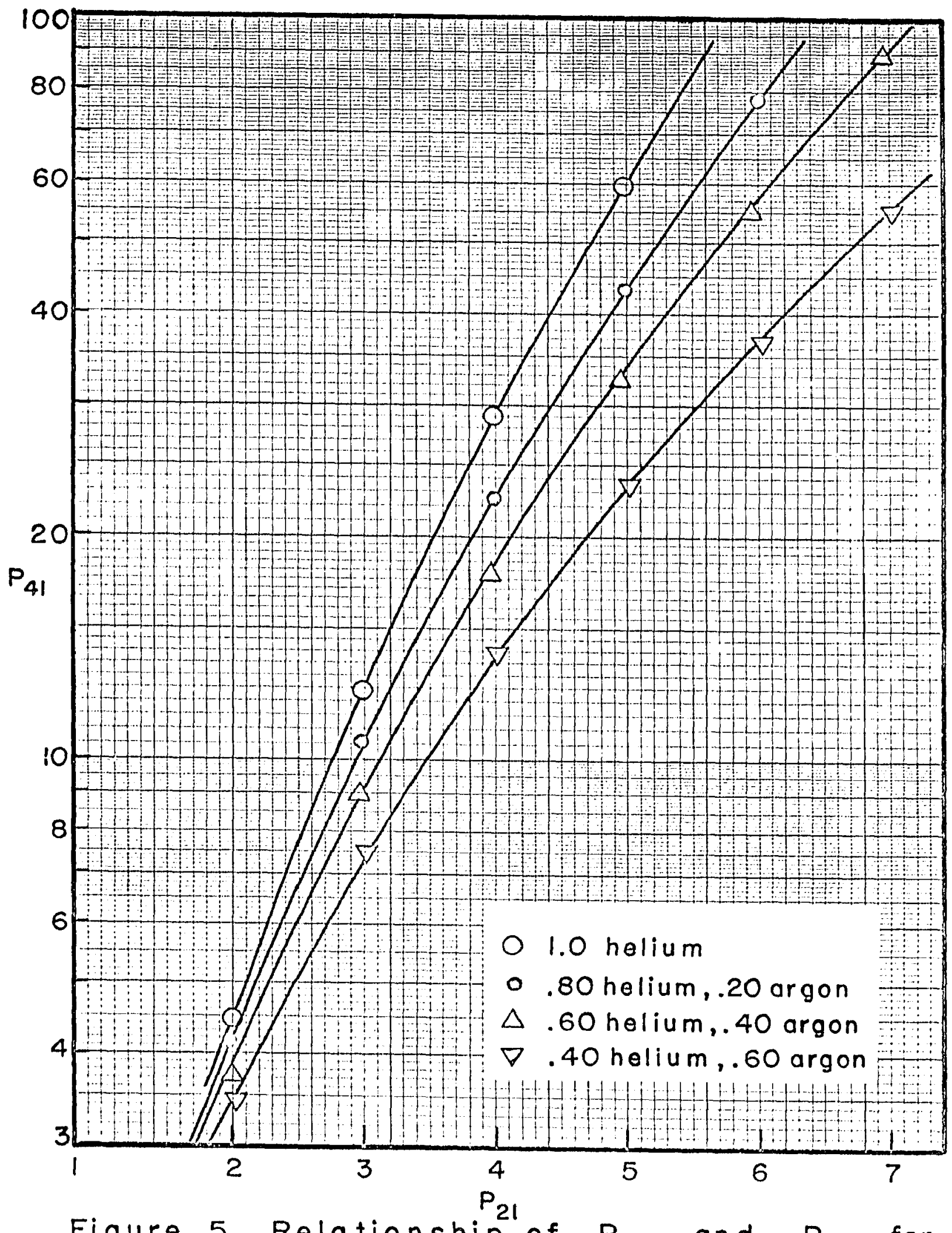

Figure 5. Relationship of $P_{41}$ and $P_{21}$ for Helium-Argon mixtures and Pure Helium. 


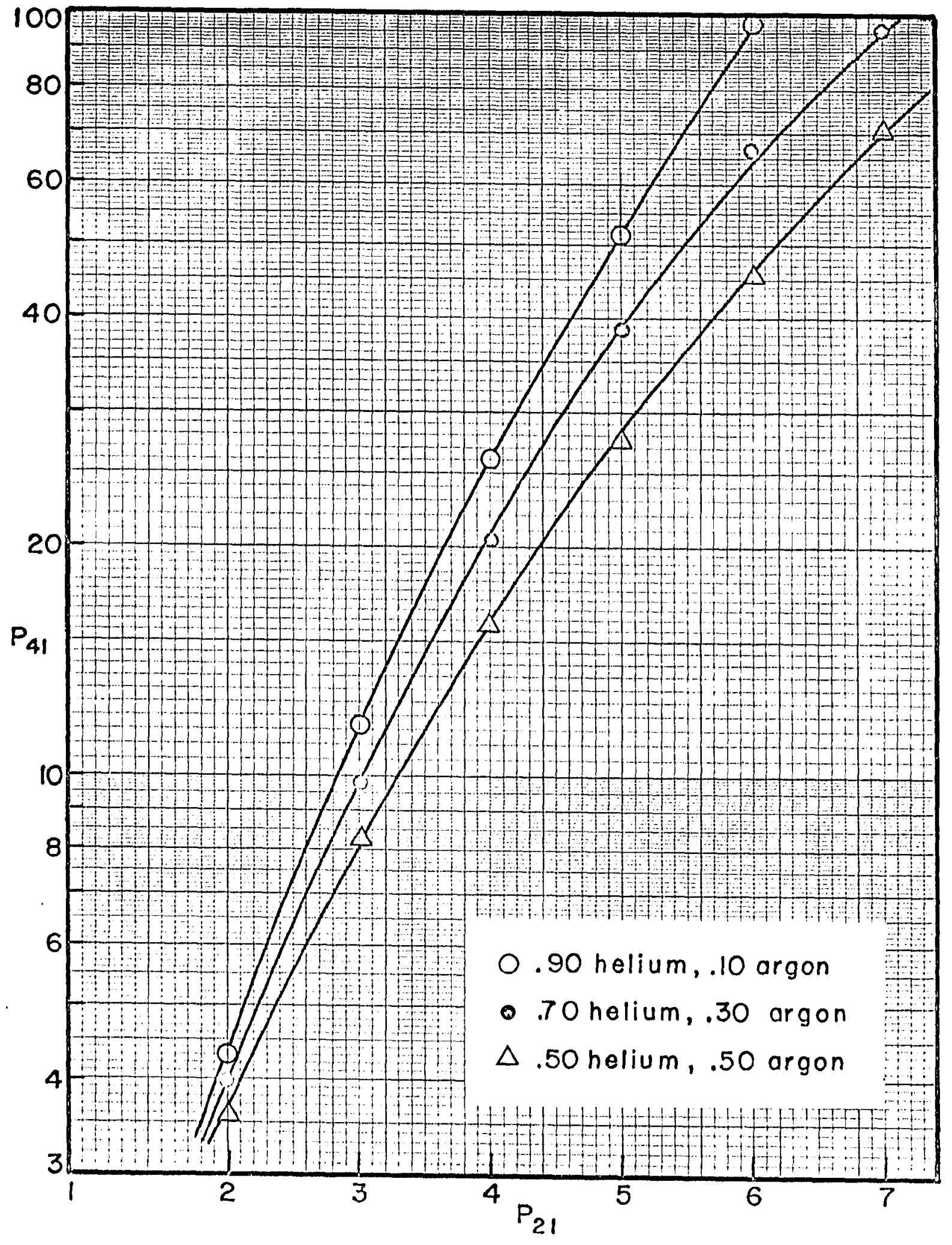

Figure 6. Relationship of $P_{41}$ and $P_{21}$ for Helium-Argon mixtures and Pure Helium. 
relationships may be evaluated. They are as follows:

Density ratios:

$$
\begin{gathered}
\Gamma_{21}=\frac{\rho_{2}}{\rho_{1}}=\frac{1+\alpha_{1} P_{21}}{\alpha_{1}{ }^{+} P_{21}} \\
\Gamma_{34}=\frac{\rho_{3}}{\rho_{4}}=\left[\mathrm{P}_{14} \mathrm{P}_{21}\right] \frac{1}{\gamma_{4}}
\end{gathered}
$$

Temperature ratios:

$$
\begin{aligned}
& \mathrm{T}_{21}{ }^{\frac{1}{2}}=\left[\frac{\mathrm{T}_{2}}{\mathrm{~T}_{1}}\right]^{\frac{1}{2}}=\left[\frac{\mathrm{P}_{21}\left(\alpha_{\left.1+\mathrm{P}_{21}\right)}\right.}{1+\alpha_{1} \mathrm{P}_{21}}\right]^{\frac{1}{2}} \\
& \mathrm{~T}_{34}{ }^{\frac{1}{2}}=\left[\mathrm{P}_{34}\right]^{\beta_{4}}=\left[\mathrm{P}_{14} \mathrm{P}_{21}\right]^{\beta_{4}}
\end{aligned}
$$

Mach number:

$$
w_{11}=\frac{w_{1}}{a_{1}}=\left[\beta_{1}\left(1+\alpha_{1} P_{21}\right)\right]^{\frac{1}{2}}
$$

Speed of sound:

$$
\begin{aligned}
& A_{21}=\frac{a_{2}}{a_{1}}=\left[\frac{T_{2}}{T_{1}}\right]^{\frac{3}{2}} \\
& A_{34}=\frac{a_{3}}{a_{4}}=\left(T_{34}\right)^{\frac{1}{2}}
\end{aligned}
$$

where $a_{1}$ and $a_{4}$ are calculated from the ideal gas equation.

$$
a_{1}=\sqrt{\frac{\gamma_{i} P_{i}}{\rho_{i}}}=\sqrt{\frac{\gamma_{i} \mathrm{RT}_{i}}{\mathrm{M}_{i}}}
$$

The variation of the pressure across the reflected shock wave is given in terms of the pressure ratio across the incident shock in Equation (10):

$$
P_{52}=\frac{\alpha_{1}+2-P_{12}}{1+\alpha_{1} P_{12}}
$$


The temperature ratio is obtained from Equation (11):

$$
T_{52}=\frac{P_{52}\left(\alpha_{1}+P_{52}\right)}{1+\alpha_{1} P_{52}}
$$

In the temperature range to be used in this study, the shock pressure ratio $\mathrm{P}_{21}$ will always be small and all of the above equations will be valid.

The technique of using a reflected shock to heat a reaction mixture introduces problems that are absent in studies in which the incident shock wave is used to initiate a reaction. When the shock wave is reflected from the closed end of the shock tube it moves back through a boundary layer created by the incident shock wave. Interactions of the reflected shock wave may be very severe and the homogeneity of the reaction conditions may be destroyed by the large gradients that are introduced. 52

${ }^{52}$ Mark, H., "On the Interaction of a Reflected Shock Wave with the Boundary Layer in a Shock Tube," Ph. D. dissertation, Cornell University (1957).

Experiments indicate that monoatomic gases show little shock-boundary layer interactions, while gases composed of complex molecules may be seriously affected. In a polyatomic reaction mixture, the reflected shock wave passes across the contact surface and the accompanying interaction generates two waves. It may form a transmitted shock wave which travels through the driver gas and a secondary reflected wave which may either heat or cool 
the reaction mixture. It is imperative to avoid this secondary shock interaction if the gas is to react at constant temperature. The method used to avoid this is called the "tailored-interface" technique. 53

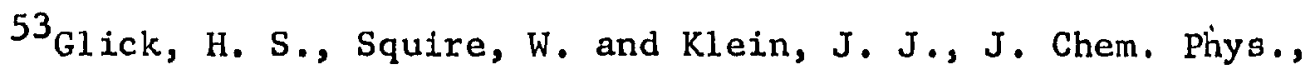
27, 850 (1957).

The "tailored-interface" technique involves the addition of a diluent gas to either the driver or the reaction mixture so that the gas density on both sides of the contact surface is approximately the same. The amount of gas necessary for this purpose can be determined by calculating and matching the "acoustic impedance" of the gases in regions 2 and 3 in the shock tube where the acoustic impedance is defined by

$$
\text { A.I. }=a \rho
$$

The fact that the shock-boundary layer interaction has been eliminated can be shown by comparing two pressure-time oscilloscope traces; one from a "tailored-interface" experiment, and the other from an experiment which had only helium in the low-pressure section (Figures 7,8 ). A detailed procedure for matching acoustic impedance is illustrated in a sample calculation.

When argon or some other diluent is added to the low-pressure gas in the shock tube, the shock pressure ratio $\mathrm{P}_{21}$ is significantly different from the $\mathrm{P}_{21}$ values obtained when only helium is used in the low-pressure section. The problem is conveniently handled 


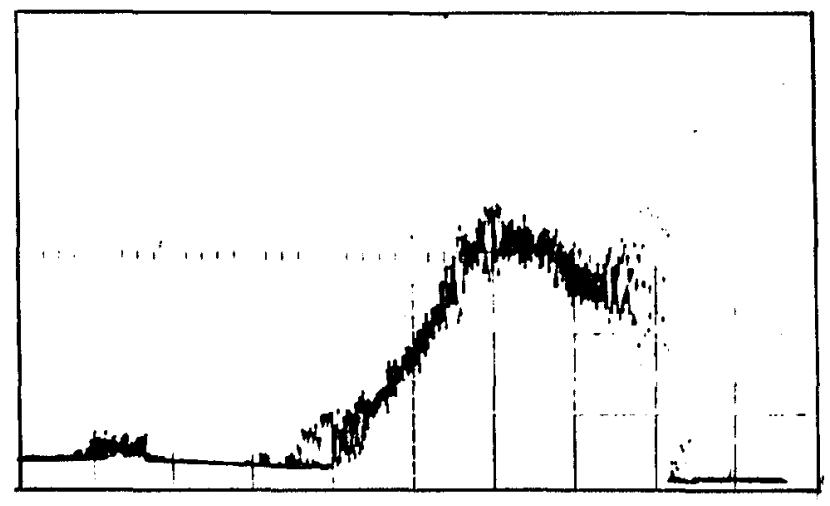

Figure 7. Oscilloscope trace of shock wave at $P_{41}=6.5, A .1$. unmatched.

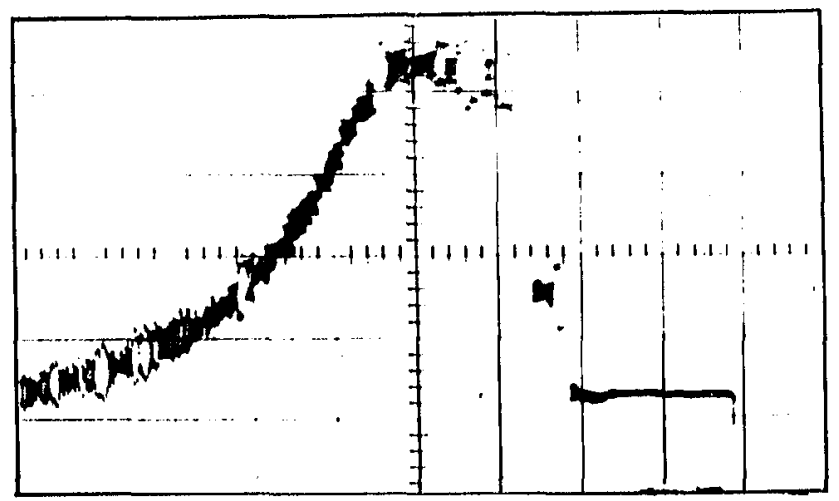

Figure 8. Oscilloscope trace of shock wave at $P_{41}=6.5$, "Tailored-Interface." 
by assuming various values of $P_{21}$, and calculating $P_{14}$ values corresponding to these, using Equation (1). A graph is then made by plotting $\log \mathrm{P}_{41}$ against $\mathrm{P}_{21}$ (Figures 5,6 ) and values of $\mathrm{P}_{21}$ for various values of $\mathrm{P}_{41}$ read from this graph.

To illustrate more clearly the preceding discussion, a detailed calculation follows:

$\mathrm{P}_{21}$ values for helium-argon mixtures were determined by first calculation $\mathrm{P}_{14}$ values for assumed $\mathrm{P}_{21}$ values; this calculation was repeated for a series of gas mixtures. Equation (1) was used to obtain these values.

$$
P_{14}=\frac{1}{P_{41}}=\frac{1}{P_{21}}\left[1-\left(P_{21}-1\right) \sqrt{\frac{\beta_{4} E_{14}}{\alpha_{1} P_{21}+1}}\right] \frac{1}{\beta_{4}}
$$

Where

$$
\begin{aligned}
& \mathrm{P}_{21}=\text { strength of the shock wave } \\
& \mathrm{P}_{41}=\frac{1}{\mathrm{P}_{14}}=\text { pressure ratio across the diaphragm } \\
& \gamma_{4}=\gamma_{1}=\text { ideal gas specific heat } \\
& \mathrm{E}_{14}=\text { internal energy ratio of gas used in the low- } \\
& \alpha_{4}=\frac{\gamma_{4}+1}{\gamma_{4}^{-1}} \\
& \beta_{4}=\frac{\gamma_{4}^{-1}}{2 \gamma_{4}}
\end{aligned}
$$

In the case of pure helium driver and a 90:10 heliumargon (wt. \%) mixture in the low-pressure section 


$$
\beta_{4}=0.2 \quad \gamma_{4}=4.0
$$

To calculate $E_{14}$, the internal energy content of state 1 must be compared to'that of state 4:

$$
\begin{aligned}
& \text { for state } 4 \text {, helium } c_{v}\left(\mathrm{cal} / \mathrm{g} /{ }^{\circ} \mathrm{C}\right)=0.745 \\
& \text { for state } 1 \text {, helium } c_{v}\left(\mathrm{cal} / \mathrm{g} /{ }^{\circ} \mathrm{C}\right)=0.745 \\
& \text { argon } \mathrm{C}_{\mathrm{v}}\left(\mathrm{cal} / \mathrm{g} /{ }^{\circ} \mathrm{C}\right)=0.075
\end{aligned}
$$

and $\frac{\mathrm{e}_{1}}{\mathrm{~T}}=(1 / 10)(0.075)+(9 / 10)(0.745)=0.6780$

and $\mathrm{E}_{14}=0.6780 / 0.745=0.910$

Solving Equation (1) when $\mathrm{P}_{21}=5$;

$$
\begin{gathered}
\mathrm{P}_{14}=(1 / 5)\left[1-(5-1) \sqrt{\frac{0.2(0.910)}{4(5)+1}}\right] \frac{1}{0.2} \\
\mathrm{P}_{14}=0.01954 \text { and } \mathrm{P}_{41}=51.2
\end{gathered}
$$

The remaining values for the $90: 10$ mixture are tabulated in Table 1 and illustrated in Figure 6 .

\section{Table 1}

Evaluation of $\mathrm{P}_{41}$ from $\mathrm{P}_{21}$ Values for $a$ Helium Driver and a 90:10 (Wt.\%) HeliumArgon Mixture in the Low-Pressure Section

\begin{tabular}{lcc}
\hline $\mathrm{P}_{21}$ & $\mathrm{P}_{14}$ & $\mathrm{P}_{41}$ \\
\hline 2 & 0.2325 & 4.30 \\
3 & 0.0862 & 11.6 \\
4 & 0.0385 & 26.0 \\
5 & 0.0195 & 51.2 \\
6 & 0.0103 & 97.1 \\
7 & 0.0057 & 175. \\
8 & 0.0032 & 313. \\
\hline
\end{tabular}


This calculation is repeated for other gas mixtures, and, from the graphs, a table of $P_{21}$ values for a fixed $P_{41}$ value is plotted against the mixture composition (Figure 9).

The acoustic impedance (A.I.) of a gas mixture is determined by

$$
\text { A.I. }=a \rho
$$

where

$$
a=\text { speed of sound (Equation 9) }
$$

and

$$
\rho=\text { gas density }
$$

The density in states 1 and 4 are obtained from Equation (13).

$$
\rho=\frac{\mathrm{PM}}{\mathrm{RT}}
$$

where

$$
\begin{aligned}
\mathrm{P}= & \text { pressure }\left(\text { dynes } / \mathrm{cm}^{2}\right) \\
\mathrm{T}= & \text { absolute temperature, degrees Kelvin, and } \\
\mathrm{R}= & \text { universal gas constant, } 8.3144 \times 10^{7} \\
& \left(\text { ergs } /{ }^{\circ} \mathrm{K} / \text { mole }\right) .
\end{aligned}
$$

The density of the gas in states 2 and 3 is found by applying either Equation (2) or Equation (3), $\rho_{1}$ and $\rho_{4}$ being known from Equation (13),

$$
\begin{aligned}
& \frac{\rho_{2}}{\rho_{1}}=\Gamma_{21}=\frac{1+\alpha_{1} P_{21}}{\alpha_{1}+\frac{P_{21}}{P_{3}}}=\Gamma_{34}=\left[P_{14} P_{21}\right]{ }^{1 /} \gamma_{4}
\end{aligned}
$$

and $P_{21}$ for various mixtures of helium and argon read from the graphs shown in Figure 9 for the chosen $\mathrm{P}_{41}$ ratio. $\mathrm{P}_{14}$ is 


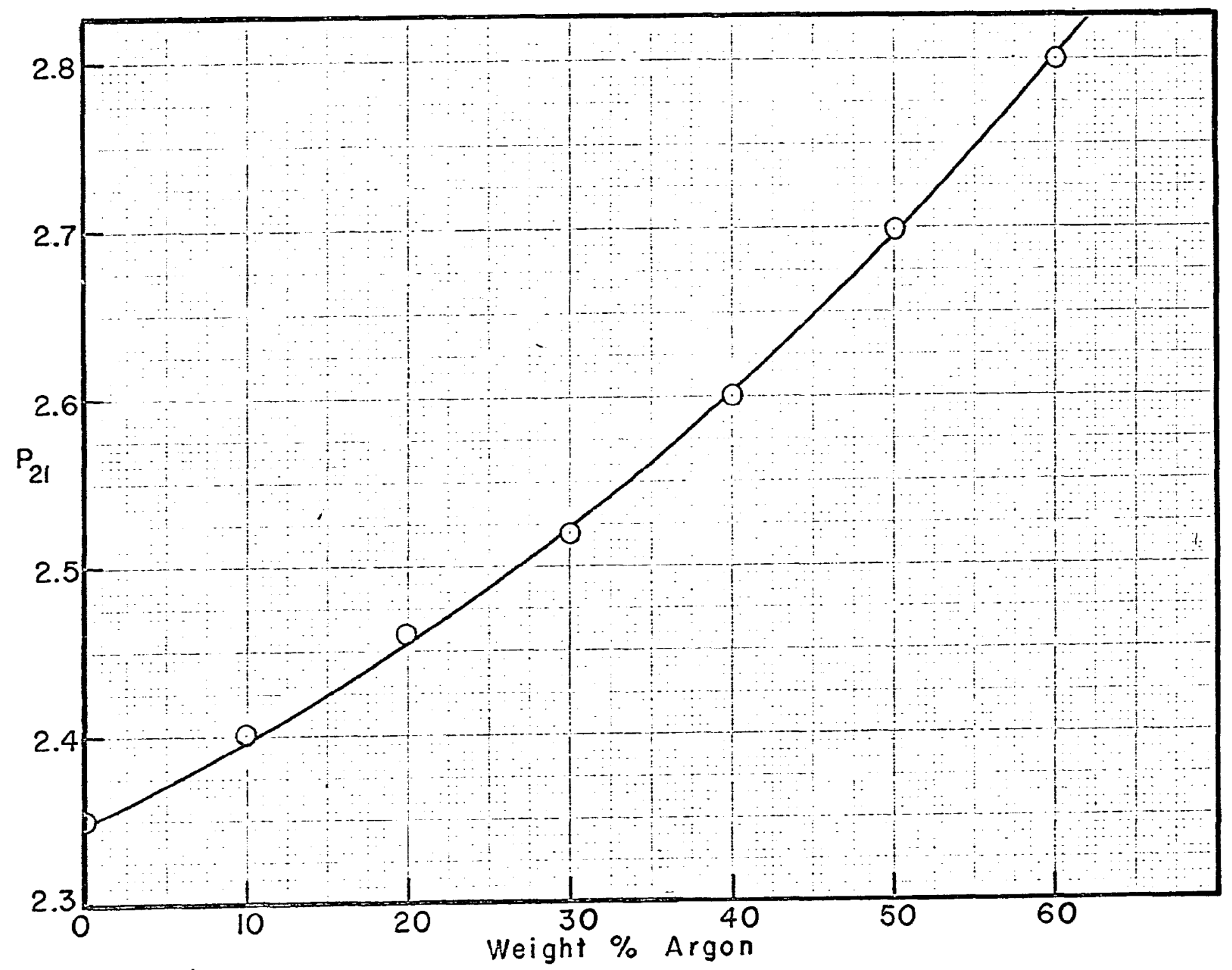

Figure 9. Relationship of $P_{21}$ and weight percent Argon at $P_{41}=6.5$. 
obtained from its reciprocal relationship with $\mathrm{P}_{41}$. Once $\rho_{2}$ and $\rho_{3}$ are known, $a_{2}$ and $a_{3}$ may be calculated from Equation (9), and acoustic impedance from Equation (12).

The acoustic impedance of states 2 and 3 were found for a series of gas mictures with a $\mathrm{P}_{41}=6.5$. The data are summarized in Tables 2 and 3.

The acoustic impedance values from these tables are plotted on a single graph against the weight 5 argon in the gaseous mixtures. The acoustic impedance of the two states match at the intersection of the two curves. This is illustrated in Figure 10. For $\mathrm{P}_{41}=6.5$, the match occurs at a helium-argon ratio of $87.5: 12.5$. From this information, the reaction temperature can be calculated.

\section{Table 2}

Acoustic Impedance of Helium-Argon Mixtures in State 2 for $\mathrm{P}_{41}=6.5$ with Pure Helium Driver

\begin{tabular}{rrrrrrr}
\hline \hline He & Ar & $P_{21}$ & $\begin{array}{r}\rho_{1 \times 10^{4}} \\
(\mathrm{~g} / \mathrm{m} 1)\end{array}$ & $\begin{array}{l}\rho_{2 \times 10^{4}} \\
(\mathrm{~g} / \mathrm{m} 1)\end{array}$ & $\begin{array}{l}a_{2 \times 10^{-5}} \\
(\mathrm{~cm} / \mathrm{sec})\end{array}$ & A.I.2 \\
& Wt $\%$ & & & & \\
\hline 100 & 0 & 2.35 & 1.636 & 2.679 & 1.217 & 32.6 \\
90 & 10 & 2.40 & 3.105 & 5.142 & 0.8879 & 45.7 \\
80 & 20 & 2.46 & 4.573 & 7.674 & 0.7358 & 56.5 \\
70 & 30 & 2.52 & 6.042 & 10.267 & 0.6438 & 66.1 \\
60 & 40 & 2.60 & 7.511 & 12.972 & 0.5818 & 75.5 \\
50 & 50 & 2.70 & 8.985 & 15.824 & 0.5369 & 85.0 \\
40 & 60 & 2.80 & 10.448 & 18.745 & 0.5023 & 94.2 \\
\hline
\end{tabular}


$\underline{\text { Table } 3}$

Acoustic Impedance of Helium-Argon Mixtures in State 3 for $\mathrm{P}_{41}=6.5$ with Pure Helium Driver

\begin{tabular}{lccccc}
\hline \hline He & Ar & $\Gamma_{34}$ & $P_{3} \times 10^{4}$ & $a_{3} \times 10^{-4}$ & A.I.3 \\
& Wt. \% & & $(\mathrm{g} / \mathrm{m} 1)$ & $(\mathrm{cm} / \mathrm{sec})$ & \\
\hline 100 & 0 & 0.5431 & 5.775 & 8.290 & 47.9 \\
90 & 10 & 0.5501 & 5.849 & 8.325 & 48.7 \\
80 & 20 & 0.5582 & 5.936 & 8.366 & 49.7 \\
70 & 30 & 0.5664 & 6.022 & 8.407 & 50.6 \\
60 & 40 & 0.5771 & 6.136 & 8.460 & 51.9 \\
50 & 50 & 0.5903 & 6.277 & 8.524 & 53.5 \\
40 & 60 & 0.6033 & 6.415 & 8.586 & 55.1 \\
\hline
\end{tabular}

The temperatures resulting from the initial and the reflected shock waves are calculated from Equations 4, 10, and 11 . For example, at $\mathrm{P}_{41}=6.5$ with pure helium driver and 12.5 weight $\%$ argon in the reaction section, $P_{21}=2.41$ (Figure 9), and the initial temperature $\mathrm{T}_{1}=\mathrm{T}_{4}=298^{\circ} \mathrm{K}$.

$$
\begin{aligned}
& \mathrm{T}_{21}=\frac{\mathrm{P}_{21}\left(\alpha_{1}+\mathrm{P}_{21}\right)}{1+\alpha_{1} \mathrm{P}_{21}} \\
& \mathrm{~T}_{21}=\frac{2.41(4+2.41)}{1+4(2.41)}=1.4519 \\
& \mathrm{~T}_{2}=298(1.4519)=433.0^{\circ} \mathrm{K} .=159.8^{\circ} \mathrm{C} . \\
& \mathrm{P}_{52}=\frac{\alpha_{1}+2-\mathrm{P}_{12}}{1+\alpha_{1} \mathrm{P}_{12}} \\
& \mathrm{P}_{52}=\frac{4+2-0.415}{1+4(0.415)}=2.1000 \\
& \mathrm{~T}_{52}=\frac{\mathrm{P}_{52}\left(\alpha_{1}+\mathrm{P}_{52}\right)}{1+\alpha_{1} \mathrm{P}_{52}}
\end{aligned}
$$




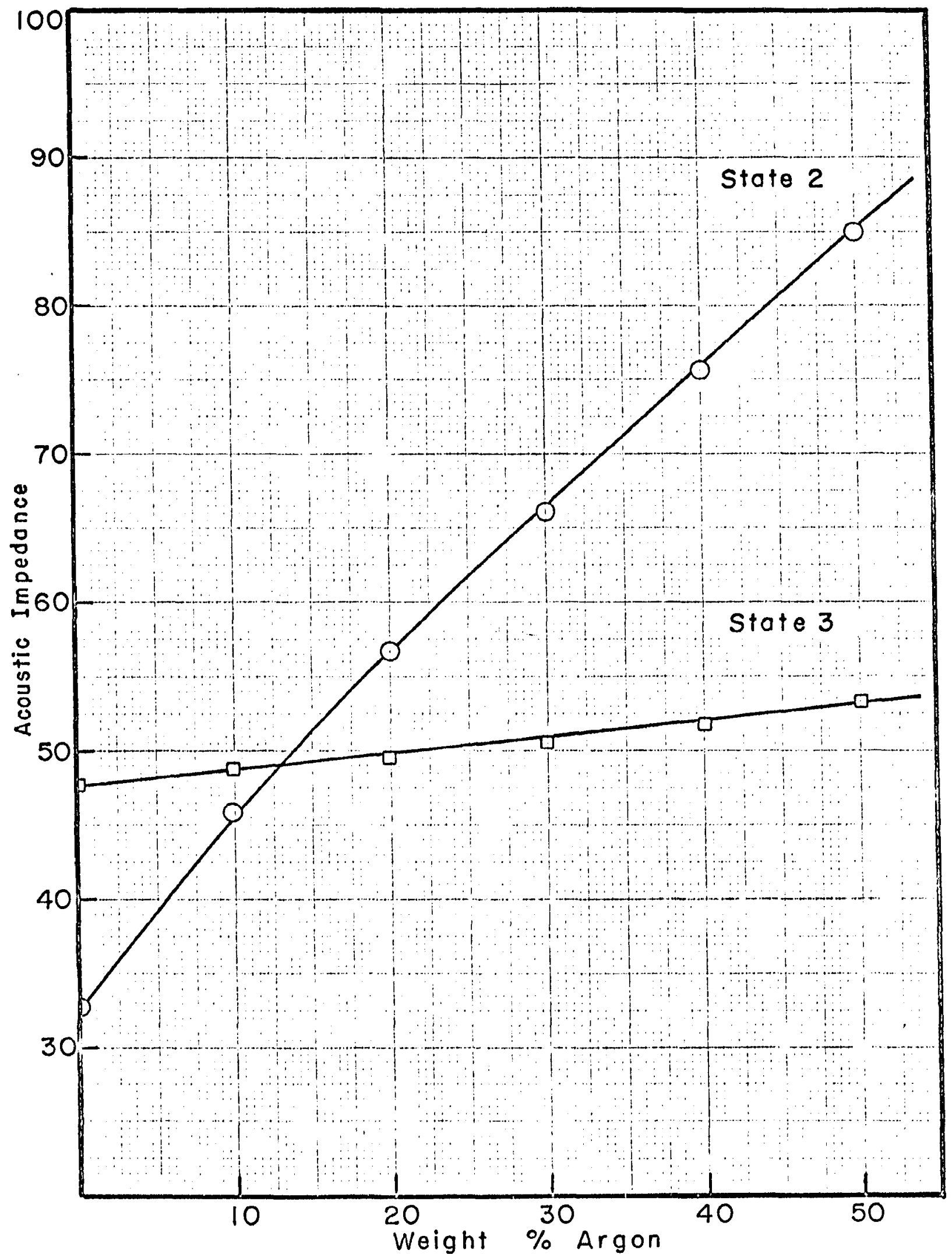

Figure 10. Acoustic impedance calculation for $P_{41}=6.5$. 


$$
\begin{aligned}
& \mathrm{T}_{52}=\frac{2.1000(4+2.1000)}{1+4(2.1000)}=1.3627 \\
& \mathrm{~T}_{5}=433.0(1.3627)=590.0^{\circ} \mathrm{K} .=316.8^{\circ} \mathrm{C} .
\end{aligned}
$$

The preceding calculations are considered ideal and usually not completely accurate. However, Strehlow ${ }^{54}$ has shown that

\footnotetext{
54Strehlow, R. A. and Cohen, A., J. Chem. Phys :, 28, 983 (1958).
}

their accuracy is not reduced at low $\mathrm{P}_{41}$ values by the addition of a few percent (2-3\% or less) of a polyatomic gas in the reaction section. $P_{5}$ and $P_{2}$ are experimentally measurable quantities, while $\mathrm{T}_{5}$ and $\mathrm{T}_{2}$ cannot be measured experimentally.

The temperatures can, however, be calculated from experimentally observable quantities utilizing Equation 6. This will be considered more fully in the next section. 
EXPERIMENTAL

The shock tube

The chemical shock tube (Figure 4) is fabricated of twoinch diameter stainless steel tubing (type 316) with a wall thickness of 0.125 inch. All sections except two are three feet in length. The sections can be connected by bolts inserted into holes on the brass flanges on the end of each metal tube. A vacuumtight seal is obtained through the use of 0 -rings seated in grooves in the flanges. A circular end plate of stainless steel, $\frac{1}{2}$ inch thick and $4 \frac{1}{2}$ inches in diameter, is used to seal the end of the shock tube. This plate has a stainless steel needle valve attached to it and is connected to a vacuum-pressure system for admitting and removing gases.

The length of the shock tube in most experiments was 14 feet, 8 inches. The driver section was 6 feet in length and the low-pressure section 8 feet, 8 inches long. The reaction section is 3 feet in length and is a part of the low-pressure section. The total volume of the shock tube in this configuration is 9.06 liters, with the volume of the reaction section being 2.02 iters. The stainless steel expansion tank has a capacity of about 75 liters. It can be connected to the shock tube by means of a brass flange. A needle valve is connected to the bottom of this tank. The tank is evacuated through this valve. 
Two of the three-foot sections are equipped to hold the fixing pin assembly for piercing the diaphragms. These two sections (those containing the firing pin assembly) are not interchangeable with the other shock tube sections. These two sections, when joined, from the six foot driver section.

The auxiliary shock tube is a device used for driving the firing pins of the diaphragm-piercing mechanism into the two main diaphragms. A $\frac{1}{4}$-inch copper tube connects the auxiliary shock tube to the nitrogen supply.

In order to isolate the reaction mixture from the buffer gas prior to the experiment, a smooth-bore, quick-opening valve is employed. The buffer gas is the gas between the high-pressure or driver section and the reaction section. This valve is an 0 -ring valve with the same inside diameter as the shock tube, thus preventing any wave disturbance from forming at the valve position.

The plastic plug (Figure 4) is employed as part of the oscilloscope triggering circuit. This plug contains two electrodes and is machined to fit a 9/16-inch diameter hole in one of the two-foot tube sections. The pressure pickups are mounted in a similar manner in the same size diameter hole.

The choice of diaphragms is very large. Lee, ${ }^{36}$ in his work, investigated a great many materials as to consistency of breaking pressure. He found that if the diaphragm were cut to a certain depth with a cutting die, a more uniform breaking pressure could be realized. In this work all diaphragms used were Alcoa aluminum 
type 3003-H14 with a thickness of 20 mils for $A$ and $B$ and 32 mils for the diaphragm in the auxiliary shock tube. These diaphragms are initially cut (i.e. scored) to a predetermined depth, usually 12 and 10 mils respectively. The cutting tool used to score the diaphragms was slightly modified from the one used by Lee in his work, to insure more consistent breaking pressures. The edges of the cutting tool were raised to a $20 \mathrm{mil}$ height in an arc of approximately 25 degrees on each side of the ends of the original cutting edge (Figure 11). The aligning block, the block used to hold the cutting die and diaphragm during the scoring procedure, originally made of wood, was machined to more stringent specifications from block aluminum. This completely prevented the diaphragm from moving while being scored.

The shock tube is prepared for reaction by first cleaning out the debris remaining from the previous experiment.

The shock tube configuration that would give the desired reaction time is chosen. The length of reaction time is governed by three separate but dependent relationships:

1. The pressure ratio $\mathrm{P}_{41}$ across the diaphragm between the highpressure driver section and the low-pressure buffer and reaction sections. The larger the $\mathrm{P}_{41}$ ratio, for a given shock tube configuration, the faster the speed of the shock wave, and hence a shorter reaction time.

2. The relative lengths of the driver and low-pressure sections of the shock tube. In general, lengthening the low-pressure 


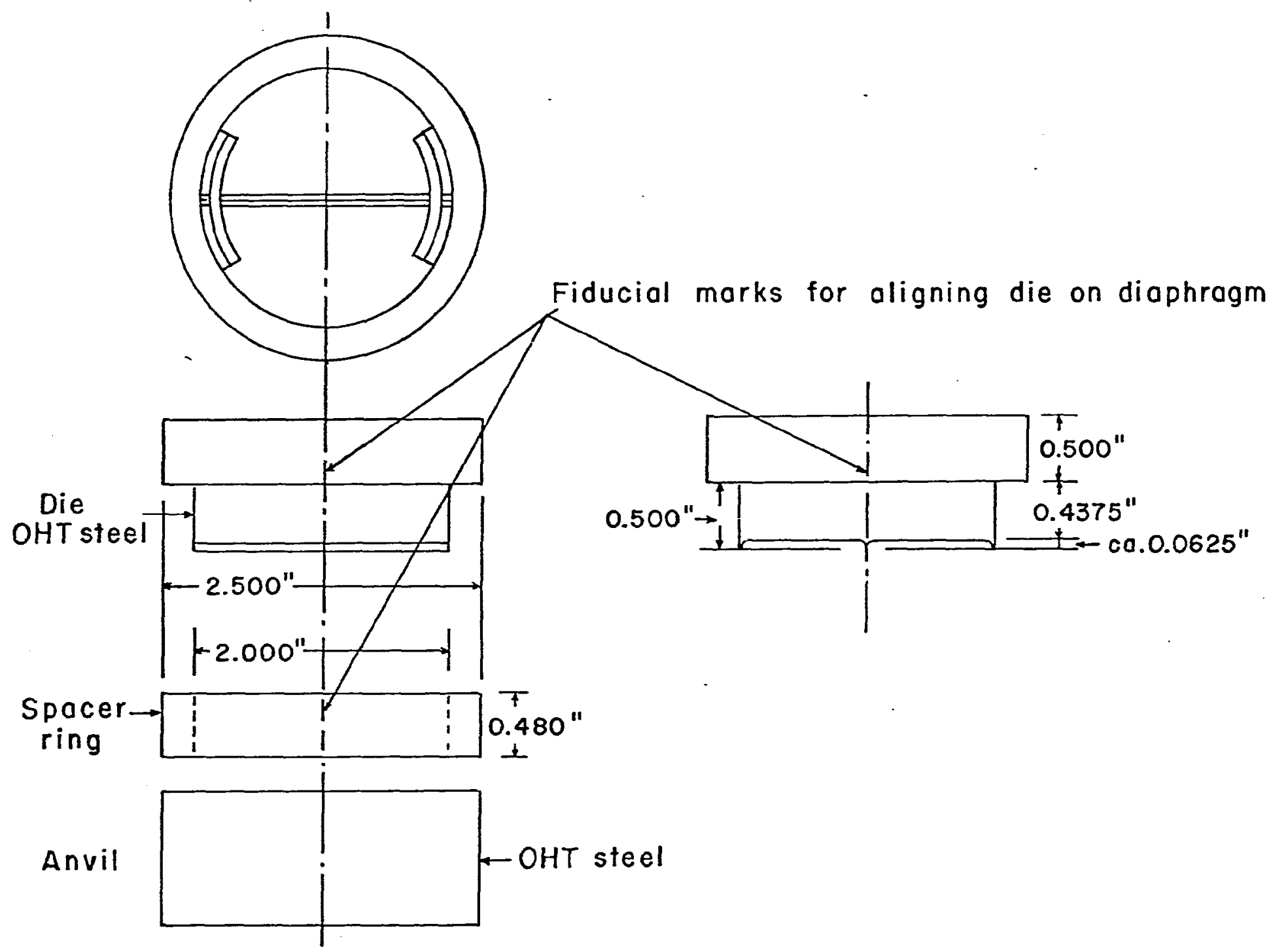

Figure 11. Modified apparatus for scoring diaphragms. 
section of the shock tube has little effect on the reaction time. If, however, the driver section is lengthened, a much longer reaction time can be attained.

3. The time difference between the breaking of the two main diaphragms.

These relationships have been experimentally determined for a variety of conditions, and reaction times differing by 0.1 millisecond can be reproduced. In the majority of the experiments, the pressure in the driver section was held constant. In order to vary the $\mathrm{P}_{41}$ ratio, the pressure in the low-pressure end of the shock tube was varied.

The two main diaphragms, $20 \mathrm{mils}$ scored to $12 \mathrm{mils}$ (A and $B$ ), are inserted in their proper places on the main shock tube and the auxiliary diaphragm, $32 \mathrm{mils}$ scored to $10 \mathrm{mils}$, is placed in the auxiliary shock tube. Coaxial leads are connected to the pressure transducers (pressure pickups). The pressure transducers are manufactured by The Swiss Locomotive and Machine Works, Winterhur, Switzerland, and distributed in this country by The Kistler Instrument Company. The transducers have a factory calibration factor of 4 pica-coulombs/psi. The leads from the transducers each go to a Charge Amplifier, Model 566. Each amplifier is equipped with various operating ranges in units of millivolts/ pica-coulomb. The amplifiers are manufactured by The Kistler Instrument Company. The charge amplifier connected to the transducer located in the reaction section of the shock tube is in 
turn connected to the input of a Type 53C vertical preamplifier on a single-sweep, dual-trace Tektronix 535 Oscilloscope. The time base of the oxcilloscope was calibrated to a tolerance of $\pm 2 \%$ in this laboratory using a time-mark generator, and the vertical deflection, measured in volts, is calibrated internally using standard square wave pulses from the oscilloscope. The other lead, from the charge amplifier connected to the transducer in the buffer section, is connected to the trigger input of a Beckman Universal Eput Timer, Model 7360. The timer starta as a result of the signal generated from the transducer located in the buffer section when the shock wave passes this transducer. To record the time-pressure events occurring in the shock tube, a Polaroid camera is attached to the face of the oscilloscope. The oscilloscope is triggered in the following manner. An aluminum loop (Alcoa foil, 1145-0, 0.00035 inches thick) is fastened across the electrodes of the plastic plug and kept in place by a conducting adhesive "Silver Print" manufactured by G. C. Electronics, Rockford; Illinois. Leads from the plug go to a DC power supply and trigger circuit (J1) designed and constructed in this laboratory (Figure 12). From the power supply, a lead is connected from $\mathrm{J} 2$ to the trigger input of the oscilloscope.

When the incident shock arrives at the transducer located in the reaction section, a vertical deflection is observed on the oscilloscope. This deflection generates a vertical signal output voltage in a ratio of two volts per centimeter vertical deflection. 


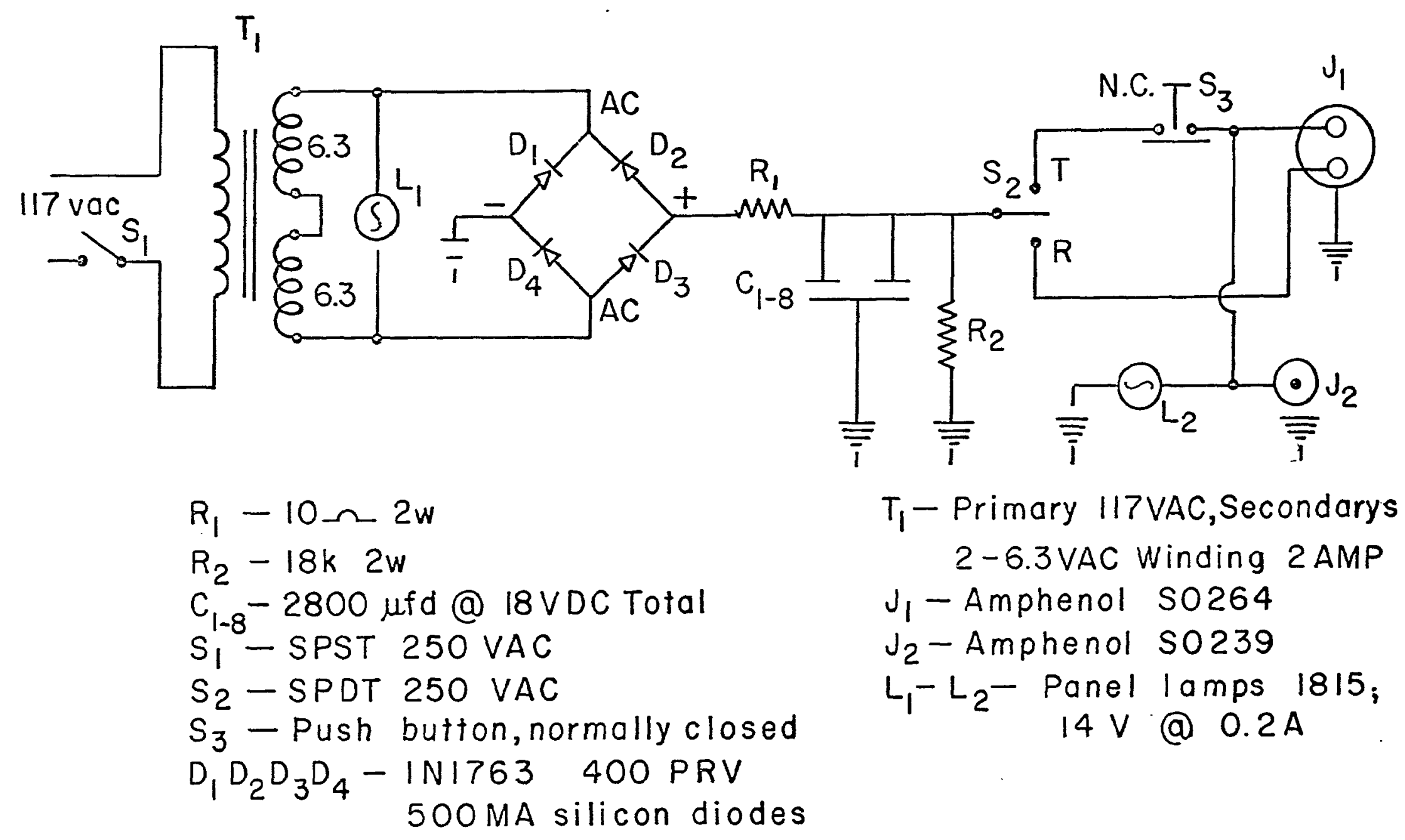

Figure 12. DC Power supply and trigger circuit. 
This voltage is utilized to stop timer by connecting a lead from the vertical signal output on the oscilloscope to the trigger stop on the timer. The time read from the timer after each experiment is the experimental wave time, and since the distance between the two transducers located on the shock tube can be accurately measured, the velocity of the shock wave can be calculated. Using the experimentally calculated shock wave velocity, an experimental reaction temperature can be calculated. This along with the trigger circuit will be discussed shortly. A block diagram of the electronic circuitry is illustrated in Figure 13.

It should be mentioned at this point that the above-described electronic circuitry was modified from the circuitry used in early experiments. The original system did not use the transducer located in the buffer section but used only the plastic plug and the transducer located in the reaction section. In this early set-up, the circuit was connected in the following manner. A coaxial cable was connected from the reaction section transducer, through a charge amplifier, to the input of the vertical preamplifier located on the oscilloscope. From the electrodes on the plastic plug, to which an aluminum loop was fastened, a lead was connected to the DC power supply and trigger circuit. From the power supply, a lead was split, one side going to the trigger input on the oscilloscope and the other side going to the trigger input on the timer. The timer started when the passing shock wave ripped the aluminum loop from the electrodes, as a result of a 


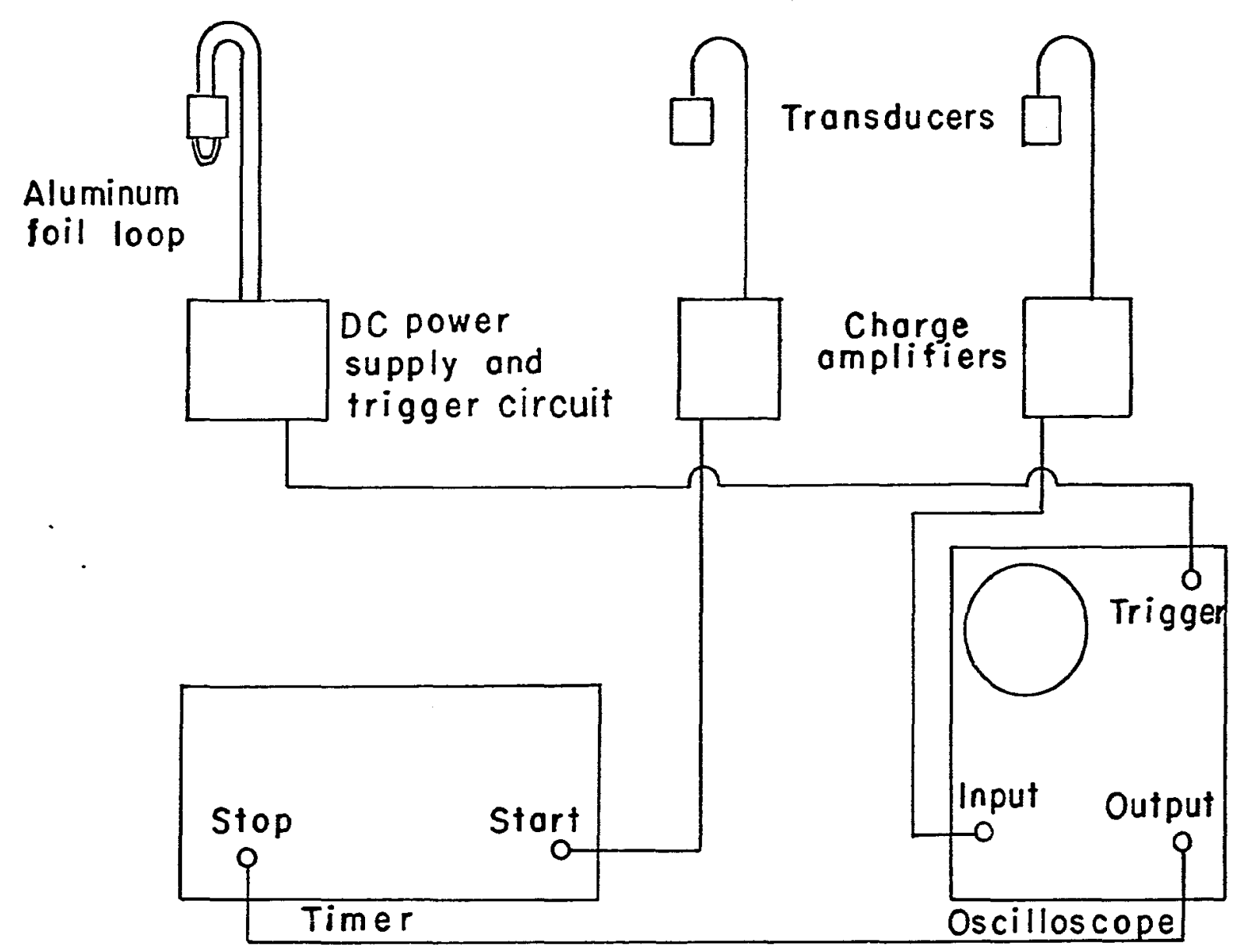

Figure 13. Block diagram of electronic circuitry. 
voltage signal generated through the power supply. The timer was stopped when the shock wave arrived at the pressure transducer 1ocated in the reaction section, since the initial vertical deflection on the oscilloscope was fed into the trigger stop on the timer. The experimental wave times obtained in this manner were not satisfactory. Calculations of reaction times based on these results yielded reaction temperatures only slightly above room temperature. The temperatures calculated by measuring pressure ratios obtained from photographs of the pressure-time oscilloscope traces were in good agreement with the theoretical calculated reaction temperature. It was decided since the aluminum loop was very close to the main diaphragm $A(12$ inches, six tube diameters), that perhaps the shock had not been formed when the gas passed the loop, and hence a longer than expected wave time was being measured. The change to the other system verified the doubts since a more realistic although not completely satisfactory wave time was obtajned using the two transducers. Using the experimental wave time and knowing the distance between the two pressure transducers, the speed of the shock wave $w_{1}$ can be calculated. Through the use of Equation (6), an experimental $\mathrm{P}_{21}$ can thus be obtained. $\mathrm{T}_{21}$ is then calculated using Equation (4) and by application of Equations (10) and (11), the temperature of the reaction $\mathrm{T}_{5}$ can be calculated. When this procedure was followed, the $\mathrm{T}_{5}$ values which were obtained were much less than the theoretical temperatures. 
The reaction temperatures recorded in this work are calculated from the pressure ratios $P_{21}$ and $P_{52}$. These were determined by measuring the heights of the pressure pulses on the pressuretime oscilloscope traces (see, for example Figure 8). These heights could be converted into units of pressure and since $\mathrm{P}_{1}$ was known, the ratios $\mathrm{P}_{21}$ and $\mathrm{P}_{52}$ could be calculated. With these two ratios and using Equations (4) and (11), the reaction temperature $\mathrm{T}_{5}$ could be calculated. The resulting temperature was in reasonable agreement with the theoretically calculated reaction temperature. For example, at $\mathrm{P}_{41}=6.5$ with a helium-argon mixture in a ratio of $87.5: 12.5$ (wt. \%) in the low-pressure section, a theoretical reaction temperature $\left(\mathrm{T}_{5}\right)$ of $317^{\circ} \mathrm{C}$. was calculated. The average reaction temperature at $\mathrm{P}_{41}=6.5$, calculated from the oscilloscope traces was $298^{\circ} \mathrm{C}$. while the reaction temperature calculated using the experimental wave times was much lower, being around $200^{\circ} \mathrm{C}$.

No completely satisfactory explanation for the poor wave times can be given. Either the shock wave was not completely formed when the mass of gas passed the first pressure transducer, (probably the case in some of the early measurements) or the timer was not functioning properly (assumed to be the case in some of the later experiments). In any case, all reaction temperatures were calculated using the measured pressure pulses obtained from the oscilloscope traces. 
The shock tube is initially evacuated to a pressure of at least 1 micron and maintained there for a period of time. The expansion tank is filled with helium to a pressure which yields a residual shock tube pressure of at least $850 \mathrm{~mm}$ after the reaction. The pressure in this tank is always between 22 and 28 inches of mercury absolute (56 to $71 \mathrm{~cm}$ ) and is read from a US Gage, Model 160 vacuum gauge. The driver section is slowly filled with helium to the desired $\mathrm{P}_{4}$ value. This pressure is read

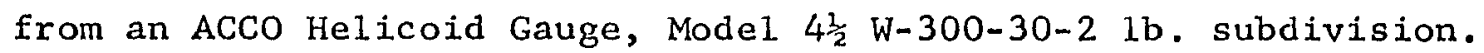
A mixture of helium and argon in the proper ratio for the "tailored-interface" method is prepared in a 622-cubic inch stainless steel tank (Figure 14). This tank (T) is equipped with

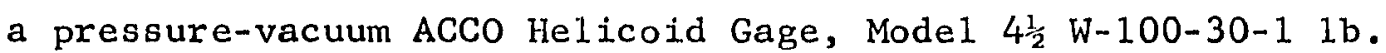
subdivision at the top $\left(G_{2}\right)$ and a Hoke bellows valve $\left(V_{1}\right)$ at the bottom. This tank is connected to both the vacuum system and to the tanks of helium $\left(V_{2}\right)$ and argon $\left(V_{3}\right)$. The mixture from this tank is used to fill the buffer and reaction sections to the desired $P_{1}$ value through $S_{1}$. This pressure is accurately read on a Wallace-Tiernan Absolute Prèssure Gage $\left(0-800 \mathrm{~mm}, \mathrm{G}_{1}\right)$. The quick-opening valve is closed and the reaction section re-evacuated to a pressure of less than 1 micron.

All gases are introduced into the low-pressure section of the shock tube through a conventional vacuum system of known volume (Figure 14). To introduce the reactant gases (pentane, oxygen, acetaldehyde and t-butylhydroperoxide) quantitatively 


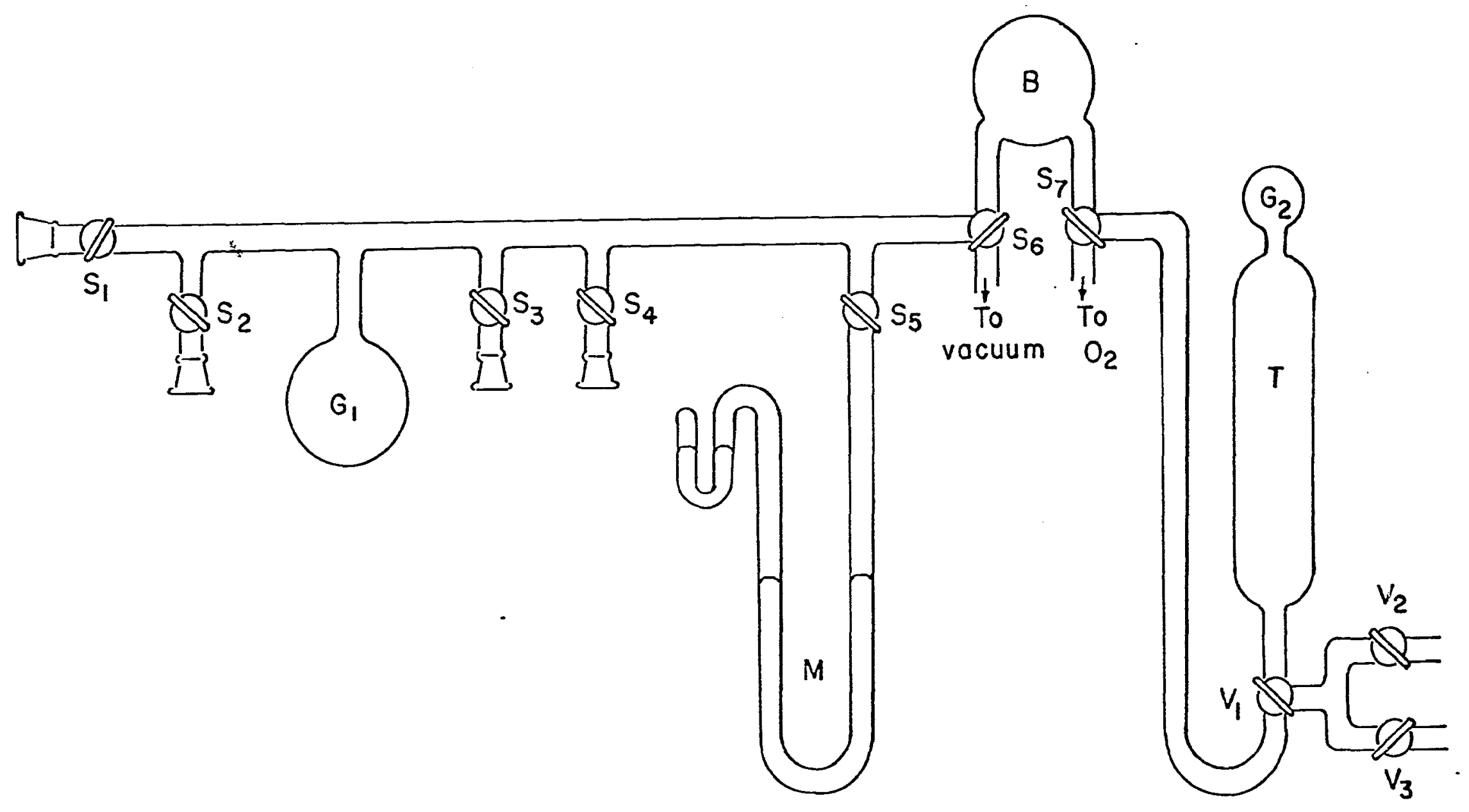

Figure 14. Vacuum system for transferring gases to and from reaction and buffer sections of shock tube. 
into the reaction section, sone novel pastures were developed. The pentane is introduced fro.l its storage bulb into the vacuum system at $\mathrm{S}_{2}$. A septum sample bulb (Ijigure 15) of known volume is atcached to the vacuum system at $\mathrm{S}_{3}$. The pentane vapor is allowed to expand into toth the septum sample bulb and into the reaction section through $S_{I}$. The approximab pressure $i:$ read from the Wallace-Tiernan Gagt. The reaction section of the shock tube and the sepium anpl, bulb : e closed ats ${ }_{1}$ and $\mathrm{S}_{3}$ respectivoly and the vacuum system re-evicua:d. A mixture of hei.ium and argum is then admittud to the systum. $S_{3}$ is npened to allow the noble gas mixtre to fill the sample septum bulb to a measured prossure i.ea: $700 \mathrm{~mm}$. The stopco ic $\mathrm{s}_{3}$ is $\mathrm{c}$ i sed and the sejtum bulb removed from the ystem. It is tiren placed on the mercury-leveling device (Figure 15). The prostite in du the bulb is adjusted to the neasured atmospheric pressure by raisine' the mercury reservoir. Samples are taken from the bull using a tamilton gas-aight syringe of cicher a $1 \cdots$ a $0.25 \mathrm{cc}$ total capacity. These samples vere injected into th gas chromatograph, and in this way the amount of pentane initially present in the shock tube could be calculated. Det....is concerning the procedures involving chromatographic andysis will be presented shorty. The oxygen was then admitted inio the vacuum system through $\$ 7$ to an approxinate prossure and allowed to expart into the reaction section of the shock abe through SI. The total pressi... of the pentane and oxyg in then read fron the mercury manometer $M$. 


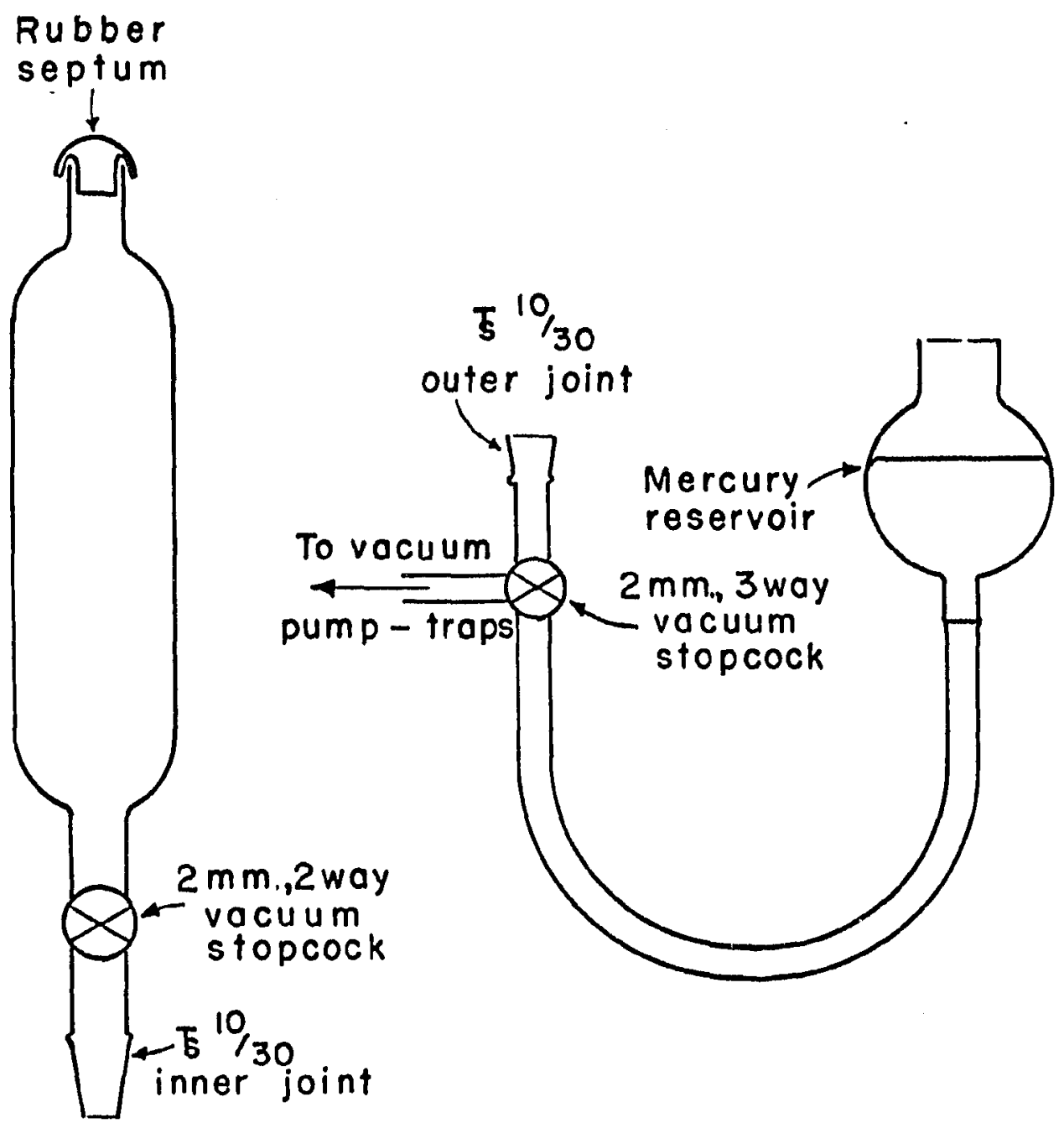

Figure 15. Calibrated septum sample bulb and mercury-leveling device. 
Knowing the number of moles of pentane obtained from the chromatographic analysis, and the temperature and the volume of the reaction section, the pressure of the pentane in the shock tube could be calculated. By the difference between it and the total pentane-oxygen pressure, the amount of oxygen initially present in the shock tube could be obtained. If pre-mixed pentane-oxygen mixtures were used, as in some experiments, the procedure was essentially the same. In this case, the pentane-oxygen mixture was admitted through $\mathrm{S}_{2}$ into the vacuum system, the septum sample bulb through $\mathrm{S}_{3}$ and the reaction section of the shock tube through $\mathrm{s}_{1}$. The pressure was read on the mercury manometer. $\mathrm{s}_{1}$ and $\mathrm{s}_{3}$ are closed and the system re-evacuated. A mixture of helium and argon is admitted to the vacuum system and admitted to the sample septum bulb as before. The remainder of the procedure is as described above.

In all of the experiments performed, the pentane concentration in the reaction section never exceeded about $2 \%$ of the total gas in the reaction section. This, on a mole basis, places the upper limit at about $1500 \mu$ moles. The majority of the experiments were carried out with the pentane concentration between 1000 to $1300 \mu$ moles.

Since in all of the acetaldehyde experiments it was desirable for the acetaldehyde concentration never to exceed about $3 \%$ of the pentane initially in the reaction system, which meant that the maximum amount of acetaldehyde put into the system never 
exceeded about $45 \mu$ moles or a pressure of $0.1 \mathrm{~mm}$, a slightly modified procedure had to be followed. On the vacuum system was inserted: the acetaldehyde storage bulb at $\mathrm{s}_{2}$, a sample bulb of known volume at $s_{3}$, and the septum sample bulb at $s_{4}$. The system was evacuated and $S_{1}$ was closed. Acetaldehyde was admitted to an approximate pressure so calculated that the amount of aldehyde in the sample bulb would, when expanded into the vacuum system and reaction section of the shock tube, be the desired amount of acetaldehyde for that particular experiment. The sample bulb and the septum sample bulb were closed with their respective stopcocks and the system again evacuated. Helium and argon from the "tailoredinterface" mixture is admitted to the system. $\mathrm{S}_{4}$ is opened to allow the noble gas mixture to fill the septum sample bulb to a measured pressure near $700 \mathrm{~mm}$. The stopcock $\mathrm{S}_{4}$ is closed and the septum bulb is removed from the system. The vacuum system is again evacuated. The septum bulb is placed on the mercury-leveling device and replicate samples analyzed gas chromatographically as before. With this analysis, the amount of acetaldehyde in the sample bulb remaining on the vacuum system could be calculated as could the amount of acetaldehyde in the reaction section after expansion of this acetaldehyde into the vacuum system and reaction section. After the acetaldehyde was expanded into the vacuum system and reaction section, $S_{1}$ was closed and the system again evacuated. Pentane and oxygen or pentane-oxygen mixtures were admitted 
as before, and the pentane analyzed according to the method described previously.

Since no convenient gas chromotographic method for t-butylhydroperoxide analysis was available, the following procedure was used. Into the vacuum system was inserted the peroxide storage bulb and a bulb of known volume. They were placed on the system at $\mathrm{S}_{2}$ and $\mathrm{S}_{3}$ respectively. The peroxide was expanded into the vacuum system and the calibrated sample bulb and the pressure measured on the mercury manometer. $\mathrm{s}_{2}$ and $\mathrm{S}_{3}$ were closed and the system re-evacuated. After completion of the evacuation, $\mathrm{S}_{1}$ and $S_{3}$ were opened and the contents of the calibrated bulb allowed to expand into the vacuum system and the reaction section of the shock tube. Since the volume of the entire system was known, a calculable dilution had been effected. $S_{1}$ is then closed and the remainder of the system again evacuated. Pentane and oxygen or pentane-oxygen mixtures were admitted as before and the pentane analyzed as described previously.

After the reactant gases and additives had been introduced into the reaction section as described, the noble gas mixture of helium and argon in the proper wt. \% to effect a "tailored-inter face" experiment was admitted through $S_{1}$ to raise the pressure to the desired $P_{1}$ The endplate valve was closed and the experiment was now ready to be initiated. The instruments which were "warming" during this time were set to their proper scales and the camera was attached to the face of the oscilloscope. The triggering 
level of the oscilloscope was adjusted in the following manner.

$\mathrm{S}_{2}$ (Figure 12) of the DC power supply and trigger circuit was switched to $\mathrm{T}$ (test) and $\mathrm{S}_{3}$ was alternately opened and closed. If the circuit was functioning properly, $\mathrm{L}_{2}$ would 1 ight when the switch was closed and go off when the switch was open. The trigger level of the oscilloscope was increased until the instrument triggered the sweep when $\mathrm{S}_{3}$ was opened. $\mathrm{S}_{2}$ was now switched to $R$ (ready) and $L_{2}$ remained illuminated since the circuit is, in this position, completed through the plastic plug. At this position $\mathrm{L}_{2}$ could only go out if the aluminum loop on the plastic plug was ripped off, or if, when placing the plug with the loop fastened to it in the shock tube, contact of the loop and the wall of the shock tube was made. The trigger level on the stop side of the timer was adjusted so that a vertical oscilloscope deflection of only $0.2 \mathrm{~cm}(0.4$ volts) would activate it. The start side of the timer triggers when the shock wave passed the transducer located in the buffer section.

A picture of the illuminated graticules on the oscilloscope is now taken with the Polaroid camera. The setting for the camera is F-16 and the exposure time is 0.5 seconds. The lights illuminating the graticules are turned off and the exposure time set to keep the shutter open. It remained open until the experiment was completed, and then closed. In this manner, a pressure-time record for each experiment is obtained. The film which proved to 
be the most satisfactory throughout this work was Polaroid, 3000 speed, Type 47.

To initiate the experiment, the quick-opening valve was opened and the pressure in the auxiliary shock tube increased with nitrogen until the diaphragm broke. The shock wave thus formed initiated the two firing pin mechanisms on the main diaphragms ( $A$ and $B$ ) to break in the desired sequence. After the experiment was completed, the quick-opening valve was closed, isolating the reaction mixture.

The shocked gases were transferred from the shock tube in one of three ways, depending upon which types of analytical experiments were to be performed upon the resulting gaseous mixture. If the amount of peroxides formed during the oxidation reaction was to be determined, the gas mixture was transferred under a slight vacuum through a gas scrubber system. This scrubber system consists of a two-piece trap in which a fritted glass filter is affixed by means of a ring-seal. The bottom of the trap is removable so that it can be filled with the analytical reagents, or emptied of the mixture that is to be analyzed for peroxides. The trap containg, prior to the scrubbing of the shocked gas mixture, a solution of alcoholic sodium iodide and glacial acetic acid. If analysis of the non-peroxidic products in the mixture of shocked gases is to be performed, two procedures can be followed. In both methods the gas chromatograph is used as the analytical tool. 
The first method utilized the fact that a calculable dilution could be effected. After the quick-opening valve is closed, after the passage of the shock wave, the endplate valve and $S_{1}$ are opened, and the shocked gases allowed to expand into the previously evacuated vacuum system. The sample septum bulb, also evacuated, is attached to the vacuum system at $\mathrm{S}_{2}$. The resulting pressure in the entire system is recorded and $S_{2}$ is closed. The septum sample bulb is removed from the system and placed on the mercury-leveling device. Replicate samples are then injected into the gas chromatograph using a gas syringe.

The second method involves the complete entrappment of the condensable gases (condensable at the boiling point of liquid nitrogen) resulting from the oxidation reaction. The entrappment was effected by passing the gases through two traps connected in series, each with a volume of about $150 \mathrm{cc}$. Both traps are immersed in baths of liquid nitrogen. The trap nearest the endplate valve is filled with glass beads and the second is empty. From the outlet of the second trap, tubing leads to a wet test flow meter. After the quick-opening valve is closed, the endplate valve is opened and the mixture of shocked gases allowed to expand into the previously evacuated traps. The traps are maintained at liquid nitrogen temperature during this time. After allowing the gaseous mixture to remain in contact with the cold traps for a period of time, the quick-opening valve is slightly opened thus initiating a slow flushing movement of the gases through the 
cold traps. This flushing process is continued until a total of 3 cubic feet of gas has passed through the flow meter. The time required for completion of this process is usually about 40 minutes. After completion of this portion of the experiment, the two traps, still immersed in liquid nitrogen, are connected to the vacuum system at: $S_{1}$ and the non-condensable gases pumped off. $S_{1}$ is closed and the liquid nitrogen removed from the two traps. $\mathrm{S}_{2}$, which had connected to it a previously evacuated U-tube septum sample container of known volume, was now opened as was $\mathrm{S}_{1}$. The condensable gases from the two traps were transferred to the septum sample holder which was now immersed in liquid nitrogen. After complete transferral of the condensable gases, $s_{1}$ and $s_{2}$ are closed and the U-tube septum holder allowed to warm to room temperature. Upon reaching room temperature, the U-tube trap is placed on the mercury-leveling device and samples for analysis removed from it using a gas syringe. The samples removed in this manner are injected into the gas chromatograph.

The size of the gas sample injected into the gas chromatograph varies with each experiment. The amount injected was a1ways in a quantity that corresponded to the concentration ranges of the standard curves that were prepared for each compound of interest. If a particular injection resulted in a peak height that was not in the range of the standard curves, a smaller amount was injected the next time.

The gas-chromatographic analysis of the pentane and the 
acetaldehyde was conducted at room temperature. The standard curves of concentration vs. peak height were also prepared under the same conditions. Peak height was used as a measure of the concentration since both the pentane and acetaldehyde peaks were symmetrical. Periodically, new standard curves had to be prepared since the "aging" of the gas-chromatographic columns changed some of their characteristics.

In the latter part of the work, it bacame necessary to alter the method of gas chromatographic analysis slightly while analyzing for products other than hydroperoxides. The column was initially cooled with liquid nitrogen to a temperature of below $-20^{\circ} \mathrm{C}$. and allowed to warm to this temperature. The gas sample to be analyzed then injected. After the elution of the pentane peak, the columns were temperature programmed at the rate of $3 \% / \mathrm{min}$. to $30^{\circ} \mathrm{C}$. In this manner, a very suitable separation of the oxidation products could be effected.

Tentative identification of the products of the oxidation reaction was determined by measuring retention times of known compounds. If while analyzing a gaseous mixture, a compound eluted that had not been expected, additional compounds were placed on the column and their retention times measured. Positive identification of an oxidation product was made in the following manner. A small amount of a known compound that was suspected to be in the reaction mixture was drawn into the syringe containing the unknown sample and the composite mixture and 
injected into the gas chromatograph. If the peak height of the compound in question was much larger than it would be if no addition had been made to the reaction mixture and no shoulders were evident, it was presumed to be the compound in question. In this way, it was also possible to eliminate other possible products of the oxidation reaction. This is possible because if, upon injection of a known compound and a sample from the oxidation mixture simultaneously into the gas chromatograph, a new peak appeared in the chromatogram that was not present when only a sample from the oxidation mixture was injected, then the known compound could not be an oxidation product.

The gas chromatograph employed throughout this study was an Aerograph Model A-350-B, dual column, temperature programmed instrument. It is manufactured by Wilkens Instrument \& Research, Inc., Walnut Creek, California. It was fitted with dual columns packed with Bis $[2-(2-m e t h o x y-e t h o x y)$ ethyl $]$ ether $25 \% \mathrm{w} / \mathrm{w}$ on $30-60$ mesh acid-washed firebrick. The stainless steel (type 316) columns were both 5 feet in length and $z_{4}$-inch in diameter. They were fitted with $x_{4}$-inch brass Swagelock fittings. The maximum usable temperature of the columns is $70^{\circ} \mathrm{C}$.

The conditions which were generally used for analysis are the following: helium head pressure was maintained at 50 psig, the temperature of the injector was $65^{\circ} \mathrm{C}$, the detector temperature was $145^{\circ} \mathrm{C}$, the DC filament bridge current was set at $220 \mathrm{ma}$, and the flow rate of the helium gas through the columns 
was $50 \mathrm{cc} / \mathrm{min}$. The flow rate was measured by means of a soap bubble counter located at the collector ports.

\section{Peroxide analysis}

The most widely used method of peroxide analysis is the iodometric method which is dependent upon the quantitative oxidation of iodide ion to iodine. The iodine can be liberated in a number of ways and is usually titrated with an aqueous sodium thiosulfate solution.

A variety of methods were used with various modifications which were seemingly dictated by the experimental results obtained. The general methods used will be discussed and as the results are presented, the modifications employed will be iterated along with the necessary supporting data. The first method of analysis attempted was the of Nozaki 55 and the procedure is as

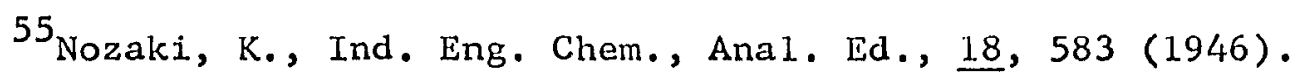

follows. To a hydroperoxide sample, 5-10 $\mathrm{ml}$. of reagent grade acetic anhydride and 1 gram of $\mathrm{NaI}(\mathrm{s})$ are added. The mixture is swirled and allowed to stand for 5-20 minutes. 50 to $75 \mathrm{ml}$. of $\mathrm{H}_{2} \mathrm{O}$ are then added and the solution titrated to the starch endpoint using standardized sodium thiosulfate.

Freshly opened reagent grade acetic anhydride is stated to give a blank of $<0.01 \mathrm{ml}$. with $0.1 \mathrm{~N}$ sodium thiosulfate after 
standing 20 minutes with NaI in air. The reaction would be

$$
\mathrm{O}_{2}+4 \mathrm{H}^{+}+4 \mathrm{I}^{-} \stackrel{\mathrm{k}}{\longrightarrow} 2 \mathrm{I}_{2}+2 \mathrm{H}_{2} \mathrm{O}
$$

and $k$ is stated to be increased in the presence of acetic acid. In the Winter method, 56 two grams of sodium bicarbonate is

${ }^{56}$ Winter, Paul K., General Motors Corporation, Private Communication, (1942).

dissolved in $50-100 \mathrm{ml}$. of acetic anhydride in a $125 \mathrm{ml}$. Erlenmeyer flask and left for 10 minutes to drive off the dissolved oxygen. The hydroperoxide sample is added with a few $\mathrm{ml}$. of saturated NaI in water; the flask is stoppered and left in the dark for 15 minutes. The sample is titrated with $0.01 \mathrm{~N}$ thiosulfate to the starch endpoint.

In the method of Kokatnur and Jelling, ${ }^{57} 25-50 \mathrm{ml}$. of $99 \%$

57 Kokatnur, V. K. and Jelling, M., J. Am. Chem. Soc., 63, 1432 (1941).

isopropanol, $1 \mathrm{ml}$. of saturated $\mathrm{KI}$ in water, $1 \mathrm{ml}$. of glacial

acetic acid, and the hydroperoxide are placed in an Erlenmeyer flask and heated to boiling for 2-5 munutes. The sample is titrated hot with standard thiosulfate to the disappearance of the yellow color. This method is stated to be accurate to $0.01 \mathrm{~m} 1$. with $0.005 \mathrm{~N}$ thiosulfate on a sample that is $0.0001 \mathrm{~N}$ in peroxygen. 
In the modified Petry method, ${ }^{58}$ freshly distilled isopropanol

58 Petry, R. C., "The Products of the Reaction Between Oxygen and Trimethylborane Below the Explosion Limits," Ph.D. dissertation, The Ohio State University (1958).

is used to prepare a saturated solution of NaI which is diluted with an equal volume of this same isopropanol. This solution then had tank nitrogen bubbled through it for 10 minutes to remove any dissolved oxygen. The solution is stored in a flask fitted with a serum cap. Glacial acetic acid is prepared and stored in a similar manner. The aix in a $50 \mathrm{ml}$. weighing bulb with a side arm attached is displaced with nitrogen and $15 \mathrm{~m} 1$. of alcoholic $\mathrm{NaI}$ and $2 \mathrm{ml}$. of glacial acetic acid are introduced by means of a syringe through a serum cap which had been placed over the opening of the side arm. The solution is degassed on the vacuum line by freezing and thawing at least 4 times at $-196^{\circ} \mathrm{C}$. The hydroperoxide sample is introduced and the flask allowed to warm to room temperature. It remains there for 90 minutes. The contents are emptied into an Erlenmeyer flask and the reaction flask is rinsed 4 times with $5 \mathrm{ml}$. portions of isopropanol. The liberated iodine is titrated with $0.05 \mathrm{~N}$ thiosulfate to the disappearance of the yellow color while agitating with a magnetic stirrer. Initially, the Nozaki method was used to analyze a number of $1 \mathrm{ml}$. samples taken from a stock solution prepared by diluting $1 \mathrm{ml}$. of 3 -pentane hydroperoxide to $100 \mathrm{ml}$. with Phillips Pure 
Grade n-pentane. The number of $\mathrm{ml}$. of $0.01 \mathrm{~N}$ sodium thiosulfate required to titrate to the starch endpoint was:

$$
\begin{array}{rrrrrrr}
10.84 & 13.22 & 12.83 & 11.18 & 9.50 & 13.29 & 13.60 \\
12.51 & 11.82 & 13.85 & 12.20 & 13.47 & 13.07 &
\end{array}
$$

On a freshly prepared stock solution of the hydroperoxide, the same analytical procedure was employed except that each step in the procedure was rigidly standardized. The following ( $\mathrm{ml}$. of $0.01 \mathrm{~N}$ thiosulfate) data on $1 \mathrm{ml}$. samples were obtained:

$$
\begin{array}{lllllll}
14.95 & 17.23 & 14.20 & 13.07 & 12.75 & 14.00 & 14.47 \\
13.10 & 13.97 & 13.13 & 11.91 & 12.15 & 13.00 &
\end{array}
$$

It must be emphasized that these sets of data should not necessarily conform to each other since the analyses were performed on different stock solutions.

In a separate set of experiments, small quantities of $\mathrm{H}_{2} \mathrm{O}(0.1-0.2 \mathrm{ml}$.$) were initially added to the reaction mixture$ along with the other reactants, while employing the Nozaki method. The data obtained on $1 \mathrm{~m} 1$. samples from the second stock solution were as follows:

$$
\begin{array}{llllllll}
19.29 & 19.75 & 21.87 & 21.98 & 19.05 & 20.00 & 20.95 & 17.73
\end{array}
$$

A few experiments were conducted under an atmosphere of nitrogen on $1 \mathrm{ml}$. samples of the second stock solution using again the Nozaki method. No visible differences in the results were, 
noted when compared to the data above. The reproducibility was no better.

The method of Kokatnur and Jelling was employed on four $1 \mathrm{~m} 1$. samples of the second stock solution. The samples were titrated hot with $0.01 \mathrm{~N}$ thiosulfate and required:

$$
31.05 \mathrm{ml} .31 .25 \mathrm{ml} .31 .13 \mathrm{ml} .31 .25 \mathrm{ml} \text {. }
$$

As can be seen, the data are fairly reproducible, but since the values at the time seemed abnormally high, they were totally disregarded.

A new stock solution was then prepared by diluting 3-pentane hydroperoxide with pentane as before. Since it was apparent that the above attempts at precision analysis yielded very diverse results, the Winter method was tried. Several $1 \mathrm{ml}$. samples were analyzed using $0.01 \mathrm{~N}$ thiosulfate and the results were poorly reproducible. The titration values varied by a factor of twenty five.

As it appeared that oxygen dissolved in the solvents might have an effect on the amount of iodine liberated, the solvents used in the Nozaki method were thoxoughly degassed by passing tank nitrogen through them for at least 4 hours. The analyses were then carried out as before and the results were:

$$
9.71 \mathrm{ml} .10 .78 \mathrm{ml} . \quad 11.60 \mathrm{ml} .8 .45 \mathrm{ml} \text {. }
$$

Again the reproducibility was very poor.

Another attempt at eliminating oxygen was to degas the 
reaction mixture, less the NaI solution, by freezing at $-196^{\circ} \mathrm{C}$., evacuating and thawing. This process was repeated several times. The mixture was allowed to warm to room temperature and the iodide solution introduced through a rubber septum by means of a syringe. The reaction was allowed to continue for an extended period of time (2-3 hours) and the mixture titrated to the starch endpoint with standard thiosulfate. The data were again very imprecise as indicated by the following values ( $\mathrm{ml}$. ) on $1 \mathrm{ml}$. samples of the stock hydroperoxide:

$$
\begin{array}{llllllll}
9.61 & 6.80 & 10.70 & 10.66 & 6.42 & 5.65 & 9.55 & 8.60
\end{array}
$$

A modified method of analysis using isopropanol-acetic acid as the reaction medium was found to be satisfactory. The alcohol was degassed overnight by bubbling tank nitrogen through it. The solution was saturated with reagent grade NaI powder, and stored in the absence of oxygen. The reagent grade glacial acetic acid was used without any treatment. The method which is a combination of Petry's and Kokatnur et al. was as follows:

$25 \mathrm{ml}$. of alcoholic NaI, $2 \mathrm{ml}$. glacial acetic acid and $1 \mathrm{ml}$. of the hydroperoxide sample were placed in a $125 \mathrm{ml}$. Erlenmeyer flask and refluxed (the condensation ring remaining below the neck of the flask) on a hot plate for a period of 2-3 minutes. The hot contents were titrated to the disappearance of the yellow color of iodine using $0.01 \mathrm{~N}$ thiosulfate. 
The data on $1 \mathrm{ml}$. samples of 2 different stock solutions are presented below:

Solution No. 1

$32.35 \mathrm{ml} . \quad 32.47 \mathrm{ml} . \quad 32.51 \mathrm{ml} . \quad 32.49 \mathrm{ml}$.

Solution No. 2

$$
\begin{aligned}
& 6.06 \mathrm{ml} .6 .05 \mathrm{ml} .6 .06 \mathrm{ml} .6 .07 \mathrm{ml} . \\
& 6.05 \mathrm{ml} .6 .05 \mathrm{ml} .6 .05 \mathrm{ml} .
\end{aligned}
$$

No blank was required in either set of analyses.

The very apparent low values and poor precision of the data obtained from the method of Nozaki can be readily explained. It is well known that acetic anhydride and some alkyl hydroperoxides react quickly and easily to form peroxyesters. Some of these esters hydrolyze very slowly under the gentle conditions of weak acid hydrolysis to form the initial hydroperoxide. Thus it appears that, using this analytical method, there was introduced into the system two competing reactions, both seeking the peroxide as the reactant. Since no rate constants are recorded for the rate of iodine formation and the rate of esterification in this system, there is no way of definitely knowing which reaction predominates although it appears qualitatively that the rate of the esterification reaction proceeds approximately twice as fast as the iodineproducing reaction. This resulted in the seemingly low values of the titer and the apparent inconsistency of the data. The high results obtained when water was initially added to the reaction mixture is due to the fact that when the water was present, the 
acetic acid formed from its anhydride hydrolyzed some of the ester formed back to the initial peroxide, or the acid catalyzed the reaction between oxygen and iodide to form iodine.

It appears from the above data that the modified method using alcoholic NaI is the best method for the analysis of alkyl hydroperoxides. The method is very precise. The accuracy of the method cannot be measured since the stock solutions were prepared from samples of the hydroperoxides with stated purities of $88-96 \%$. These samples could have partially decomposed over a period of years. But in all cases in which the stock solutions were prepared, a definite titer was aimed for and, in the case of the accepted method of analysis, the $1 \mathrm{~m} 1$. hydroperoxide samples always titered out to within $1 \mathrm{ml}$. of the expected value. Since the $1: 100$ dilutions of the "pure" peroxides were made by pipetting $1 \mathrm{ml}$. samples at low temperatures (to avoid unnecessary hazards at higher temperatures), there is an inaccuracy associated with this original dilution, and the result to with in $1 \mathrm{ml}$. of the mark is as good as can be expected.

To analyze for peroxides and hydroperoxides in the reaction section resulting from the passage of the shock wave, the above method of analysis was used. The gas scrubber system, as described earlier, was placed between the shock tube and the vacuum system. Into the gas scrubber was placed the reagents, namely alcoholic NaI and glacial acetic acid. After the experiment was completed, the endplate valve on the shock tube was opened and 
the gases in the reaction section were transferred through the fritted glass filter in the scrubber by means of a partial vacuum. After proceeding for a period of time, the quick-opening valve was again opened for a moment filling the reaction section with gas, composed primarily of helium and argon. This gas was also passed through the scrubber system. This ensured that the total amount of reactant gas had been transferred through the scrubber. The scrubber was removed from the system and its contents placed in a $125 \mathrm{ml}$. Erlenmeyer flask. The scrubber was rinsed several times with $5 \mathrm{ml}$. portions of the alcoholic NaI solution and these added to the contents in the flask. The contents of the flask were then analyzed for peroxides and hydroperoxides in the manner described above.

Stability of 3-pentane hydroperoxide in the reaction section of the shock tube

After an acceptable method for peroxide analysis had been devised, the stability of 3-pentane hydroperoxide in the reaction section of the shock tube was investigated.

A measured amount of the hydroperoxide solution was placed in a U-tube and frozen, and the tube evacuated. This U-tube was connected to the evacuated reaction section of the shock tube. After warming to room temperature, the contents of the U-tube were expanded into the reaction section of the shock tube, and helium-argon was added to a total pressure of about $700 \mathrm{~mm}$. By 
titrating the hydroperoxide remaining in the U-tube and knowing the titer of the amount of hydroperoxide originally in the U-tube, the amount of hydroperoxide that entered the reaction section of the shock tube could be determined by difference.

After a period of time, the contents of the reaction section were removed and passed through the gas scrubber system, and the contents titrated for peroxides using the method described above. This procedure was repeated for several different times corresponding to the length of time the hydroperoxide remained in the shock tube, prior to removal, in actual oxidation experiments. The results indicate that the hydroperoxide does not decompose in the shock tube for at least ten minutes. No data were obtained for times greater than this.

\section{Materials}

n-Pentane: Throughout the entire course of this work, Phillips Pure Grade n-pentane ( 99 mole \% pure) was used. It was passed through a Silica Gel (6-16 mesh, Fisher Scientific) column $20 \mathrm{~cm}$. in height and $2.5 \mathrm{~cm}$. in diameter to remove any possible peroxidic materials. It was then transferred to a vacuum system where it was degassed by freezing and thawing at $-196^{\circ} \mathrm{C}$, at least 4 times. A portion of it was then distilled under vacuum to a vacuum storage bulb. A portion of this was analyzed mass spectrometrically and the mass spectra obtained agreed very well with the API known spertra of $n$-pentane. The pentane was stored in the refrigerator when not in use. In later sample preparations, mass 
spectra were not obtained. The procedure for preparation was not altered however.

Oxygen: Tank oxygen (Liquid Carbonic) was used without further treatment.

Nitrogen: Tunk nitrogen (Liquid Carbonic) was used without further treatment.

Helium: Tank helium (Liquid Carbonic) was used without further treatment.

Argon: Tank argon (Liquid Carbonic) was used without further treatment.

Acetaldehyde: Eastman Kodak "White Label" acetaldehyde was used throughout the course of this research. It was degassed under vacuum by freezing and thawing at $-196^{\circ} \mathrm{C}$. at least 3 times. A portion of this was distilled under vacuum to a vacusm storage bulb. When not in use, it was stored in the refrigerator. 1-Pentene: A product of Matheson, Coleman and Be11, 1-pentene had a minimum purity of 99 mole $\%$ and was used without further treatment.

2-Pentene: A qualitative gas chromatographic standard, 2-pentene was obtained from Polyscience Corporation, Evanston, Illinois and had a minimum stated purity of 97 mole \%. It was used without further treatment.

Butyraldehyde: This compound was degassed under vacuum in the manner described above and distilled into a vacuum storage bulb. It was stored in the refrigerator when not in use. 
It is an Eastman Kodak "White Label" reagent.

Acetone: "Baker Analyzed" reagent grade acetone was used. Aftex degassing and distillation under vacum, it was stored in the refrigerator.

2-Butanone: This is an Eastman Kodak "White Label" chemical. It was treated under vacuum as described above and stored in the refrigerator.

Methanol: Anhydrous methanol was a Mallinkrodt AR reagent. It was treated in the manner described above and stored in the refrigerator.

3-Pentanone: This chemical was of "Practical Grade" Matheson, Coleman \& Bell origin. It was treated under vacuun and stored in the refrigerator.

2-Pentanone: This chemical was supplied by $\mathrm{K} \& \mathrm{~K}$ Laboratories, Inc. and had no stated purity. It was treated under vacuum and stored in the refrigerator.

Crotonaldehyde: This chemical was Eastman Kodak "Practical Grade". It was used with no further treatment.

Valeraldehyde: An extremely pure sample of valeraldehyde was provided by Mr. Gerald Kaufmann of the Organic Division of the Chemistry Department of Ohio State University. It was originally Purified from Eastman Kodak "Practical Grade" valeraldehyde. It was used with no further treatment.

2-Methyl Acrolein: A sample was provided by the Organic Division of the Chemistry Department of Ohio State University. Its purity 
was about $80-85 \%$, and the major impurity was acrolein. It was used without further treatment. tertiary-Butyl Hydroperoxide: This peroxide was obtained from the Cadet Chemical Corporation. It was degassed and distilled under vacuum. When not in use, it was stored in a freezer. 3-Pentane Hydroperoxide: Quantities of this peroxide were in the laboratory. They were prepared by Mr. C. Y. Yao in 1955 and the purity varied from sample to sample. The variation was $85-96 \%$. It was stored in the freezer when not in use and no attempt was made to enhance its purity.

iso-Propyl Alcohol: This chemical was supplied by Matheson, Coleman \& Bell. It had a boiling point range of $82-83^{\circ} \mathrm{C}$. and came from lot 33. It was used without further treatment. Acetic Acid: Glacial acetic acid was a "Baker Analyzed" reagent. It was used with no further treatment. Sodium Iodide: This salt was a "Baker Analyzed" reagent. It was used with no further treatment. Sodium Thiosulfate: Standardized $0.01 \mathrm{~N}$ sodium thiosulfate was supplied by the Reagent Laboratory of The Ohio State University. Potassium Iodate: Standardized $0.05 \mathrm{~N}$ potassium iodate was supplied by the Reagent Laboratory of The Ohio State University. 
RESULTS

Pentane was oxidized in the shock tube at temperatures ranging from $298^{\circ}$ to $435^{\circ} \mathrm{C}$. with reaction times from 1.3 to 3.7 milliseconds. The reflected shock wave was used in each experiment to compress and heat the gas mixture. The initial pentane concentration was of the order of 450 to $750 \mu$ moles per liter of gas in most experiments. The volume of the reaction section was 2.02 iters. The oxygen concentration was varied from a $1: 1$ mole ratio of oxygen-pentane to $8: 1$ mole ratio which is the stoichiometric amount needed to completely oxidize the fuel to carbon dioxide and water. The initial pressure of the helium-argon-pentane-oxygen mixture in the reaction section was varied from $591 \mathrm{~mm}$ to $760 \mathrm{~mm}$. The desired temperature was achieved by adjusting the pressure in both the high- and low-pressure sections of the shock tube. The pressure in the high-pressure section $P_{4}$ was essentially constant through all the experiments. $P_{1}$ was varied by the largest amount in order to obtain the correct $\mathrm{P}_{41}$ ratio. The "tailored-interface", a condition in which the acoustic impedance of the state 2 and state 3 regions correspond, was used in all of the experiments. The reaction temperatures were calculated for each experiment from the pressure-time oscilloscope trace obtained from that experiment. The temperatures recorded for each $\mathrm{P}_{41}$ is the average for a con'siderable number of experiments performed at each $\mathrm{P}_{41}$. The deviation from this average at a particular $\mathrm{P}_{41}$ was very slight. 
The results of peroxide formation as a function of the mole ratio oxygen: pentane for a $P_{41}=6.5$ and a reaction temperature of $298^{\circ} \mathrm{C}$. at various reaction times are summarized in Table 4, and are illustrated in Figure 16. As can be seen, the yield of peroxide is essentially constant throughout the entire range of oxygen: pentane molar ratios. The peroxide yield is expressed on the basis moles peroxide out/mole of pentane initially put into the shock tube. This is the only convenient way of expression since the peroxide formation experiments were of a destructive nature, preventing analysis of any component other than the peroxides.

To check on the analytical procedure for peroxide analysis, blanks were periodically run in the following manner. A mixture of oxygen-pentane-helium-argon was placed in the shock tube reaction section. The unshocked gases were then transferred under slight vacuum through the gas scrubber system containing the alcoholic NaI-glacial acetic acid mixture. This resulting mixture was analyzed for peroxides in the manner described earlier. In all cases, there was a blank correction of less than $0.01 \mathrm{cc}$ of the standard thiosulfate. The standard titer of the thiosulfate was also checked periodically against standardized $\mathrm{KIO}_{3}$ solution. It was found that the thiosulfate titer did not change throughout the course of the investigation.

Product analysis was attempted in several experiments. The shocked gases from the reaction section were expanded into a known volume, part of which consisted of the sample septum bulb. Samples 
Table 4

Peroxide Formation as a Function of Oxygen: Pentane Molar Ratios at $\mathrm{P}_{41}=6.5$ and a Reaction Temperature of $298^{\circ} \mathrm{C}$.

\begin{tabular}{|c|c|c|c|c|c|c|}
\hline Exp. No. & $\begin{array}{c}\text { Reaction } \\
\text { Temperature } \\
\left({ }^{\circ} \mathrm{C}\right)\end{array}$ & $\begin{array}{l}\text { Reaction } \\
\text { Time } \\
\text { (msec.) }\end{array}$ & $\begin{array}{l}\text { RH in } \\
\text { (ymoles) }\end{array}$ & $\frac{\mathrm{O}_{2}}{\mathrm{RH}}$ in & $\begin{array}{l}\text { ROOH out } \\
\text { (Mmoles) }\end{array}$ & $\frac{\mathrm{ROOH}}{\mathrm{RH}} \times 10^{3}$ \\
\hline 62 & $a$ & 1.6 & 1576 & 0.44 & 2.75 & 1.74 \\
\hline 63 & 282 & 1.6 & 1293 & 1.51 & 3.20 & 2.47 \\
\hline 68 & $a$ & 1.6 & 1495 & 3.93 & 4.75 & 3.18 \\
\hline 66 & $a$ & 1.6 & 1556 & 5.22 & 4.30 & 2.76 \\
\hline 65 & $a$ & 1.6 & 1202 & 7.09 & 3.80 & 3.16 \\
\hline 57 & 291 & 2.3 & 1414 & 0.53 & 5.10 & 3.61 \\
\hline 59 & 297 & 2.3 & 1374 & 2.45 & 6.40 & 2.47 \\
\hline 56 & 298 & 2.3 & 1333 & 4.28 & 4.20 & 3.15 \\
\hline 61 & 292 & 2.3 & 1202 & 7.09 & 4.80 & 3.99 \\
\hline 69 & 304 & 2.5 & 1505 & 0.51 & 5.50 & 3.65 \\
\hline 76 & 314 & 2.5 & 1222 & 0.77 & 4.20 & 3.44 \\
\hline 71 & 307 & 2.5 & 1556 & 2.75 & 4.10 & 2.63 \\
\hline 72 & 307 & 2.5 & 1495 & 4.07 & 5.75 & 3.85 \\
\hline 70 & 304 & 2.5 & 1536 & 5.37 & 5.15 & 1.97 \\
\hline 77 & 304 & 2.5 & 1293 & 6.96 & 4.00 & 3.09 \\
\hline 74 & $a$ & 2.7 & 1253 & 0.73 & 4.10 & 3.27 \\
\hline 75 & 309 & 2.7 & 1536 & 5.31 & 4.25 & 2.77 \\
\hline
\end{tabular}

RH, pentane; ROOH, peroxides

a, due to experimental difficulties, an oscilloscope trace was not obtained. 

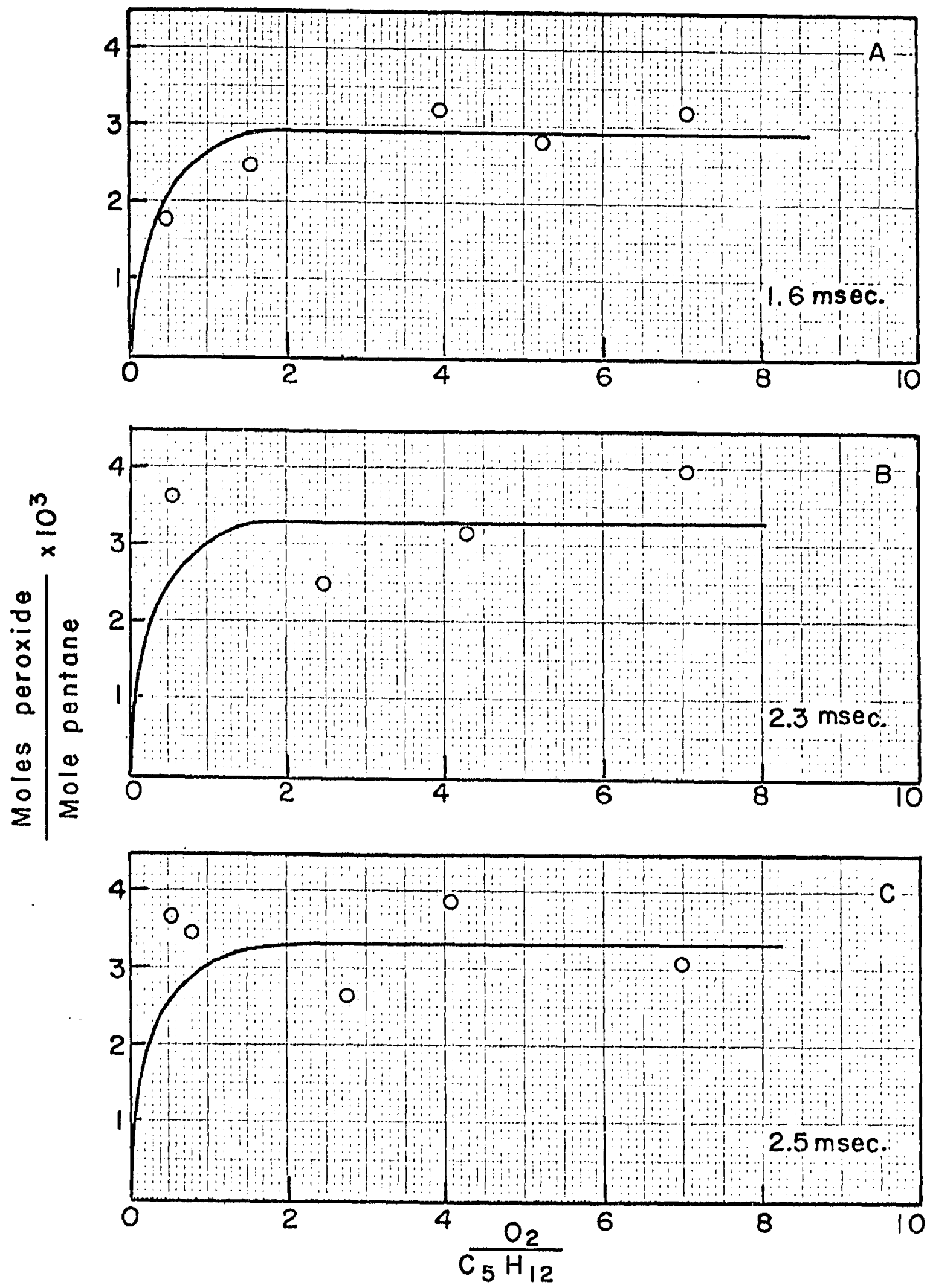

Figure 16. Peroxide formation at $298^{\circ} \mathrm{C}$. 
were transferred from this bulb using a gas-tight syringe to the gas chromatograph. No products could be definitely found. With the analysis however, it was possible to calculate the amount of pentane recovered. These data are listed below in Table 5 .

\section{$\underline{\text { Table } 5}$}

Product Analysis at $298^{\circ} \mathrm{C}$.

\begin{tabular}{ccccccc}
\hline \hline Exp. No. & $\begin{array}{c}\text { Reaction } \\
\text { Temperature } \\
\text { (Deg. C.) }\end{array}$ & $\begin{array}{c}\text { Reaction } \\
\text { Time } \\
\text { (msec.) }\end{array}$ & $\begin{array}{l}\text { RH } \\
\text { (Mmoles) }\end{array}$ & $\begin{array}{c}\text { Recovery } \\
\%\end{array}$ & $\frac{2}{\mathrm{RH}}$ in \\
\hline 64 & 298 & 1.6 & 1505 & 1488 & 98.9 & 0.80 \\
67 & $\mathrm{a}$ & 1.6 & 1475 & 1104 & 74.8 & 5.63 \\
58 & 294 & 2.3 & 1445 & 1527 & 105.7 & 2.23 \\
60 & 300 & 2.4 & 1505 & 1155 & 76.7 & 5.43 \\
73 & 289 & 2.5 & 1293 & 1155 & 89.5 & 6.35 \\
\hline
\end{tabular}

$\mathrm{RH},=$ pentane

a, due to experimental difficulties, an oscilloscope trace was not obtained.

As can be seen from the above data, the \% recovery of pentane varies considerably. Upon expanding the shocked gases and taking an aliquot portion of it, the dilution factor becomes approximately 1:2500. Thus serious error can easily be introduced. The fact that oxidation products were not found using this technique, can be explained on this same basis. For example, the gas chromatograph was sensitive enough to detect as 1 ittle as $0.01 \mu$ moles or less of most compounds placed on its columns. In order to be able to see a compound using this expansion technique, a minimum of about 25 
$\mu$ moles of a product would have to be formed during the oxidation reaction. This would seem to indicate that the expansion technique for product analysis is unsatisfactory. Results using a different procedure for product analysis are discussed later.

In order to ascertain if all the reactants and products remained in the reaction section of the shock tube after the shock wave had passed, an experiment was performed in which, after the quick-opening valve was closed isolating the reaction mixture, the gases remaining in the rest of the shock tube were transferred under vacuum through two cold traps maintained at liquid nitrogen temperature. These traps were located at the expansion tank. Analysis indicated that less than $0.5 \%$ of the gas escaped from the reaction section after the shock wave had passed through the section. This is based upon the amount of pentane recovered from the cold traps and compared to the amount of pentane originally placed into the reaction section of the shock tube.

Some exploratory experiments were carried out in an attempt to identify which peroxides were formed during the oxidation reaction. Using the technique of paper chromatography, 22 known samples of hydrogen peroxide and the pentane hydroperoxides were sucessfully separated and identified. When the method was applied to a mixture of shocked gases that had been trapped at liquid nitrogen temperatures, the method proved fruitless. Apparently, an insufficient amount of peroxide was formed. The quantity of condensate obtained could not successfully be placed on the paper chromatogram. 
This method of analysis was not attempted at any other reaction temperature.

The largest amount of work on peroxide formation was obtained at $\mathrm{P}_{41}=7.4$ which corresponded to a reaction temperature of $327^{\circ} \mathrm{C}$. These data are tabulated in Table 6 and illustrated in Figures 17-21. The data were treated in a manner similar to the data obtained at $298^{\circ} \mathrm{C}$.

The remaining temperatures studied were $403^{\circ}$ and $435^{\circ} \mathrm{C}$. At $403^{\circ} \mathrm{C}$. the $\mathrm{P}_{41}=9.0$ and the "tailored-interface" was composed of a 65:35 helium-argon mixture and at $435^{\circ} \mathrm{C} ., \mathrm{P}_{41}=8.0$ and the mixture was $66: 34$ heli.um-argon.

The data obtained from these temperatures are tabulated in Tables 7 and 8 and illustrated in Figures 22-27.

From the data obtained, it can be seen that at any experimental condition, a surprising constancy is maintained. This, despite the fact that the shock tube was evacuated prior to each experiment for varying lengths of time. The evacuation times varied from 3-4 hours to as much as three weeks. In the usual studies on hydrocarbon oxidation, this evacuation time is a critical experimental parameter, since it directly affects the surface of the reaction vessel. In all of the experiments conducted in this investigation, no apparent surface effects could be observed.

The relationship of peroxide formation as a function of time at any partiuular reaction time is illustrated in Figures 28-31. The comparison of peroxide formation as a function of time on a 
Table 6

Peroxide Formation as a Function of Oxygen: Pentane Molar Ratios at $\mathrm{P}_{41}=7.4$ and a Reaction Temperature of $327^{\circ} \mathrm{C}$.

\begin{tabular}{|c|c|c|c|c|c|c|}
\hline Exp. No. & $\begin{array}{l}\text { Reaction } \\
\text { Temperature } \\
\text { (Deg. C.) }\end{array}$ & $\begin{array}{l}\text { Reaction } \\
\text { Time } \\
\text { (msec.) }\end{array}$ & $\begin{array}{l}\mathrm{RH} \text { in } \\
\text { (umoles) }\end{array}$ & $\frac{\mathrm{O}_{2}}{\mathrm{RH}}$ & $\frac{\mathrm{ROOH}}{\text { (Amoles) }}$ & $\frac{\mathrm{ROOH}}{\mathrm{RH}} \times 10^{3}$ \\
\hline 117 & 317 & 1.7 & 1446 & 0.78 & 10.30 & 7.12 \\
\hline 118 & 321 & 1.7 & 1485 & 0.88 & 8.80 & 5.93 \\
\hline 114 & 315 & 1.6 & 1222 & 2.60 & 7.80 & 6.38 \\
\hline 116 & 321 & 1.6 & 1344 & 4.44 & 8.40 & 6.25 \\
\hline 119 & 323 & 1.6 & 1677 & 5.55 & 11.25 & 6.71 \\
\hline 178 & 325 & 1.5 & 1400 & 7.40 & 9.30 & 6.64 \\
\hline 115 & 318 & 1.6 & 768 & 11.27 & 5.10 & 6.64 \\
\hline 177 & $\mathrm{a}$ & 1.9 & 1277 & 0.66 & 12.20 & 9.55 \\
\hline 176 & 332 & 1.8 & 1334 & 1.23 & 15.25 & 11.43 \\
\hline 173 & $a$ & 1.9 & 1368 & 2.83 & 14.60 & 10.67 \\
\hline 174 & 325 & 1.9 & 1277 & 3.99 & 13.85 & 10.85 \\
\hline 175 & $a$ & 1.9 & 1501 & 5.09 & 16.55 & 11.03 \\
\hline 179 & 313 & 1.8 & 1196 & 7.28 & 12.55 & 10.49 \\
\hline 172 & 319 & 2.2 & 1237 & 3.08 & 14.20 & 11.48 \\
\hline 170 & 325 & 2.2 & 1228 & 3.18 & 16.15 & 13.15 \\
\hline 128 & 327 & 2.3 & 1158 & 1.43 & 11.90 & 10.28 \\
\hline 126 & 342 & 2.3 & 757 & 3.23 & 8.10 & 10.70 \\
\hline 125 & 326 & 2.3 & 1283 & 3.63 & 13.95 & 10.87 \\
\hline
\end{tabular}

$a$, no oscilloscope trace obtained 
Table 6 (contd.)

\begin{tabular}{|c|c|c|c|c|c|c|}
\hline Exp. No. & $\begin{array}{l}\text { Reaction } \\
\text { Temperature } \\
\text { (Deg. C.) }\end{array}$ & $\begin{array}{l}\text { Reaction } \\
\text { Time } \\
\text { (msec.) }\end{array}$ & $\begin{array}{l}\mathrm{RH} \text { in } \\
\text { (umoles) }\end{array}$ & $\frac{\mathrm{O}_{2}}{\mathrm{RH}}$ in & $\begin{array}{l}\text { ROOH out } \\
\text { ( } \mu \text { moles) }\end{array}$ & $\frac{\mathrm{ROOH}}{\mathrm{RH}} \times 10^{3}$ \\
\hline 127 & 326 & 2.3 & 1303 & 4.91 & 13.25 & 10.17 \\
\hline 129 & 327 & 2.3 & 1081 & 7.99 & 11.40 & 10.55 \\
\hline 120 & 322 & 2.4 & 1192 & 3.09 & 10.50 & 8.81 \\
\hline 133 & 325 & 2.4 & 2021 & 3.19 & 16.35 & 8.09 \\
\hline 122 & 326 & 2.4 & 1249 & 3.25 & 10.80 & 8.65 \\
\hline 134 & 324 & 2.4 & 1016 & 3.32 & 8.85 & 8.42 \\
\hline 132 & 330 & 2.4 & 1158 & 3.91 & 9.65 & 8.33 \\
\hline 121 & 334 & 2.4 & 1233 & 4.90 & 10.85 & 8.80 \\
\hline 123 & 317 & 2.4 & 1182 & 6.64 & 9.55 & 8.08 \\
\hline 109 & 329 & 2.5 & 1394 & 0.46 & 5.30 & 3.80 \\
\hline 111 & 326 & 2.5 & 1141 & 1.54 & 7.00 & 6.13 \\
\hline 105 & 325 & 2.5 & 1000 & 2.67 & 6.10 & 6.10 \\
\hline 169 & 315 & 2.5 & 1136 & 3.44 & 7.90 & 6.95 \\
\hline 103 & 327 & 2.5 & 1030 & 3.70 & 7.60 & 7.38 \\
\hline 124 & 332 & 2.5 & 1152 & 4.12 & 7.75 & 6.72 \\
\hline 104 & 328 & 2.5 & 1293 & 5.83 & 8.25 & 6.38 \\
\hline 110 & 322 & 2.5 & 1157 & 7.37 & 6.95 & 6.01 \\
\hline 106 & 329 & 2.7 & 1071 & 1.32 & 2.25 & 2.10 \\
\hline 135 & 315 & 3.0 & 541 & 3.55 & 1.80 & 3.33 \\
\hline 130 & 325 & 3.1 & 1253 & 3.91 & 1.85 & 1.48 \\
\hline 131 & 329 & 3.7 & 1117 & 3.34 & 1.40 & 1.25 \\
\hline
\end{tabular}

$\mathrm{RH}$, pentane; $\mathrm{ROOH}$, peroxides 


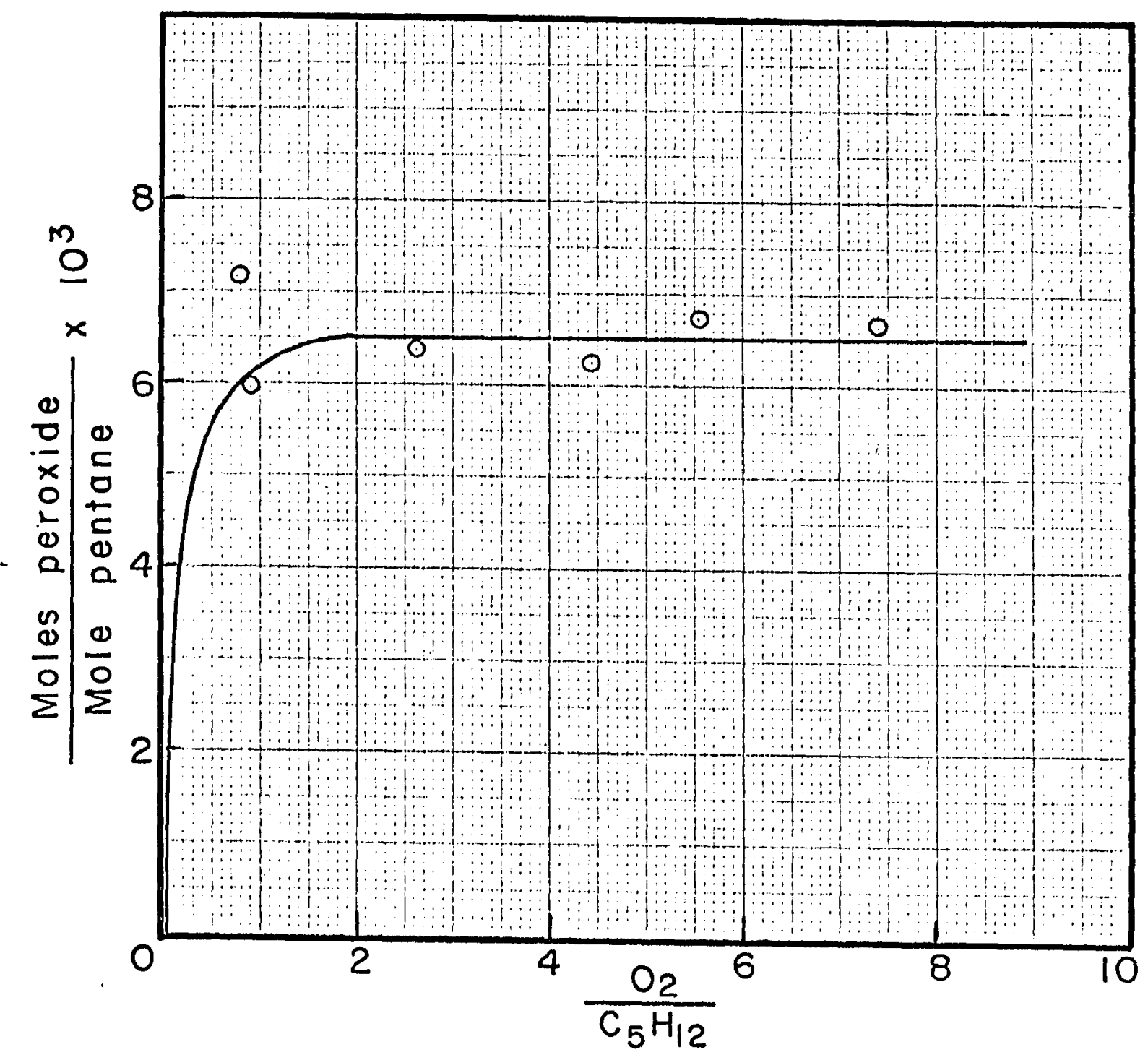

Figure 17. Peroxide formation at $327^{\circ} \mathrm{C}$. and a reaction time of $1.6 \mathrm{msec}$. 


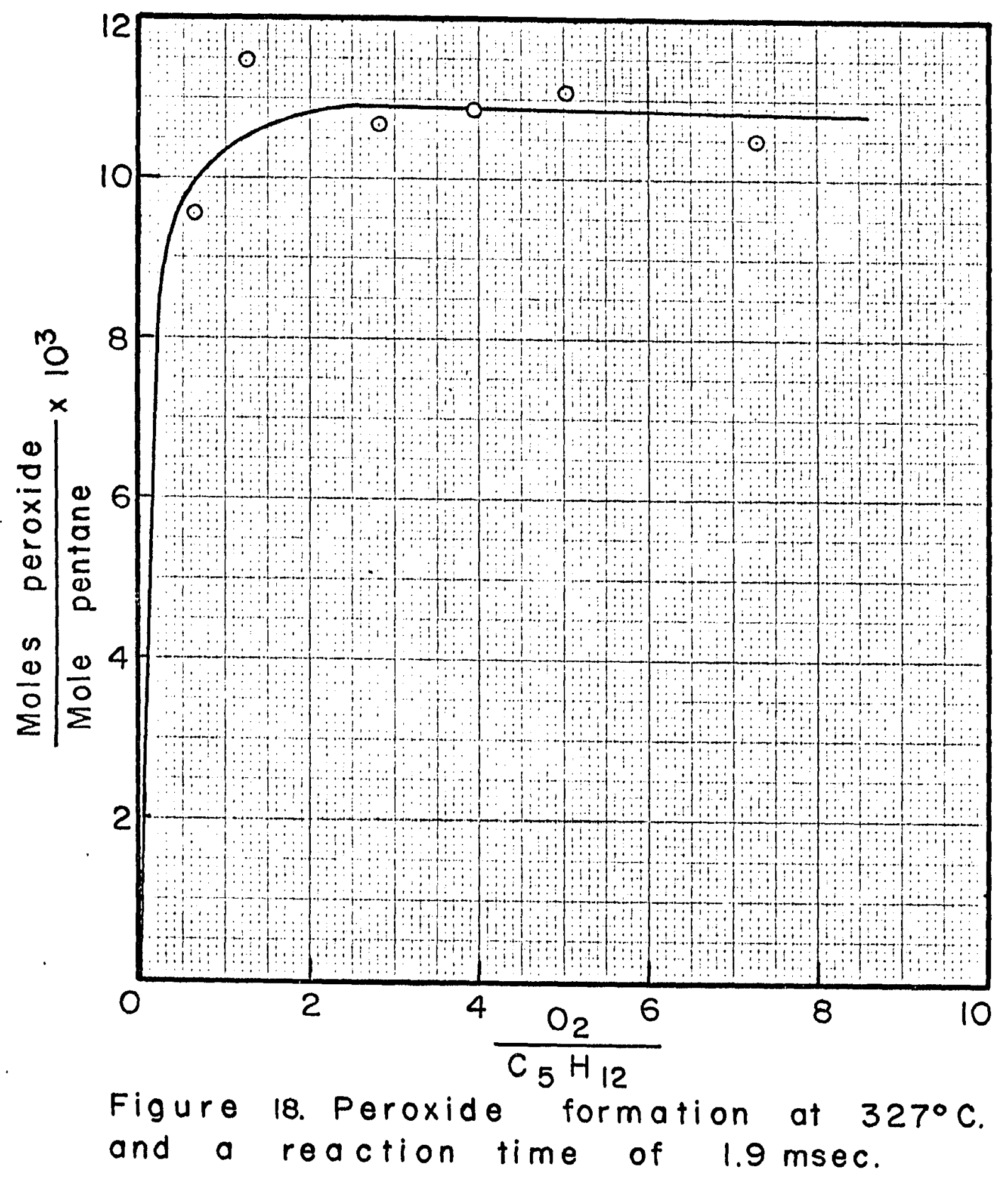




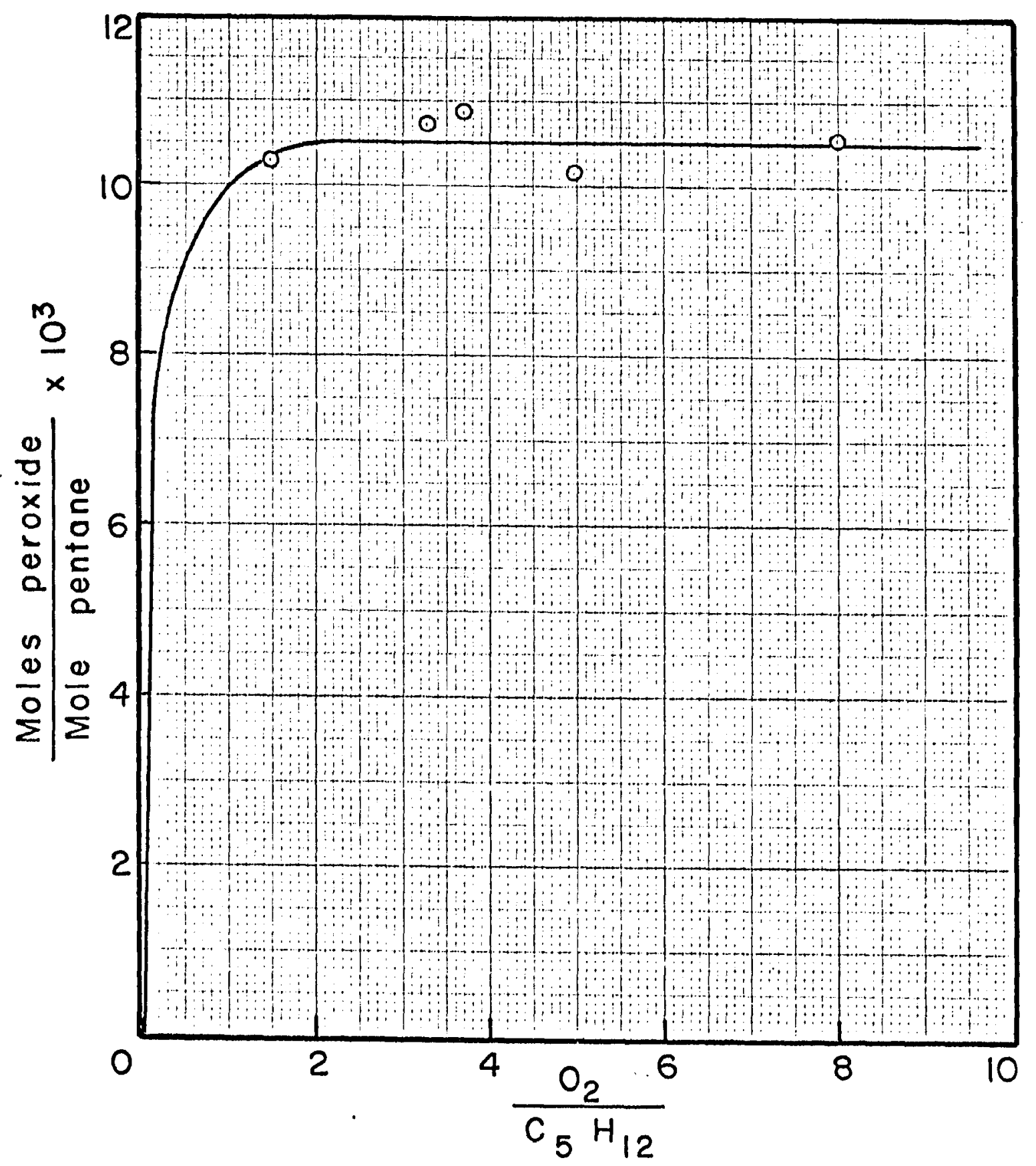

Figure 19. Peroxide formation at $327^{\circ} \mathrm{C}$. and a reaction time of $2.3 \mathrm{msec}$. 


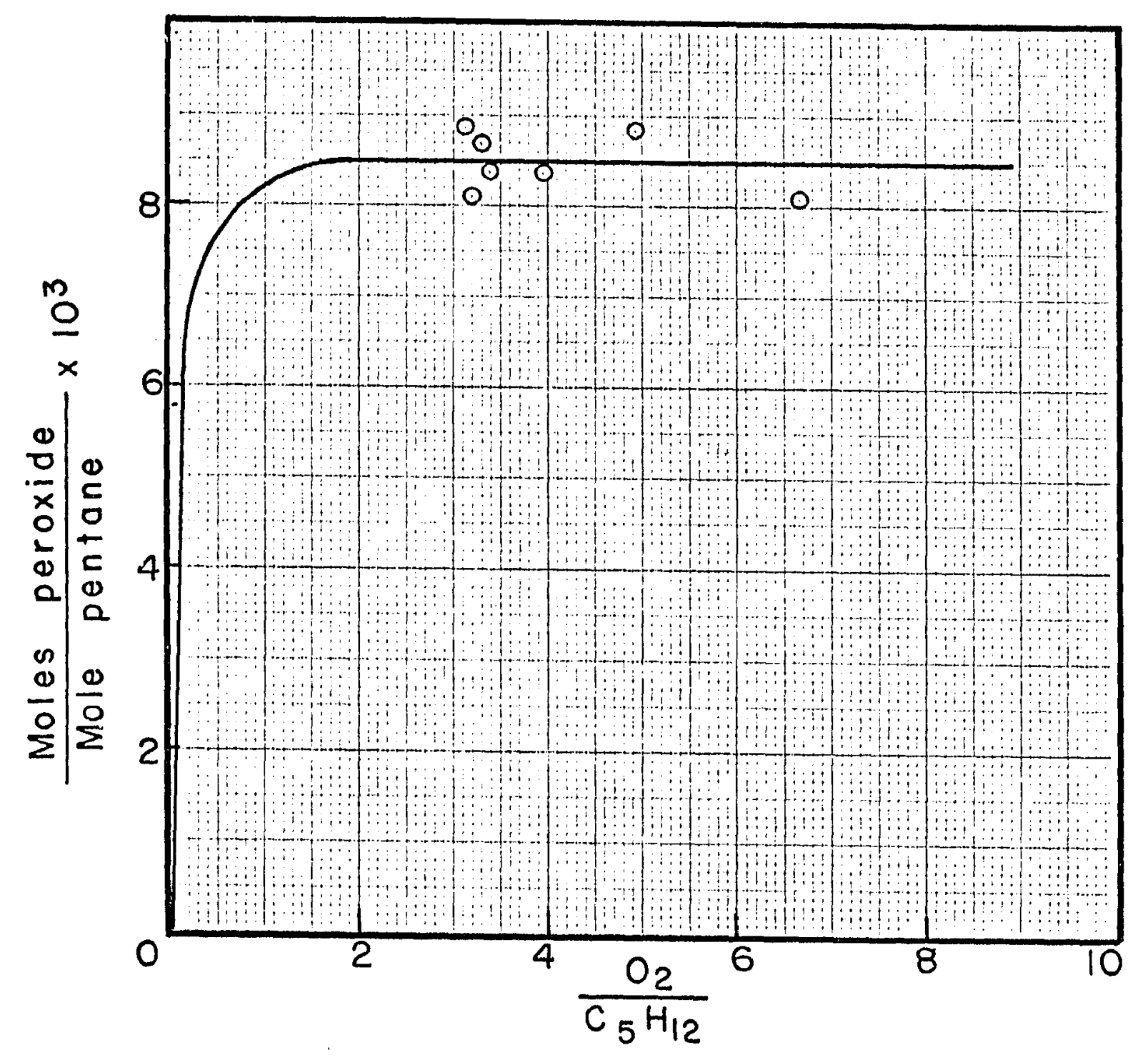

Figure 20. Peroxide formation at $327^{\circ} \mathrm{C}$. and a reaction time of $2.4 \mathrm{msec}$. 


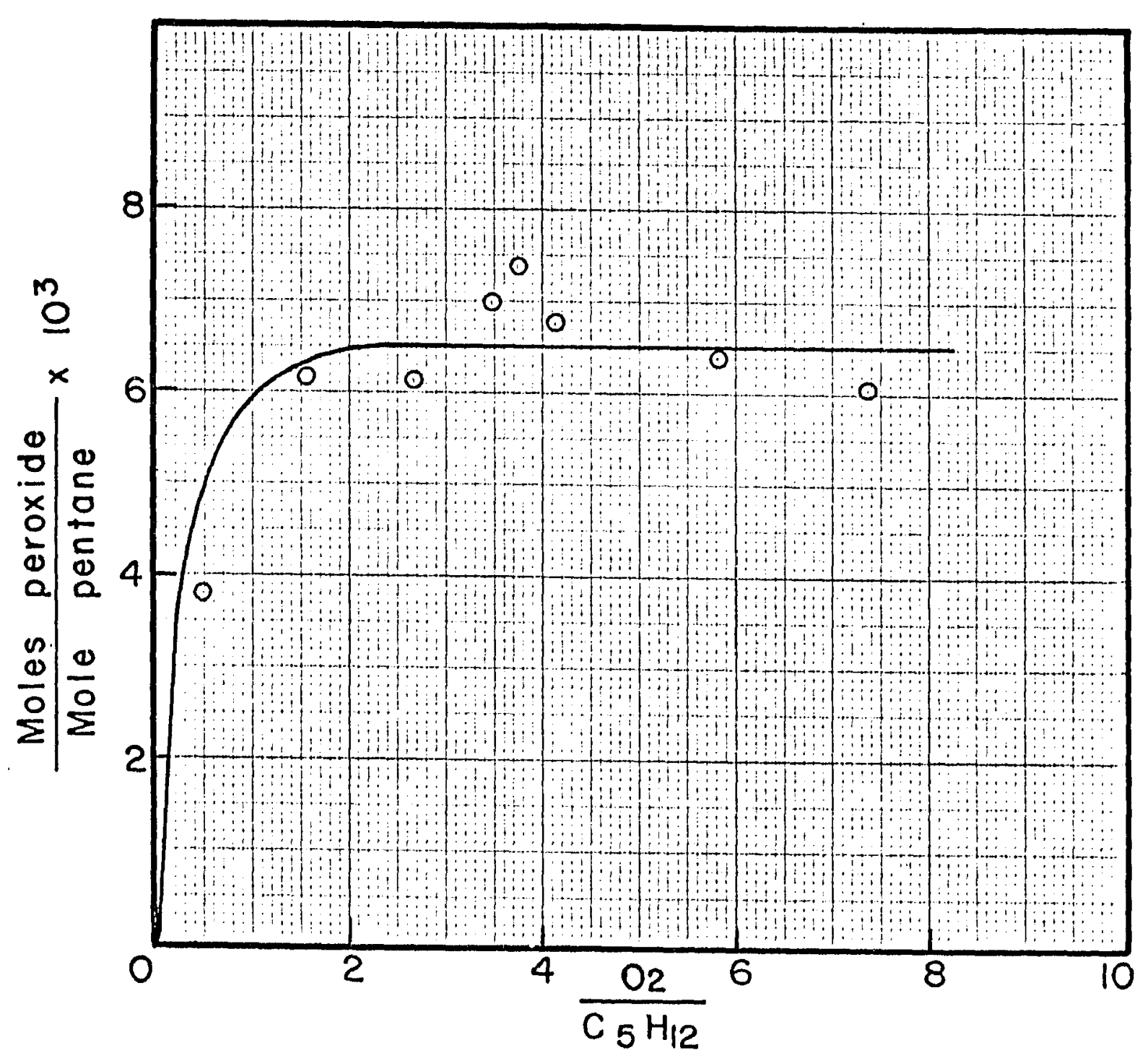

Figure 21. Peroxide formation at $327^{\circ} \mathrm{C}$. and a reaction time of $2.5 \mathrm{msec}$. 
Table 7

Peroxide Formation as a Function of Oxygen: Pentane Molar Ratios at $\mathrm{P}_{41}=9.0$ and a Reaction Temperature of $403^{\circ} \mathrm{C}$.

\begin{tabular}{|c|c|c|c|c|c|c|}
\hline Exp. No. & $\begin{array}{l}\text { Reaction } \\
\text { Temperature } \\
\text { (Deg. C.) }\end{array}$ & $\begin{array}{l}\text { Reaction } \\
\text { Time } \\
\text { (msec.) }\end{array}$ & $\begin{array}{l}\text { RH in } \\
\text { (umoles) }\end{array}$ & $\frac{\mathrm{O}_{2}}{\mathrm{RH}}$ in & $\begin{array}{l}\text { ROOH out } \\
\text { (umoles) }\end{array}$ & $\frac{\mathrm{ROOH}}{\mathrm{RH}} \times 10^{3}$ \\
\hline 204 & 408 & 1.3 & 1041 & 0.97 & 5.05 & 4.85 \\
\hline 203 & 404 & 1.3 & 1152 & 1.62 & 4.70 & 4.08 \\
\hline 200 & 404 & 1.3 & 1188 & 2.99 & 5.10 & 4.29 \\
\hline 201 & 410 & 1.3 & 909 & 5.04 & 3.90 & 4.29 \\
\hline 205 & 407 & 1.3 & 1196 & 6.20 & 4.45 & 3.72 \\
\hline 202 & 406 & 1.3 & 1095 & 7.85 & 4.25 & 3.88 \\
\hline 199 & 413 & 1.5 & 1115 & 0.64 & 5.75 & 5.16 \\
\hline 196 & 397 & 1.5 & 1212 & 0.87 & 4.70 & 4.19 \\
\hline 198 & $a$ & 1.5 & 1152 & 1.39 & 6.75 & 5.86 \\
\hline 194 & 408 & 1.5 & 1162 & 2.07 & 5.90 & 5.08 \\
\hline 193 & 398 & 1.5 & 960 & 4.29 & 6.15 & 6.41 \\
\hline 195 & 392 & 1.5 & 1180 & 6.41 & 6.50 & 5.51 \\
\hline 197 & 397 & 1.5 & 1101 & 7.90 & 6.75 & 6.13 \\
\hline 210 & 398 & 1.7 & 1214 & 0.94 & 3.55 & 2.92 \\
\hline 207 & 404 & 1.7 & 1051 & 1.36 & 3.35 & 3.19 \\
\hline 206 & 410 & 1.7 & 1198 & 3.67 & 4.75 & 3.96 \\
\hline 211 & 393 & 1.7 & 1180 & 3.71 & 4.35 & 3.69 \\
\hline 209 & 393 & 1.7 & 1253 & 5.08 & 4.80 & 3.83 \\
\hline 208 & $a$ & 1.7 & 1115 & 6.53 & 4.20 & 3.77 \\
\hline
\end{tabular}

$\mathrm{RH}$, pentane; $\mathrm{ROOH}$, peroxides; a, no oscilloscope trace 


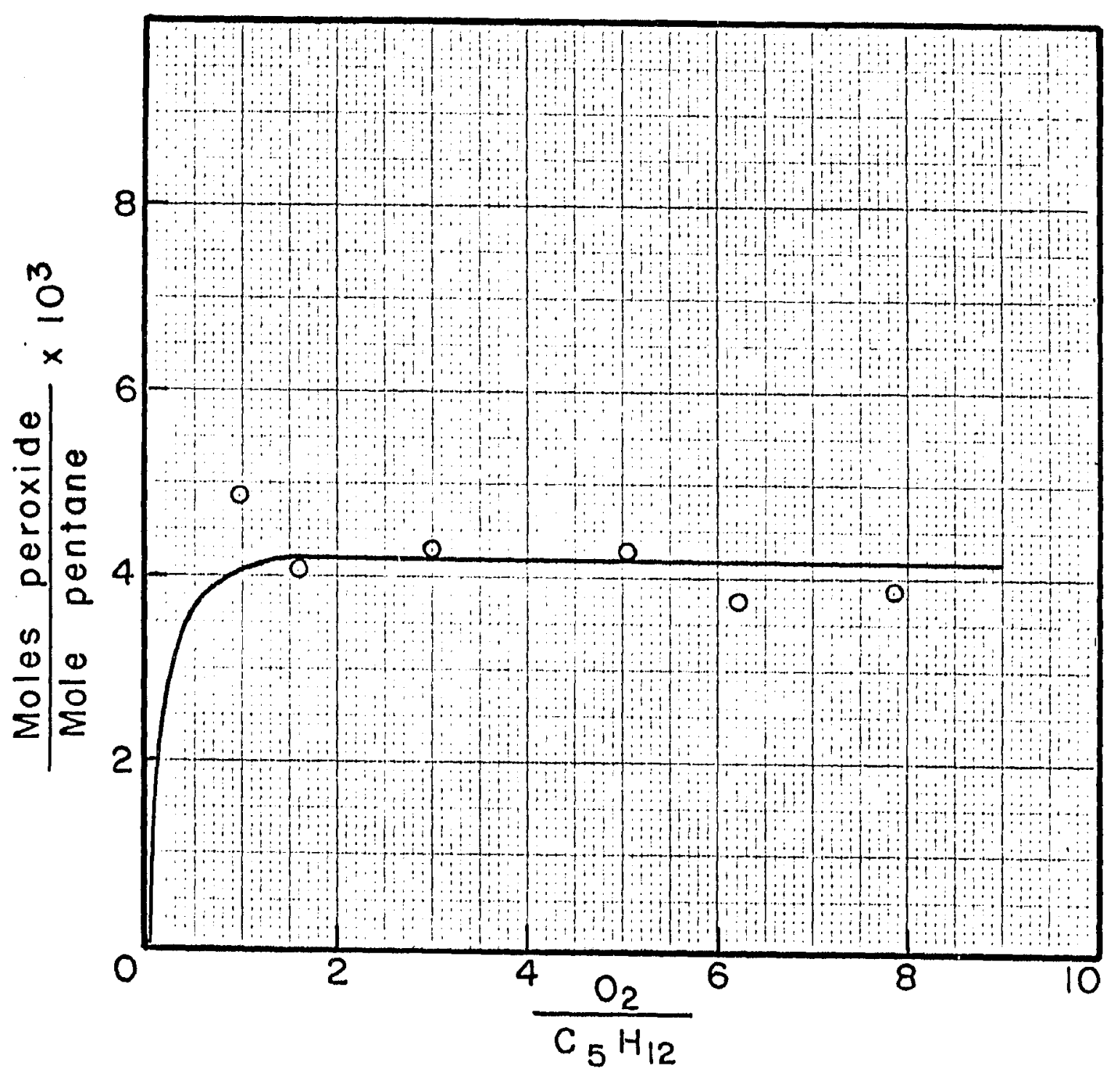

Figure 22. Peroxide formation at $403^{\circ} \mathrm{C}$. and a reaction time of $1.3 \mathrm{msec}$. 


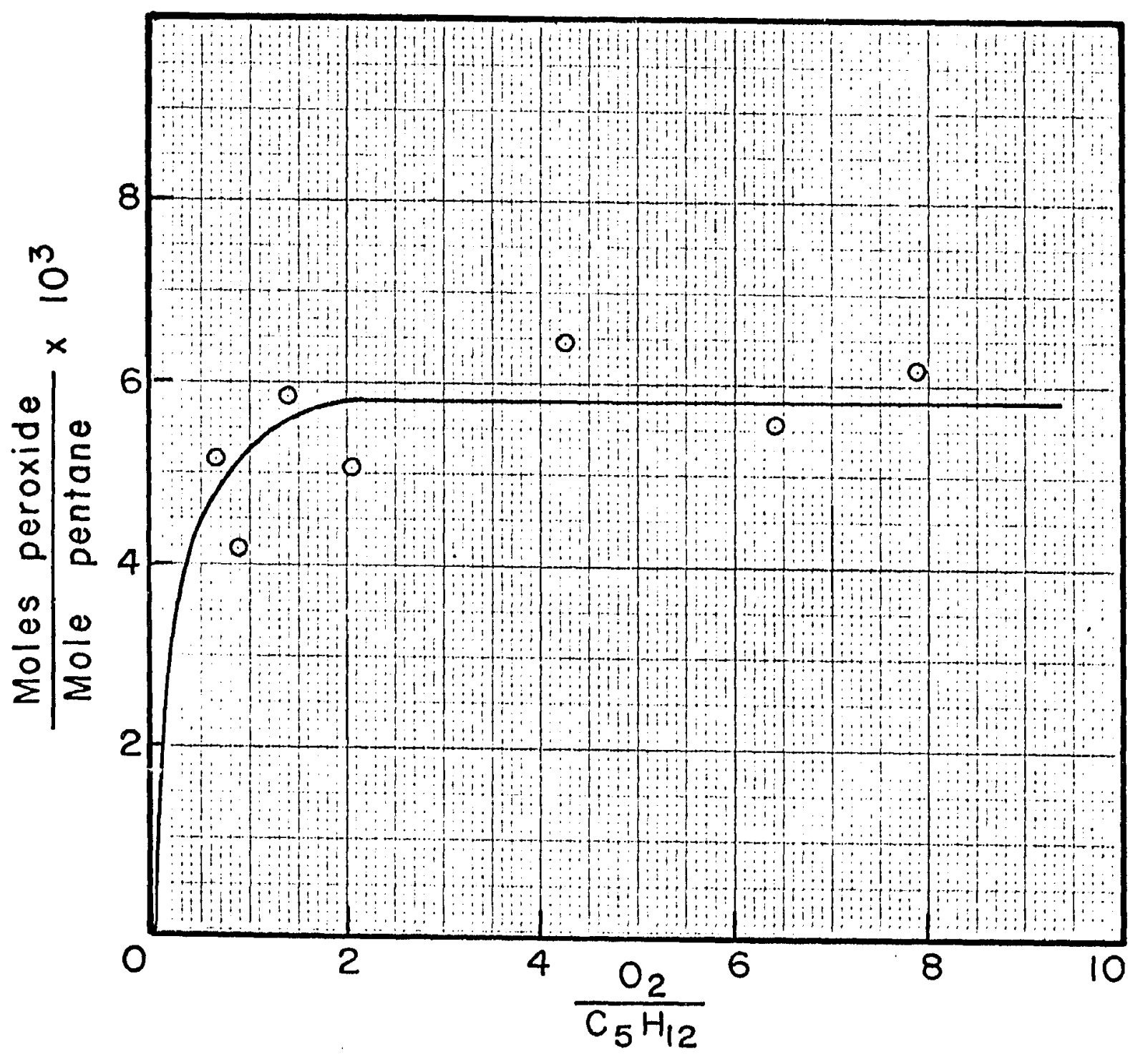

Figure 23. Peroxide formation at $403^{\circ} \mathrm{C}$. and a reaction time of $1.5 \mathrm{msec}$. 


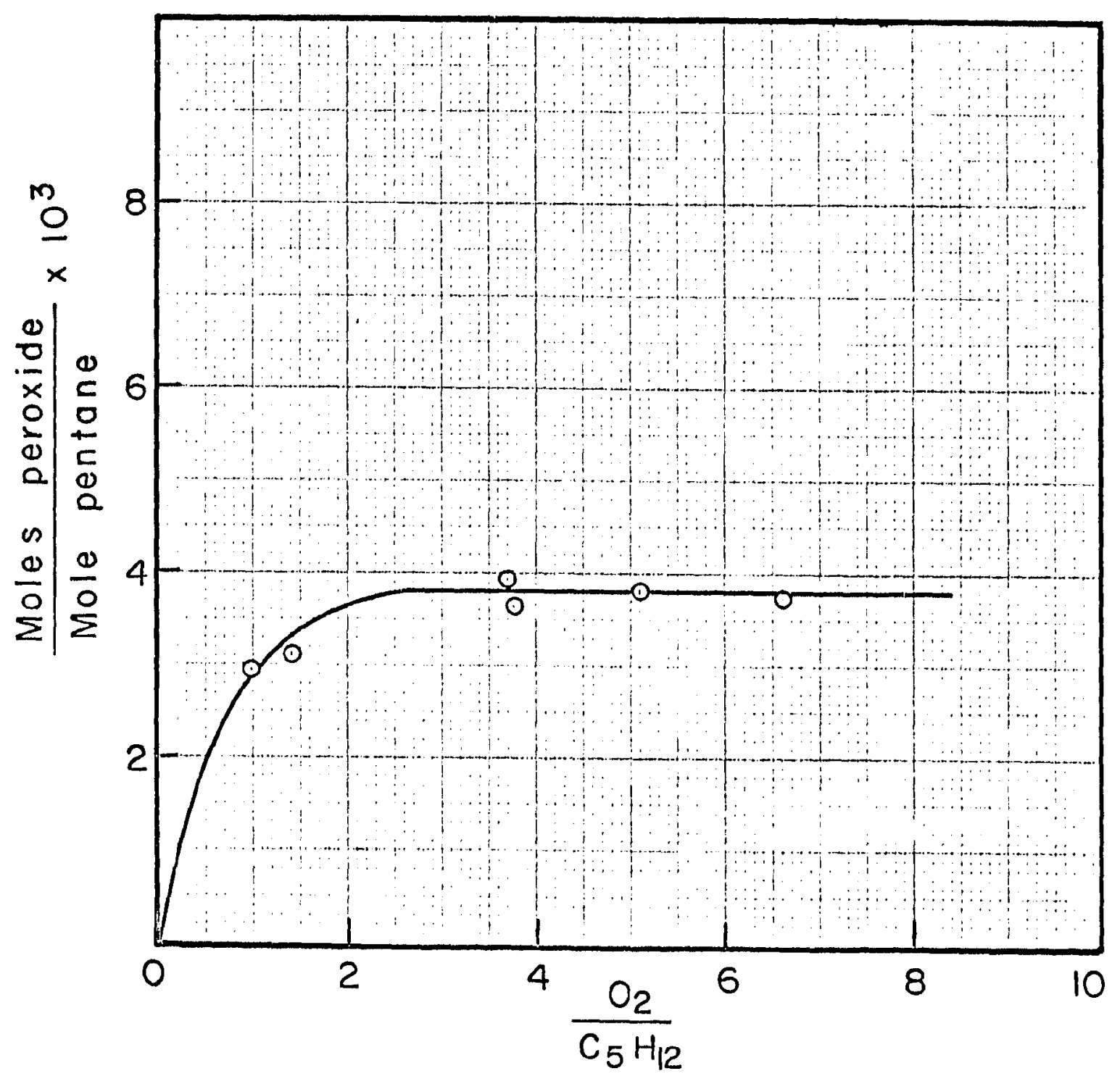

Figure 24. Peroxide formation at $403^{\circ} \mathrm{C}$. and a reaction time of $1.7 \mathrm{msec}$. 
Table 8

Peroxide Formation as a Function of Oxygen: Pentane Molar Ratios

at $\mathrm{P}_{41}=8.0$ and a Reaction Temperature of $435^{\circ} \mathrm{C}$.

\begin{tabular}{|c|c|c|c|c|c|c|}
\hline Exp. No. & $\begin{array}{l}\text { Reaction } \\
\text { Temperature } \\
\text { (Deg. C.) }\end{array}$ & $\begin{array}{l}\text { Reaction } \\
\text { Time } \\
\text { (msec.) }\end{array}$ & $\begin{array}{l}\mathrm{RH} \text { in } \\
\text { (umoles) }\end{array}$ & $\frac{\mathrm{O}_{2}}{\mathrm{RH}} \mathrm{in}$ & $\begin{array}{l}\text { ROOH out } \\
\text { (Mmoles) }\end{array}$ & $\frac{\mathrm{ROOH}}{\mathrm{RH}} \times 10^{3}$ \\
\hline 96 & 444 & 1.4 & 1647 & 1.08 & 7.80 & 4.74 \\
\hline 98 & 429 & 1.4 & 697 & 2.23 & 3.80 & 5.45 \\
\hline 99 & $a$ & 1.4 & 1263 & 2.40 & 8.05 & 6.37 \\
\hline 94 & 438 & 1.4 & 1818 & 3.31 & 10.90 & 6.00 \\
\hline 95 & 429 & 1.4 & 1344 & 5.89 & 8.10 & 6.03 \\
\hline 97 & 424 & 1.4 & 1293 & 7.88 & 7.35 & 5.68 \\
\hline 87 & 442 & 1.6 & 1243 & 1.16 & 8.50 & 6.84 \\
\hline 92 & 429 & 1.6 & 1404 & 2.77 & 10.25 & 7.30 \\
\hline 93 & 425 & 1.6 & 1512 & 5.60 & 11.95 & 7.90 \\
\hline 91 & 434 & 1.6 & 1222 & 6.34 & 9.50 & 7.77 \\
\hline 88 & 436 & 1.6 & 1051 & 8.29 & 8.10 & 7.71 \\
\hline 85 & 424 & 1.8 & 1495 & 0.40 & 4.00 & 2.68 \\
\hline 102 & $a$ & 1.8 & 1243 & 0.99 & 5.75 & 4.63 \\
\hline 84 & 434 & 1.8 & 1195 & 1.70 & 6.00 & 5.02 \\
\hline 78 & 434 & 1.8 & 717 & 1.97 & 3.40 & 4.74 \\
\hline 81 & 436 & 1.8 & 1364 & 3.39 & 7.60 & 5.57 \\
\hline 101 & $a$ & 1.8 & 1627 & 4.91 & 8.85 & 5.44 \\
\hline 100 & $a$ & 1.8 & 1515 & 7.50 & 8.65 & 5.71 \\
\hline
\end{tabular}

$\mathrm{RH}$, pentane; $\mathrm{ROOH}$, peroxides; a, no oscilloscope trace 


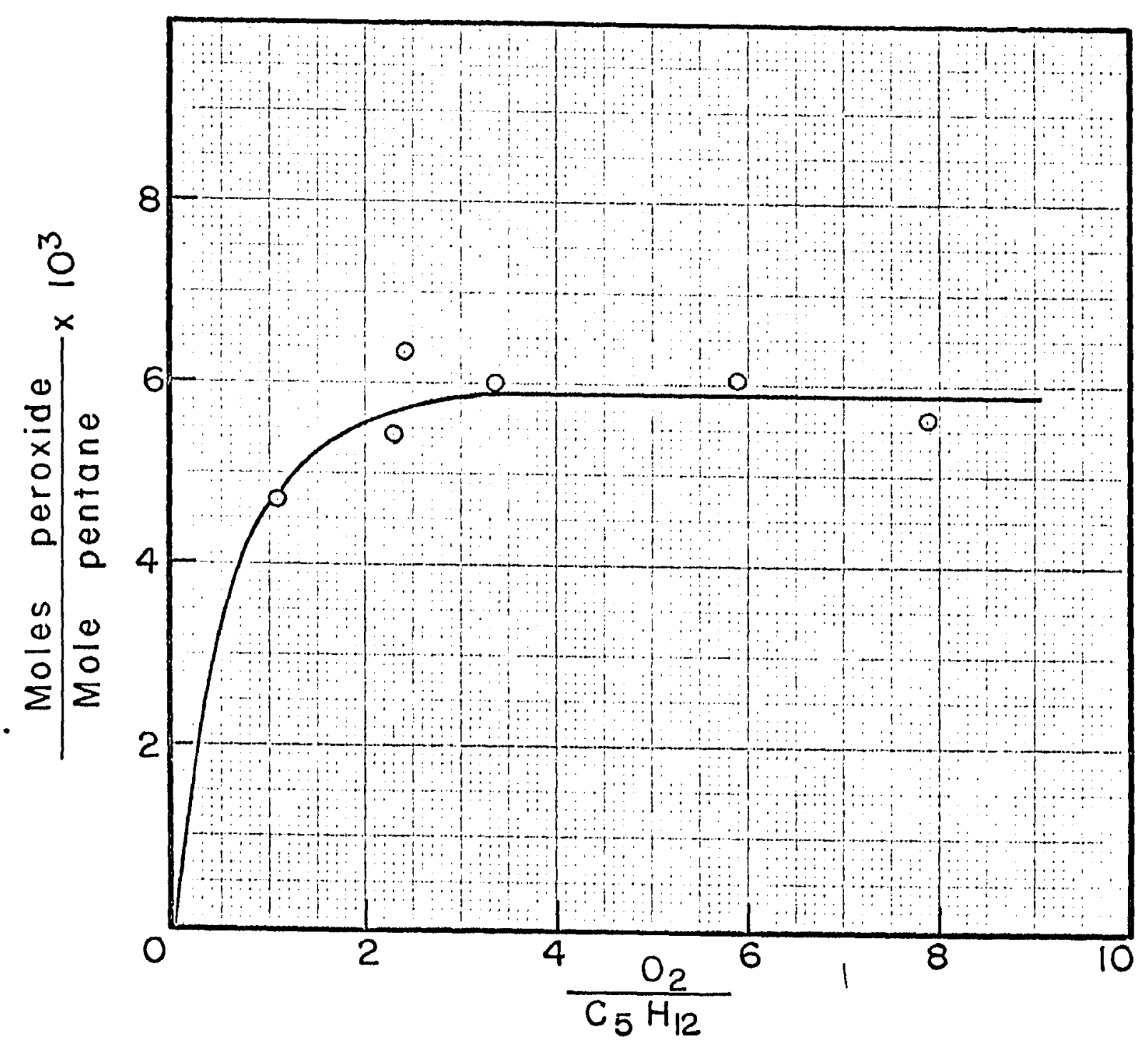

Figure 25. Peroxide formation at $435^{\circ} \mathrm{C}$. and a reaction time of $1.4 \mathrm{msec}$. 


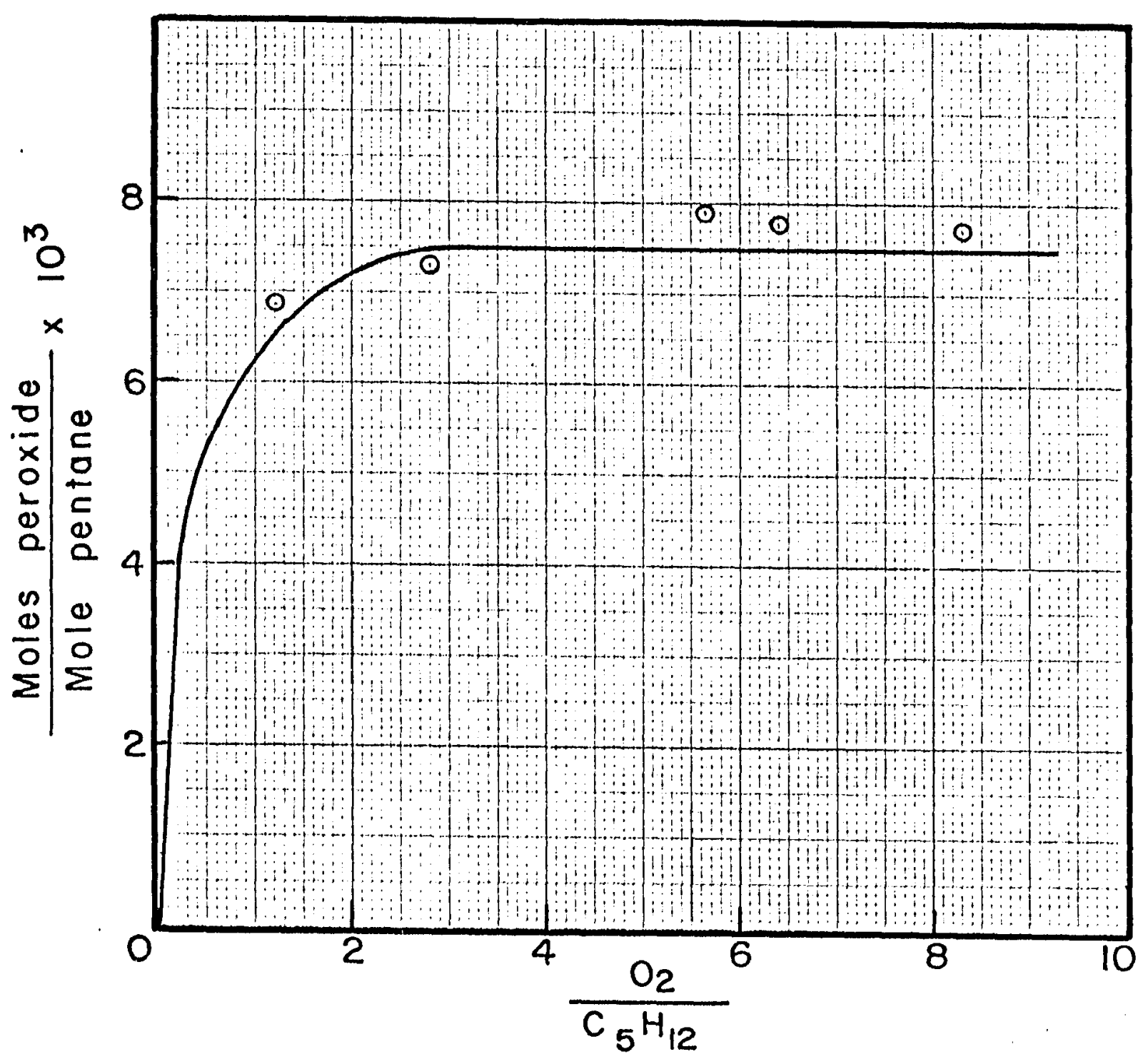

Figure 26. Peroxide formation at $435^{\circ} \mathrm{C}$. and a reaction time of $1.6 \mathrm{msec}$. 


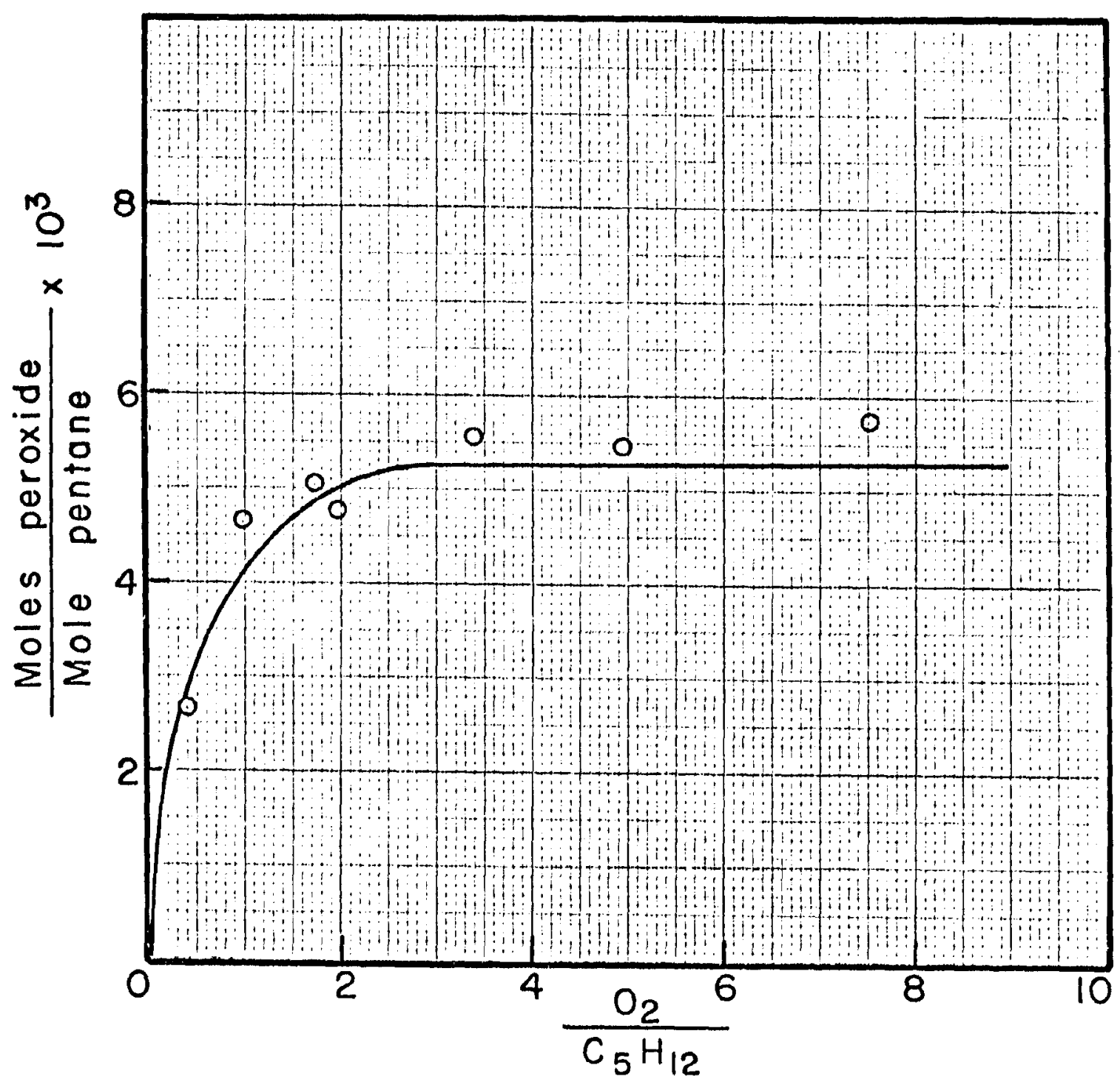

Figure 27. Peroxide formation at $435^{\circ} \mathrm{C}$. and a reaction time of $1.8 \mathrm{msec}$. 
single plot is illustrated in Figure 32. The amount of peroxide formed at any time was obtained by averaging the experimental values at that particular reaction time. This was possible since, as mentioned earlier, the peroxide formation as a function of oxygen: pentane molar ratios was constant. From the figures, it can be seen that as the reaction temperature is increased, the maxima which are found become much sharper and that this maximum shifts to shorter times as the temperature increases. At the two highest temperatures investigated, the maxima are very distinct although it is difficult to place them exactly. There are very few noticeable differences between the results obtained at these two temperatures. The hash-marks on Figures 28-31 are the positions of the maxima obtained at each temperature.

Several different relationships were attempted in order to find a reasonable method of illustrating the peroxide formation as a function of temperature. The results are illustrated in Figures 33 and 34 . Figure 33 is a plot of the logarithm of the maximum peroxide concentration at a reaction temperature as a function of reaction temperature. The maxima were directly obtained from Figures 28-31. Figure 34 is a plot of the logarithm of the maximum peroxide concentration divided by the reaction time at which the maximum occurs, as a function of temperature. The other relationships attempted, will not be chronicaled here. It is sufficient to say that all of the relationships attempted yielded plots which were similar in structure. They were, as the figures presented 


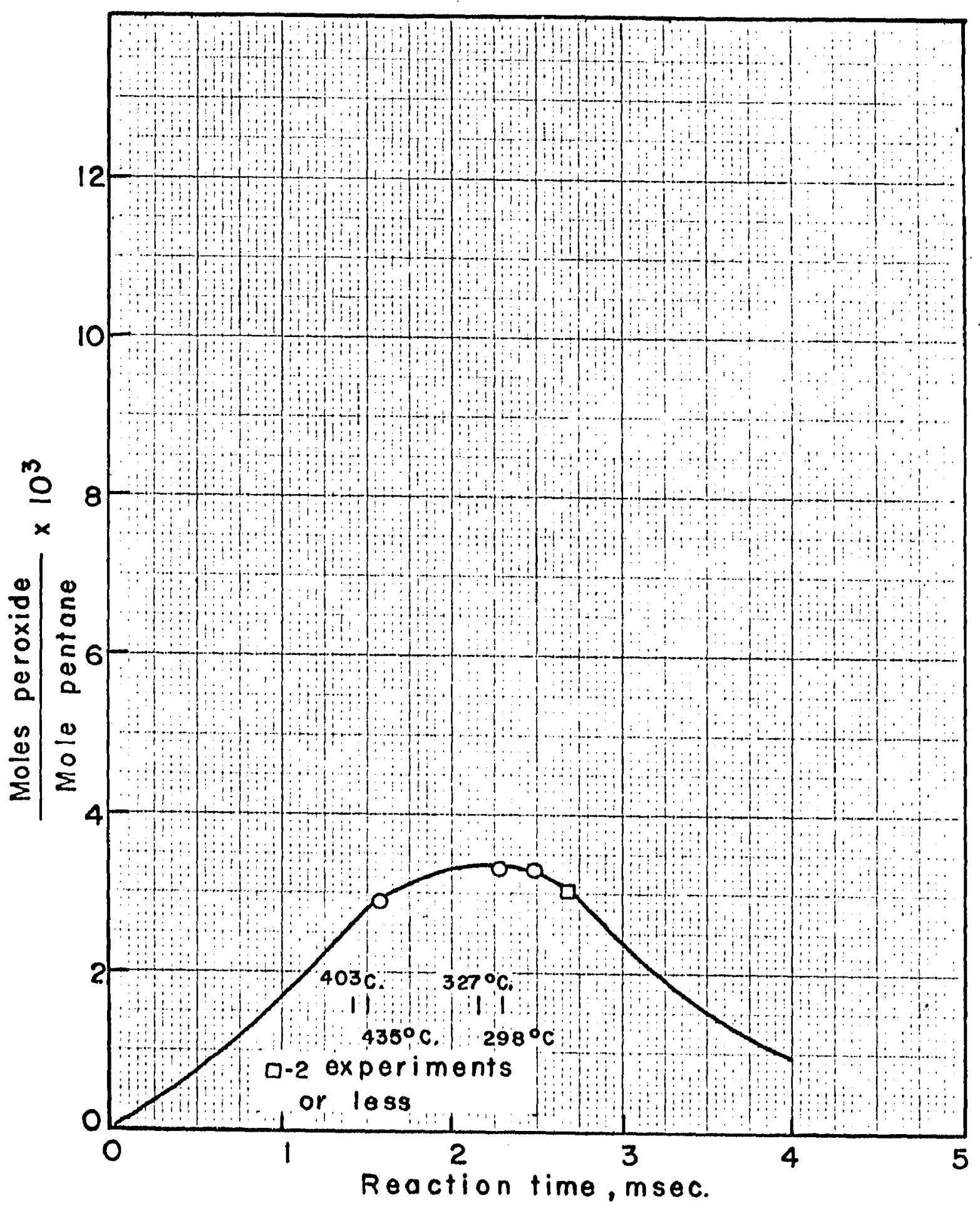

Figure 28. Peroxide formation of $298^{\circ} \mathrm{C}$. 


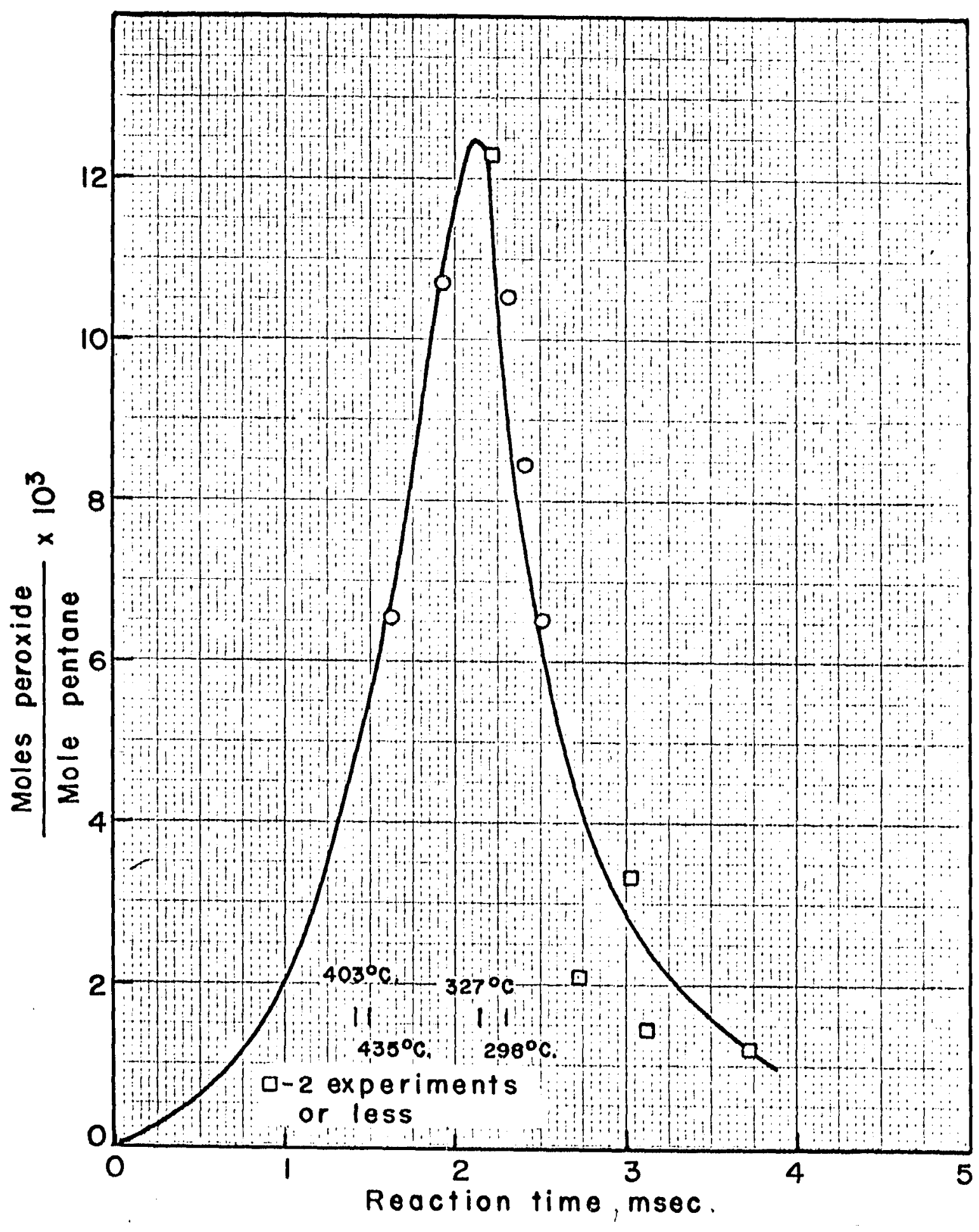

Figure 29. Peroxide formation at $327^{\circ} \mathrm{C}$. 


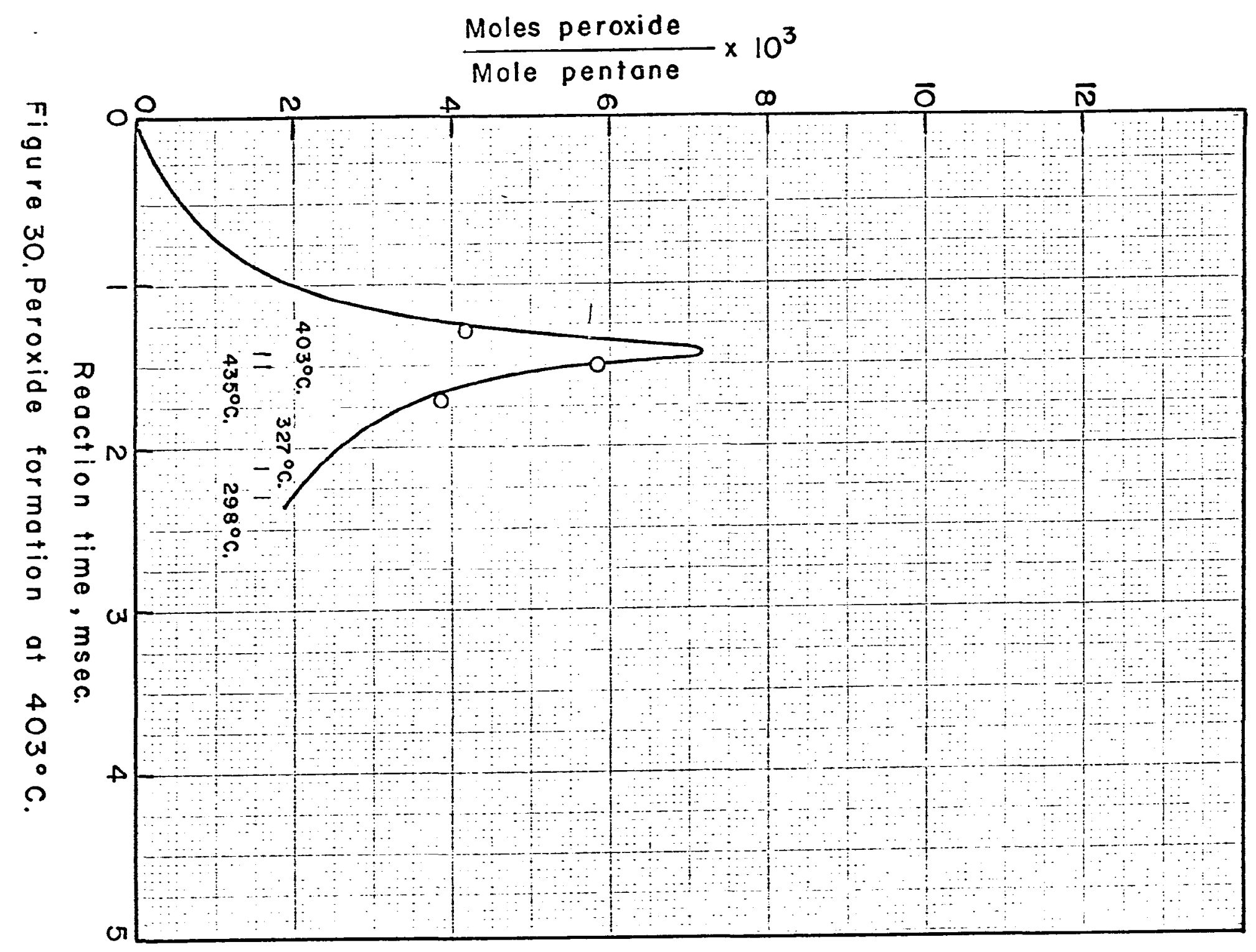




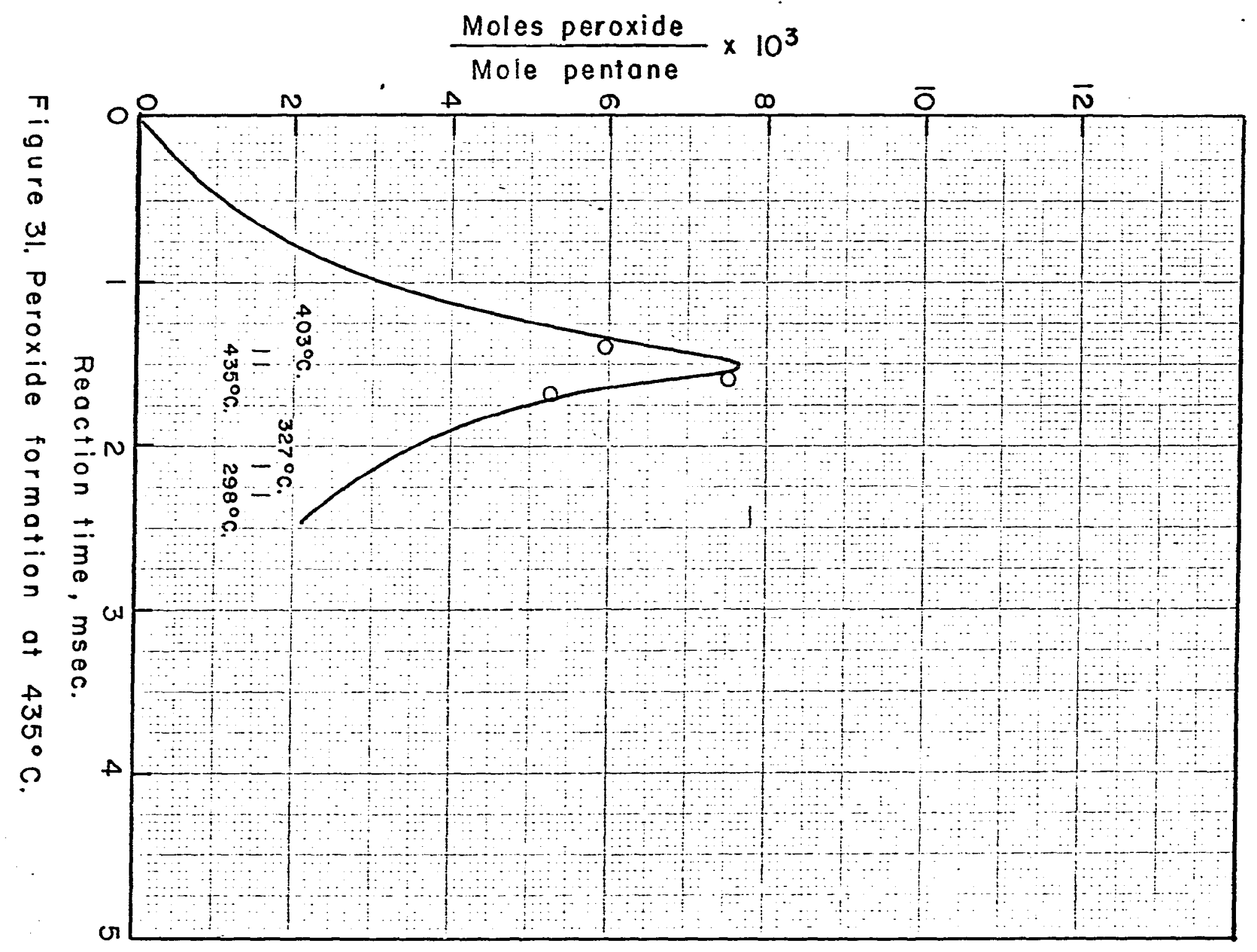




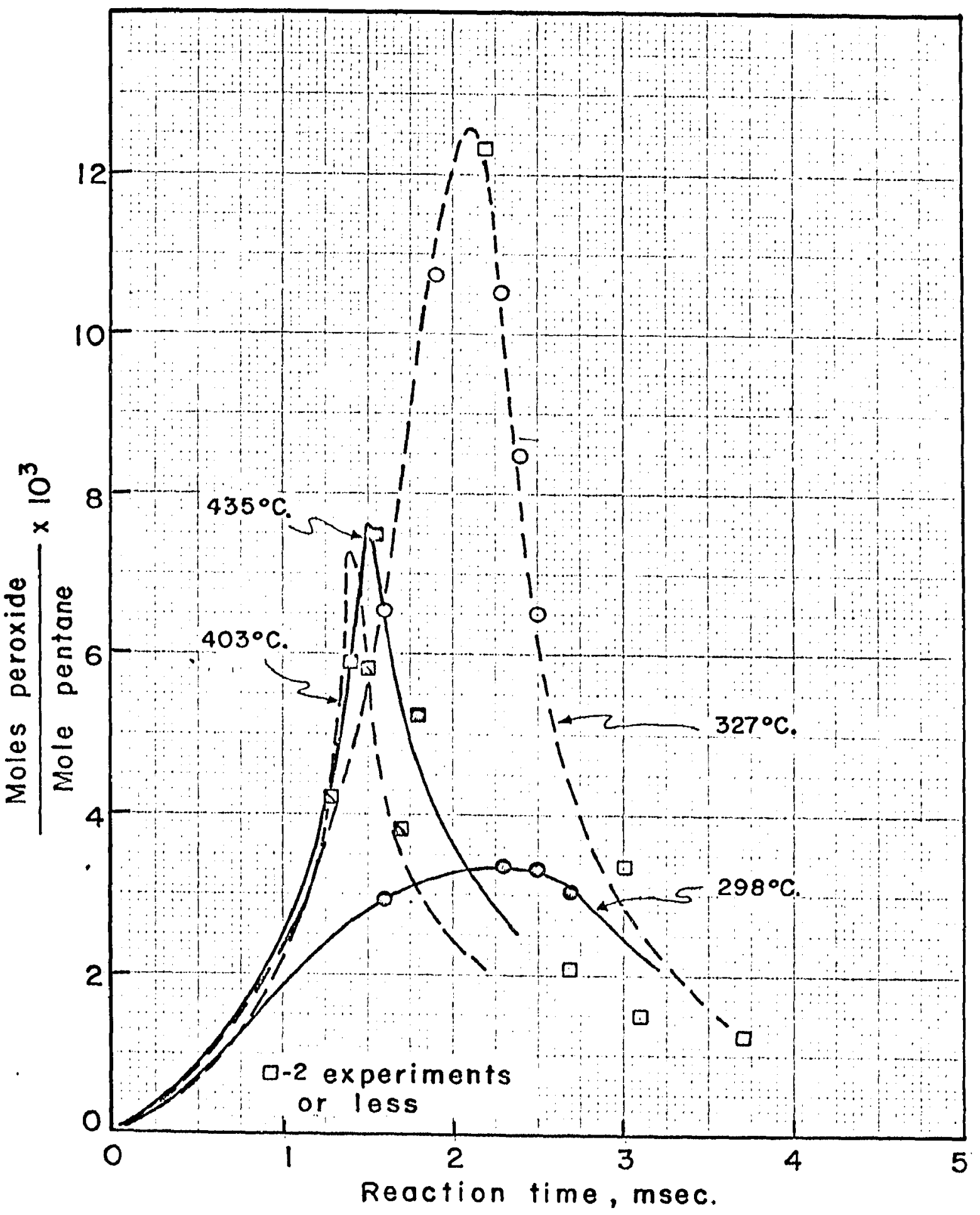

Figure 32. Peroxide formation as a function of time at various temperatures. 


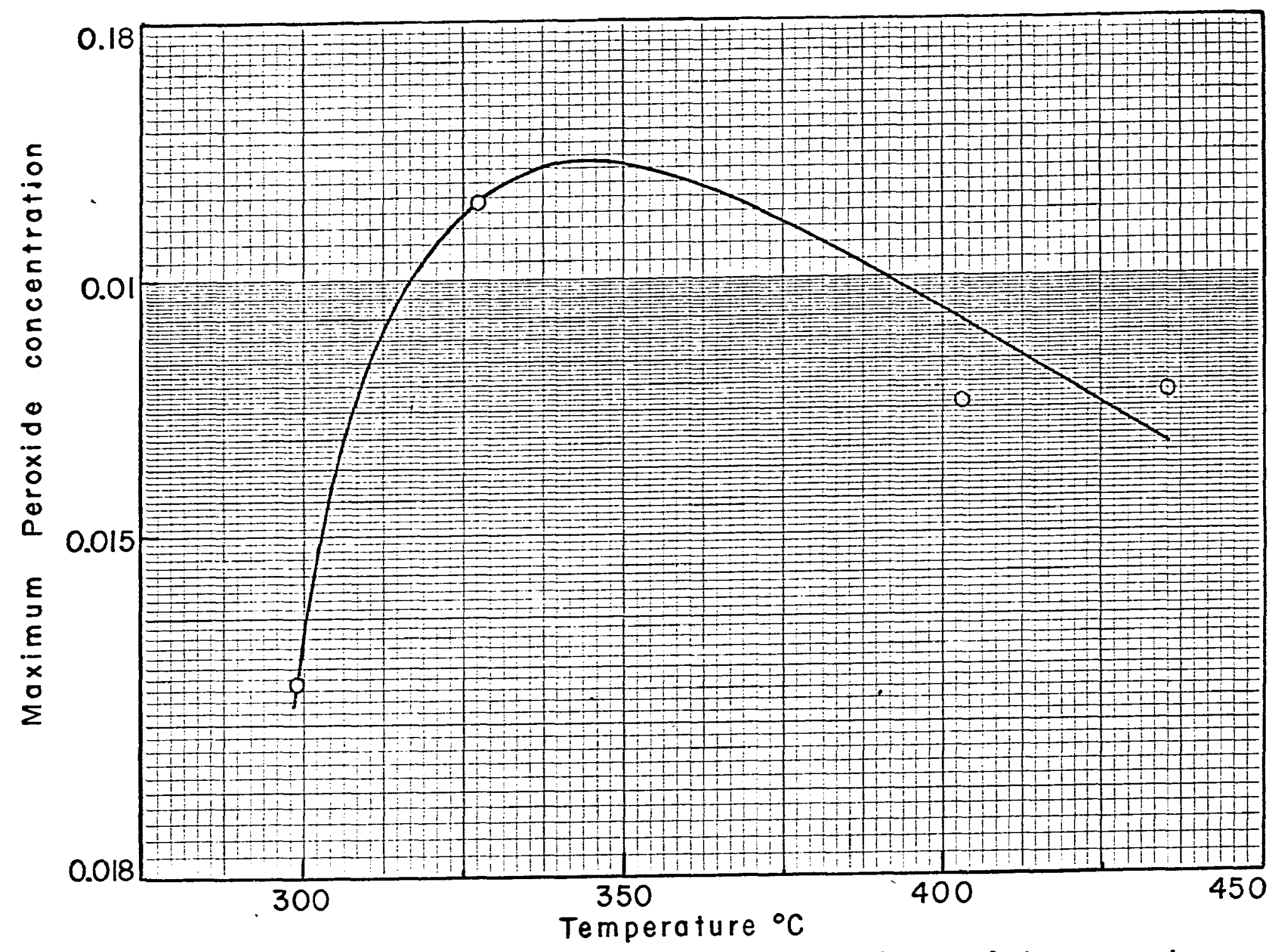

Figure 33. Peroxide formation as a function of temperature. 


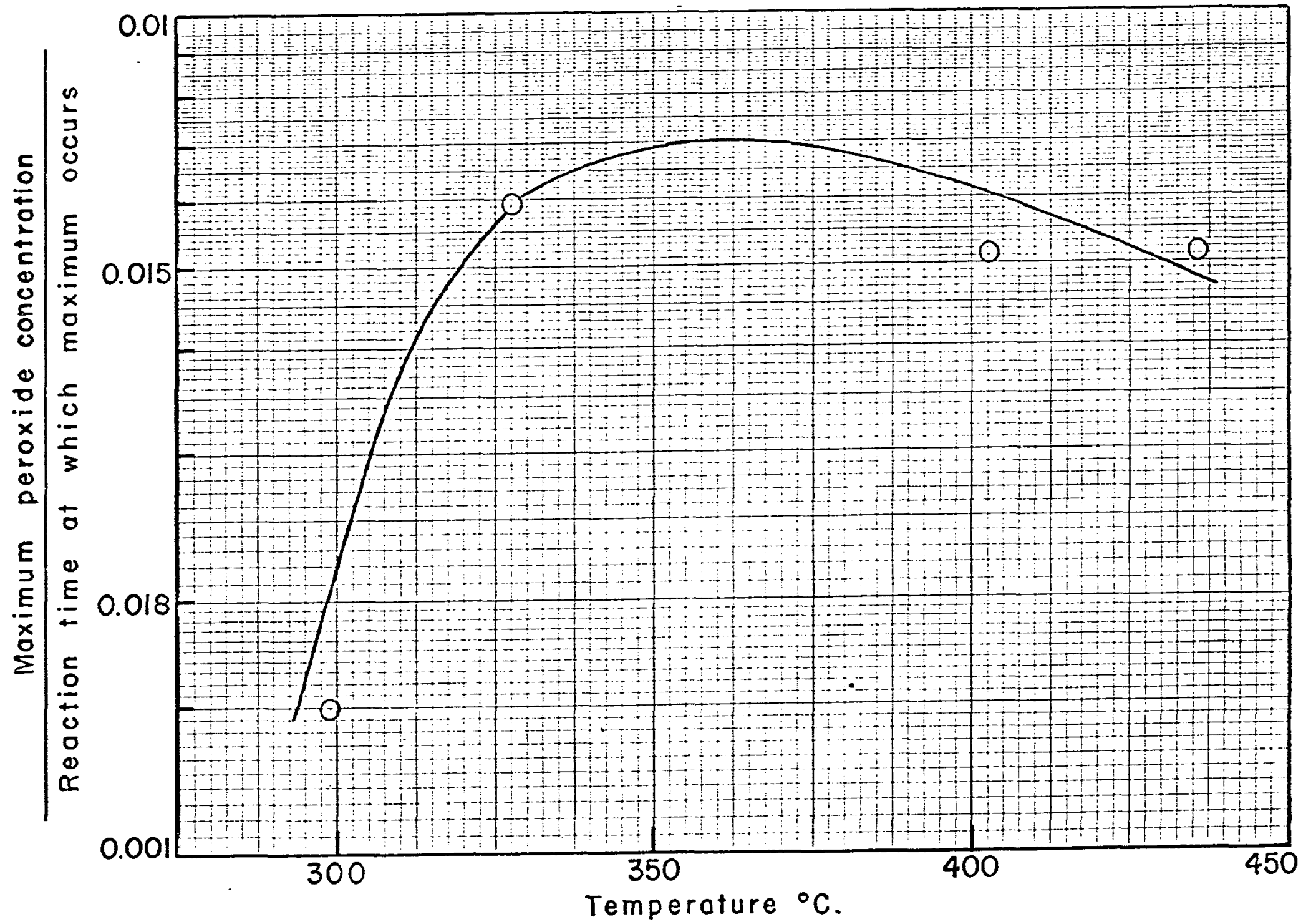

Figure.34. Maximum peroxide concentration/reaction time at which the maximum occurs as a function of temperature. 
are, very difficult to place a maximum on.

An apparent activation energy of $2.9 \mathrm{Kcal} / \mathrm{mole}$ was obtained from Figure 35. It is a logarithmic plot of the time required for the peroxide concentration to reach a maximum as a function of reciprocal Kelvin degrees.

\section{Acetaldehyde addition}

experiments

Acetaldehyde addition experiments were carried out at $327^{\circ} \mathrm{C}$. at three different reaction times and at various mixture compositions. The total amount of acetaldehyde in the reaction section varied fxom 5 to $40 \mu$ moles. This amounted to $0.6-4.0 \%$ of the pentane initially placed in the shock tube which ranged from 900 to $1500 \mu$ moles. The data obtained from these experiments are tabulated in Table 9 and illustrated in Figures 36-38. The acetaldehyde: pentane ratios illustrated in the figures is an average of the data obtained at any particular reaction time. The exact data for each experiment is 1 isted in the table.

The peroxide analysis was carried out as described earlier. In order to see if the acetaldehyde was affecting the peroxide analysis, several control experiments were performed. Two sets of samples were analyzed for peroxides in the conventional manner. The first set contained replicate samples from a pentane hydroperoxide stock solution, while the second set in addition to the hydroperoxide, contained $1 \mathrm{cc}$. of added acetaldehyde in each 


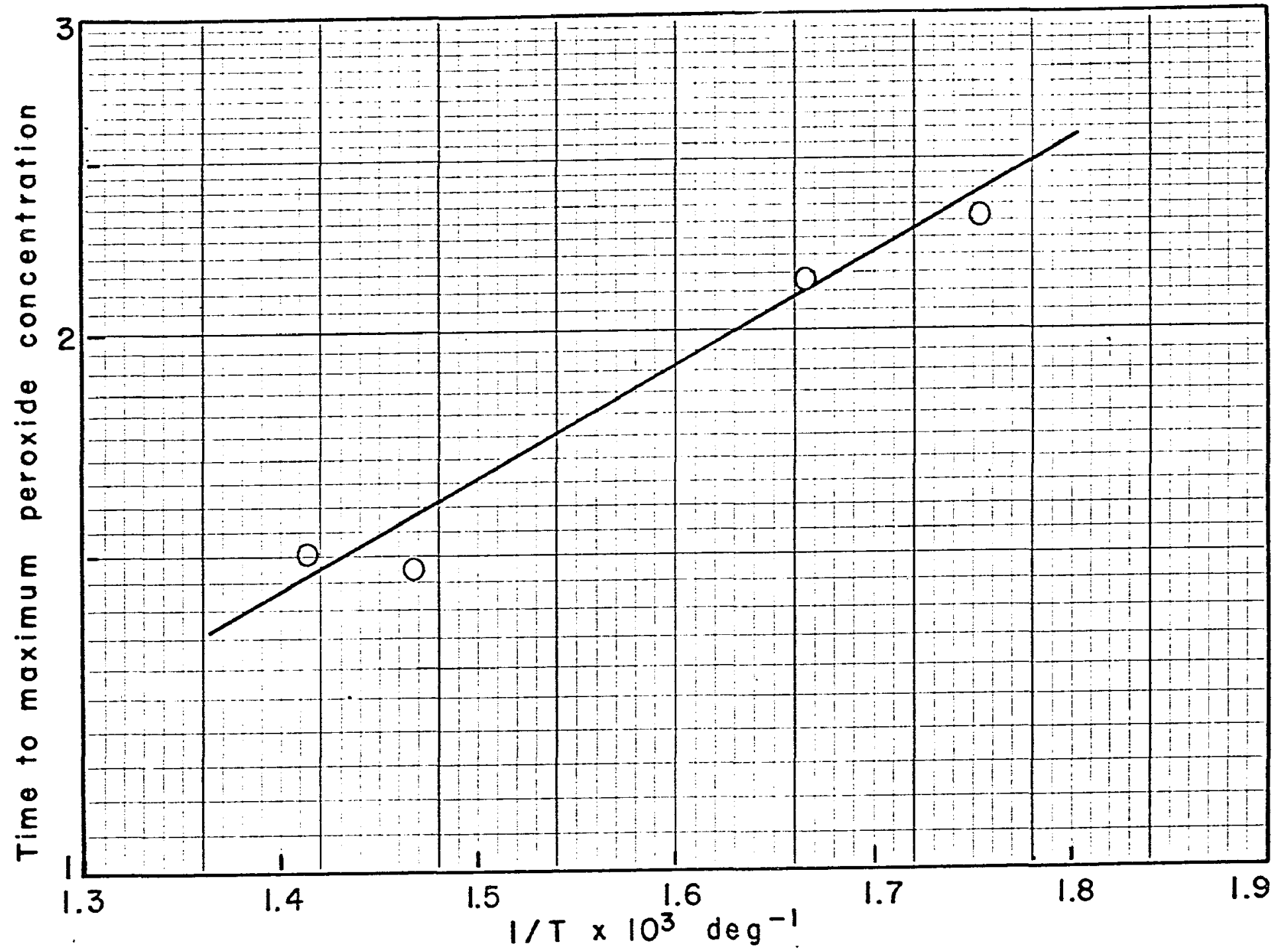

Figure 35. An Arrhenius plot of time to maximum peroxide concentration as a function of reciprocal temperature in degrees Kelvin. 
Table 9

Effect of Added Acetaldehyde on Peroxide Formation at $327^{\circ} \mathrm{C}$.

\begin{tabular}{|c|c|c|c|c|c|c|c|}
\hline Exp. No. & $\begin{array}{l}\text { Reaction } \\
\text { Time } \\
\text { (msec.) }\end{array}$ & \multicolumn{2}{|c|}{$\begin{array}{l}\text { Reactants in } \\
\text { (从moles) }\end{array}$} & $\frac{\mathrm{O}_{2}}{\mathrm{RH}}$ & $\frac{\mathrm{AcH}}{\mathrm{RH}} \times 10^{2}$ & $\begin{array}{l}\text { ROOH out } \\
\text { (umoles) }\end{array}$ & $\frac{\mathrm{ROOH}}{\mathrm{RH}} \times 10^{3}$ \\
\hline 146 & 1.6 & 1208 & 38.4 & 3.25 & 3.18 & 5.30 & 4.39 \\
\hline 149 & 1.6 & 1081 & 38.4 & 5.43 & 3.55 & 9.45 & 8.74 \\
\hline 154 & 1.7 & 404 & 10.7 & 7.42 & 2.65 & 5.05 & 12.50 \\
\hline 152 & 1.7 & 1226 & 42.1 & 7.61 & 3.43 & 15.25 & 12.44 \\
\hline 144 & 1.6 & 1277 & 17.9 & 1.25 & 1.40 & 5.60 & 4.39 \\
\hline 182 & 1.5 & 994 & 15.6 & 2.03 & 1.57 & 4.70 & 4.73 \\
\hline 147 & 1.6 & 1022 & 11.9 & 2.95 & 1.16 & 5.40 & 5.28 \\
\hline 150 & 1.6 & 1176 & 15.1 & 5.14 & 1.28 & 10.55 & 8.97 \\
\hline 153 & 1.6 & 1334 & 17.1 & 6.96 & 1.28 & 16.20 & 12.14 \\
\hline 145 & 1.6 & 1380 & 10.5 & 1.24 & 0.761 & 7.40 & 5.36 \\
\hline 148 & 1.6 & 1168 & 9.61 & 3.36 & 0.823 & 6.40 & 5.48 \\
\hline 151 & 1.6 & 1188 & 9.24 & 5.08 & 0.778 & 10.80 & 12.14 \\
\hline 180 & 1.9 & 1000 & 36.3 & 1.93 & 3.63 & 10.65 & 10.65 \\
\hline 185 & 1.8 & 1061 & 34.6 & 5.35 & 3.26 & 13.50 & 12.72 \\
\hline 188 & 1.8 & 873 & 38.0 & 9.01 & 4.35 & 10.95 & 12.54 \\
\hline 183 & 1.9 & 1067 & 17.3 & 1.93 & 1.62 & 12.20 & 11.43 \\
\hline 186 & 1.9 & 976 & 15.6 & 5.68 & 1.60 & 13.70 & 14.04 \\
\hline
\end{tabular}


Table 9 (contd.)

\begin{tabular}{|c|c|c|c|c|c|c|c|}
\hline \multirow[t]{2}{*}{ Exp. No. } & \multirow{2}{*}{$\begin{array}{l}\text { Reaction } \\
\text { Time } \\
\text { (msec.) }\end{array}$} & \multicolumn{2}{|c|}{$\begin{array}{l}\text { Reactants in } \\
\text { (umoles) }\end{array}$} & \multirow[t]{2}{*}{$\frac{\mathrm{O}_{2}}{\mathrm{RH}}$} & \multirow[t]{2}{*}{$\frac{A c H}{R H} \times 10^{2}$} & \multirow[t]{2}{*}{$\begin{array}{l}\mathrm{ROOH} \text { out } \\
\text { (Amoles) }\end{array}$} & \multirow[t]{2}{*}{$\frac{\mathrm{ROOH}}{\mathrm{RH}} \times 10^{3}$} \\
\hline & & $\mathrm{RH}$ & $\mathrm{AcH}$ & & & & \\
\hline 184 & 1.8 & 849 & 7.88 & 2.18 & 0.928 & 8.85 & 10.42 \\
\hline 187 & 1.9 & 960 & 8.53 & 5.77 & 0.889 & 13.85 & 14.43 \\
\hline 189 & 1.8 & 891 & 5.38 & 8.81 & 0.604 & 11.50 & 12.91 \\
\hline 164 & 2.5 & 1176 & 37.5 & 1.45 & 3.19 & 4.15 & 3.53 \\
\hline 155 & 2.5 & 1176 & 37.0 & 3.18 & 3.15 & 5.05 & 4.29 \\
\hline 161 & 2.5 & 1131 & 36.6 & 7.26 & 3.24 & 6.40 & 5.66 \\
\hline 167 & 2.5 & 1024 & 37.0 & 8.08 & 3.61 & 6.30 & 6.15 \\
\hline 156 & 2.5 & 1168 & 17.4 & 3.38 & 1.49 & 5.50 & 4.71 \\
\hline 159 & 2.5 & 950 & 14.5 & 6.52 & 1.53 & 5.80 & 6.11 \\
\hline 162 & 2.5 & 1152 & 16.7 & 6.85 & 1.45 & 6.70 & 5.82 \\
\hline 163 & 2.5 & 566 & 11.7 & 9.97 & 2.07 & 4.10 & 7.24 \\
\hline 166 & 2.5 & 1168 & 8.85 & 1.55 & 0.756 & 5.55 & 4.75 \\
\hline 157 & 2.5 & 1160 & 9.07 & 3.63 & 0.782 & 5.80 & 5.00 \\
\hline 160 & 2.5 & 1071 & 10.5 & 6.06 & 0.980 & 6.80 & 6.35 \\
\hline 168 & 2.5 & 1103 & 11.1 & 7.91 & 1.01 & 7.90 & 7.16 \\
\hline
\end{tabular}

$\mathrm{RH}$, pentane; $\mathrm{AcH}$, acetaldehyde; ROOH, peroxides 


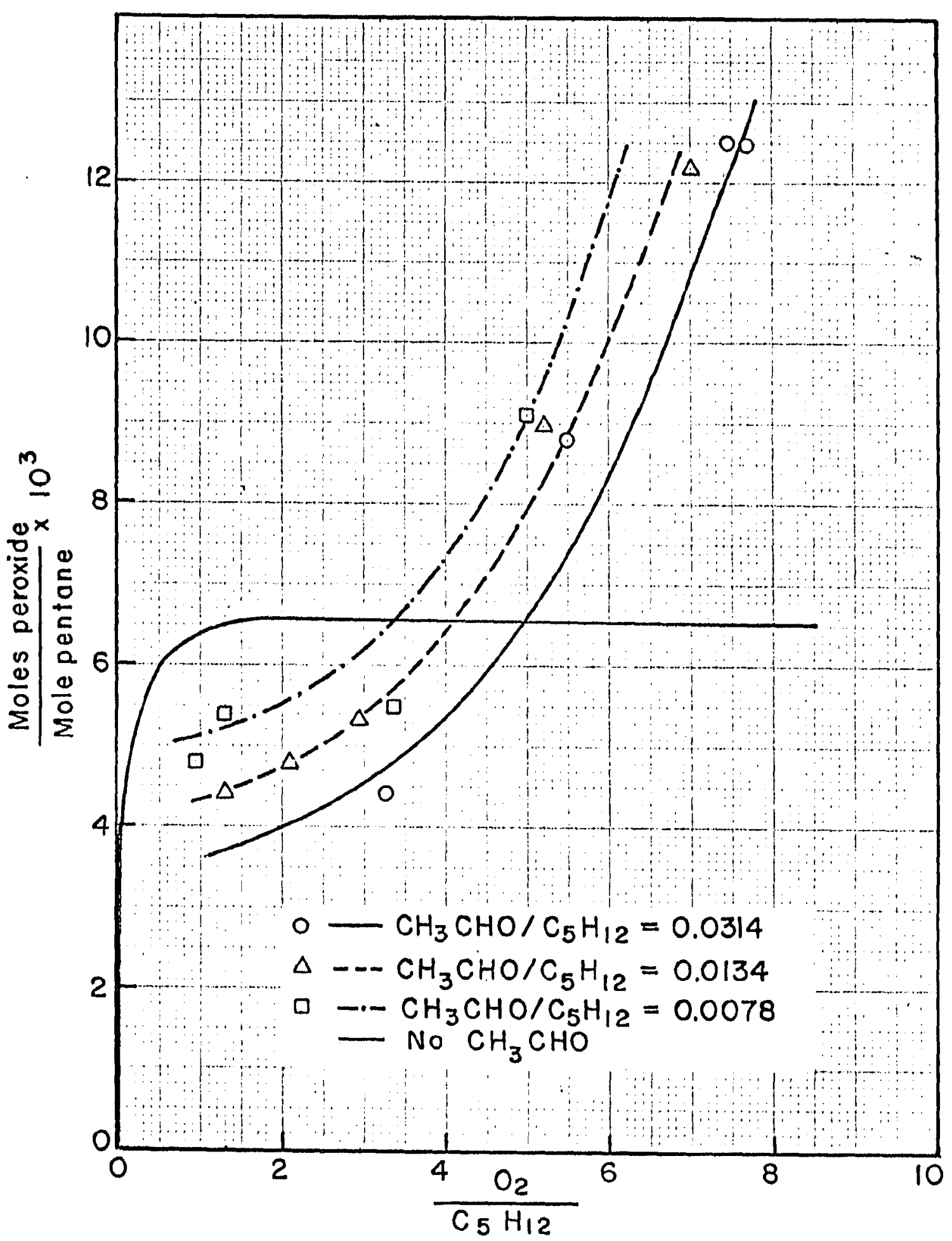

Figure 36. Effect of added Acetaldehyde on peroxide formation of $327^{\circ} \mathrm{C}$ and a reaction time of $1.6 \mathrm{msec}$. 


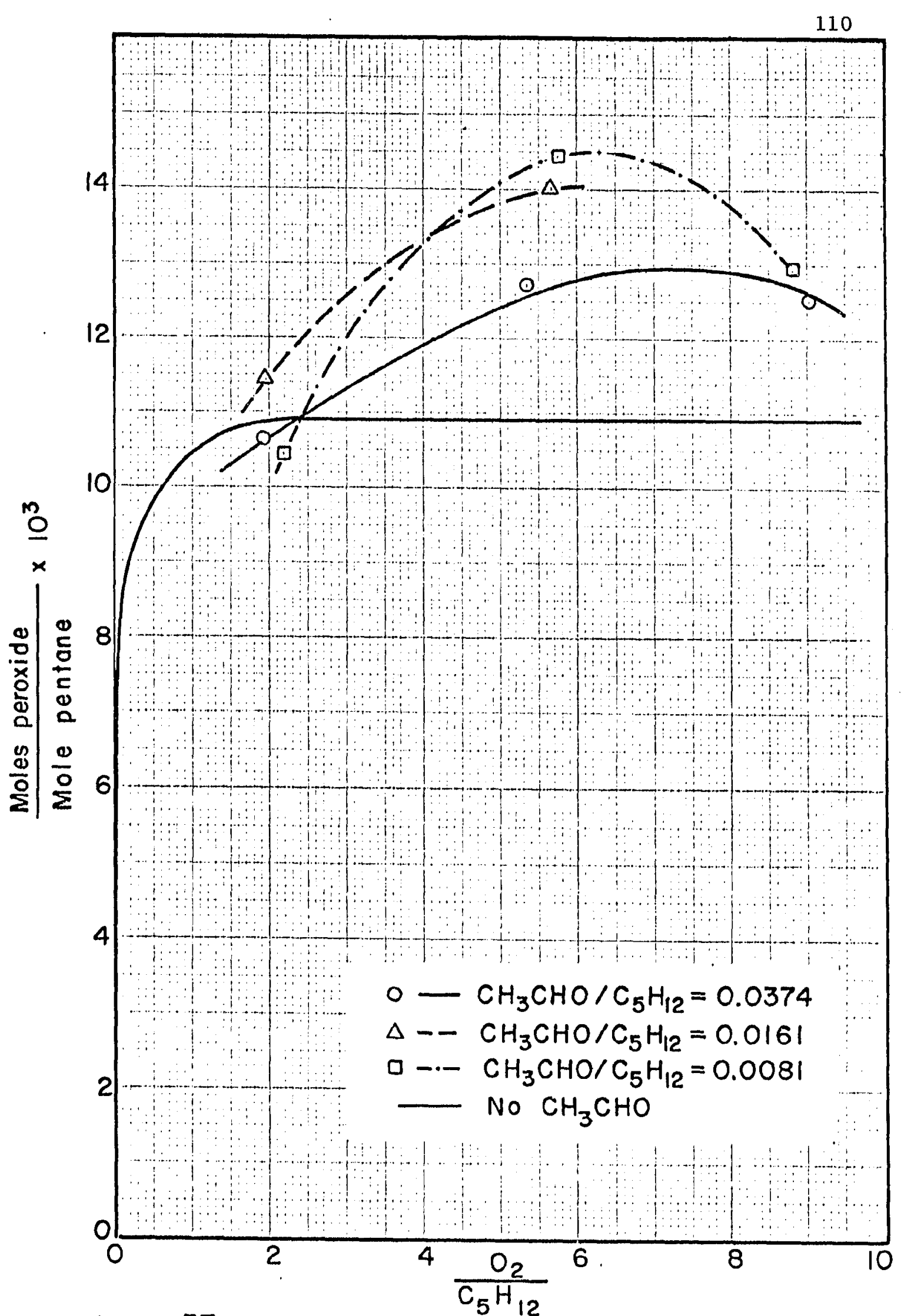

Figure 37. Effect of added Acetaldehyde on Peroxide formation at $327^{\circ} \mathrm{C}$ and a reaction time of $1.9 \mathrm{msec}$. 


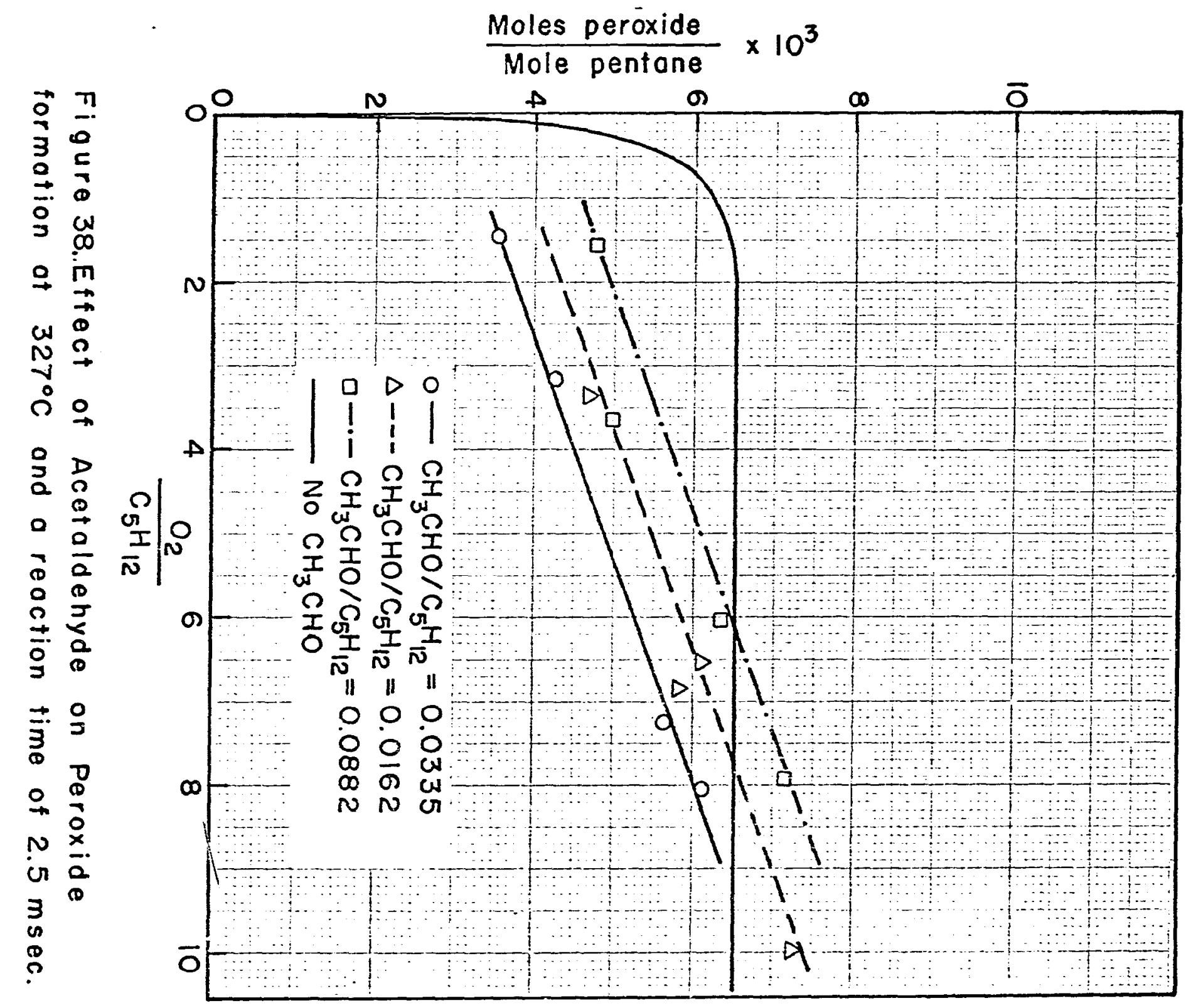


solution. These samples, along with several blank solutions were analyzed for peroxides. No differences could be obtained between the two sets of samples. Thus, under these experimental conditions, acetaldehyde does not interfere with the analysis of hydroperoxides. Unshocked mixtures were placed in the shock tube and passed through the gas scrubber system as described previously. The mixtures contained, in addition to helium, argon, pentane and oxygen, measured amounts of acetaldehyde. The amounts approximated those which were used in an actual experiment. The analysis for peroxides yielded, as before, a blank of less than $0.01 \mathrm{cc}$ in all cases.

\section{Tertiary butylhydroperoxide addition}

\section{experiments}

Several experiments were performed at $327^{\circ} \mathrm{C}$. in which small amounts of tertiary butylhydroperoxide were added to the reaction mixture. The resulting mixture of shocked gases was analyzed for peroxides in two of the experiments and for non-peroxidic compounds in the third experiment. In the experiments in which the peroxides were determined, approximately $50 \%$ of the tertiary butylhydroperoxide was recovered as unreacted peroxide. This \% recovery figure is based upon the assumption that the tertiary butylhydroperoxide does not interfere with the normal peroxide-producing reactions in the oxidation system. Details of the calculations are demonstrated in the appendix.

In the product analysis experiment, acetone was recovered but no attempt was made quantitatively to determine the amount formed. 
Several other products were also found during this experiment. No attempt was made to identify them.

In two separate experiments, known amounts of the tertiary butylhydroperoxide were expanded into the shock tube and allowed to remain there for about 20 minutes. The gaseous mixture was then transferred under vacuum through the gas scrubber system and analyzed for peroxides according to the procedure outlined earlier. In both cases, the amount of peroxide recovered, based upon the assumption that the peroxide was $100 \%$ pure, was 95.46 and $96.73 \%$ in the two experiments. This indicates that the peroxide did not decompose significantly during the period of time it remained in the reaction section of the shock tube.

Analysis of products other than peroxides

Analysis for products other than peroxides was performed on experiments carried out at all four reaction temperatures. In all experiments, the resulting mixture of shocked gases was transferred under its own pressure into two traps where it remained for a period of time. The two traps were maintained at liquid nitrogen temperature. After a period of time, a flushing of the gas was started by allowing some of the gas in the remaining parts of the shock tube to push the reactant gases through the two cold traps. The amount of gas passing through the cold traps was measured on a wet-test flow meter. After 3 cubic feet of gas had been passed through this system, the traps were placed on the vacuum system and the non- 
condensable gases pumped off, while maintaining the traps at liquid nitrogen temperature. The condensate was then transferred by distillation to a sampling system equipped with a serum cap. This sample bulb was then filled to a measured pressure with part of the remaining helium-argon mixture. The sample bulb was placed on the pressure-leveling device and samples were transferred by means of a gas syringe to the gas chromatograph. Analysis was performed under the conditions mentioned in a previous section.

In a11 of these experiments, the oxygen: pentane molar ratio was maintained between 1.8 and 3.6. As in the earlier experiments, the majority of the results were obtained at $327^{\circ} \mathrm{C}$.

At the two lowest temperatures, the only product definitely identified was crotonaldehyde. Many other possibilities were eliminated. With the acetaldehyde addition experiments at $327^{\circ} \mathrm{C}$, the formation of this unsaturated aldehyde was completely inhibited except at the longest reaction time. In the peroxide addition experiments, also at this temperature, the formation of crotonaldehyde was enhanced.

At the two highest temperatures, and only at some reaction conditions, traces of crotonaldehyde were observed. At $403^{\circ} \mathrm{C}$, amounts of acetaldehyde were found, while at the highest temperature, $435^{\circ} \mathrm{C}$, no products could be definitely identified, although some were observed. The acetaldehyde found at $403^{\circ} \mathrm{C}$. apparently decreased as a function of time.

The data for these experiments are tabulated in Table 10. The crotonaldehyde found is expressed on a relative basis, the amount 
Table 10

Products of the Oxidation Reaction

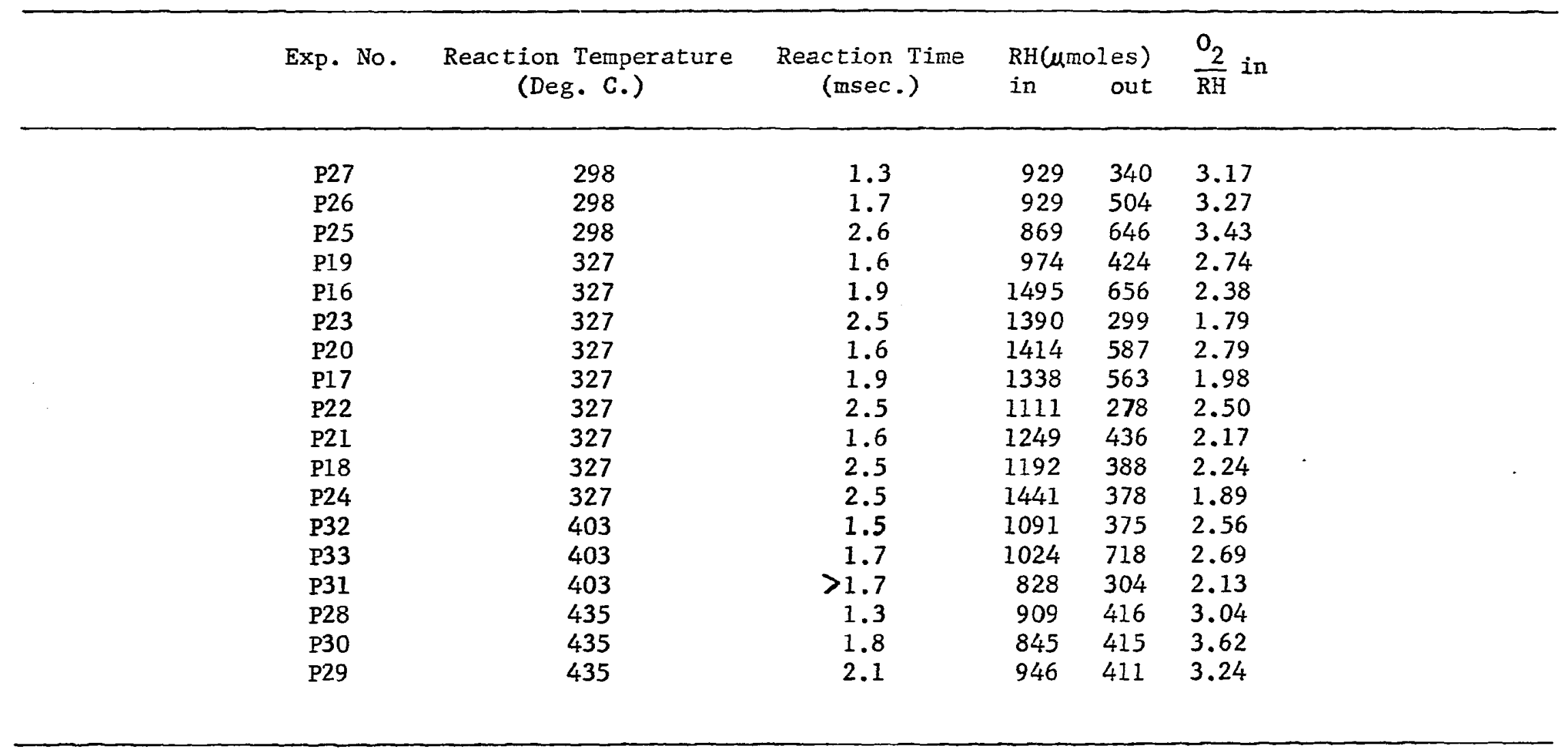

RH, pentane 
Table 10 (contd)

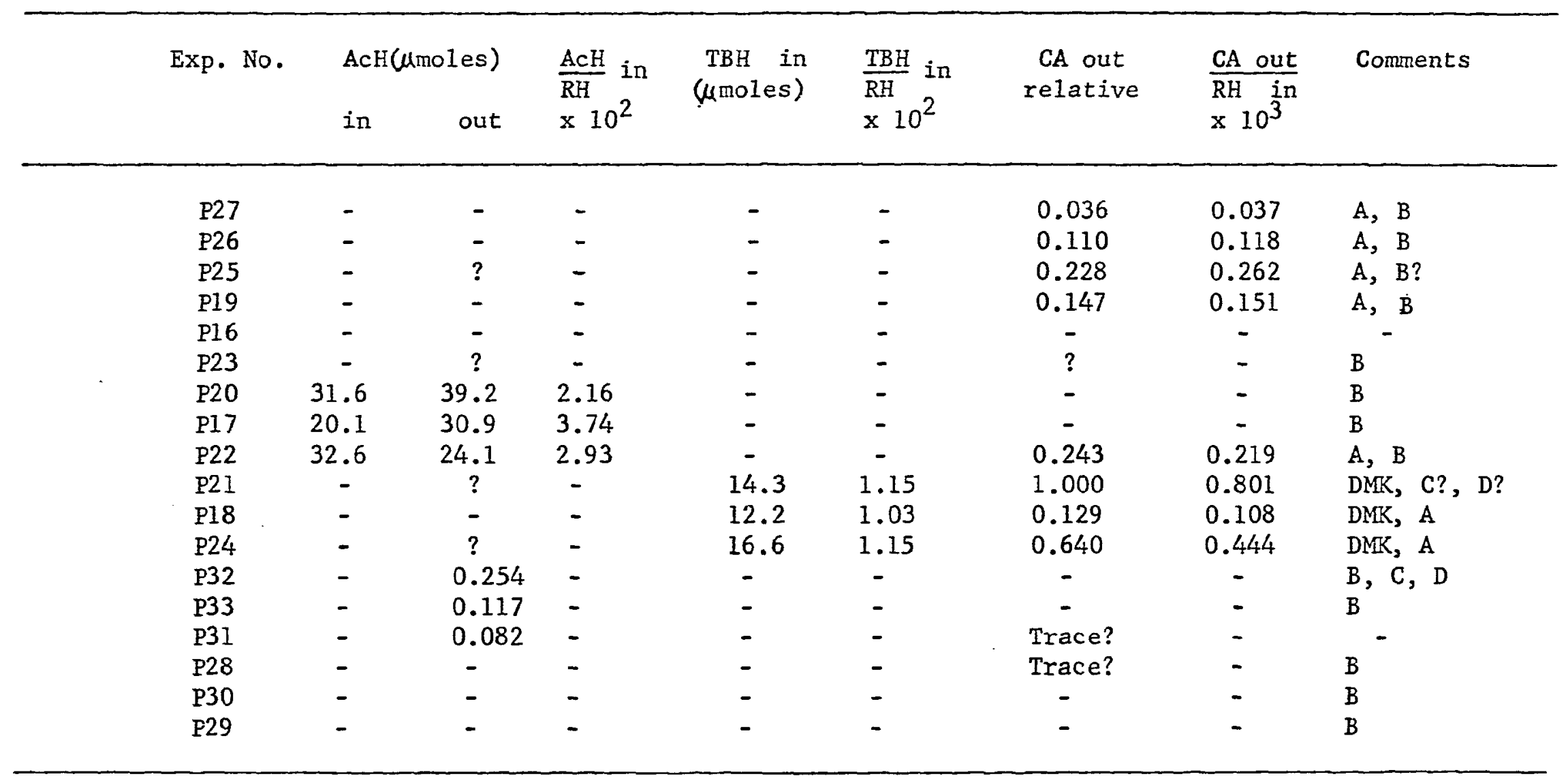

$\mathrm{RH}$, pentane; $\mathrm{AcH}$, acetaldehyde; $\mathrm{TBH}$, tertiary butylhydroperoxide

DMK, acetone; CA, crotonaldehyde 
found in experiment P21 taken to be equal to unity. This amount is then compared, also on this same relative basis, to the amount of pentane initially introduced into the shock tube. The unidentified products that were found in each experiment are labeled as A, B, C, etc. under comments in Table 10. A sample chromatogram illustrating their elution times as well as the elution times for the products that were identified is given in the appendix.

The compounds definitely eliminated as products of the oxidation reaction under the experimental conditions used during this study are as follows: acetone, methanol, 2-pentanone, 3-pentanone, valeraldehyde, butyraldehyde, butanone, 1-pentene, 2-pentene and acrolein. There are, of course, other possible oxidation products, but known samples could not at the time be obtained. It should be pointed out, that the non-condensable products were not analyzed for, and that the alkanes and alkenes with fewer than five carbon atoms could not be analyzed for on the analytical column in use throughout this study. $\mathrm{CO}_{2}$ and water were found in some of the earlier experiments, but since these compounds could have been present as impurities in some of the cylinder gases used, their presence was disregarded.

From the data presented in Table 10, it can be noticed that the per cent recovery of the pentane was rather low in the experiments in which the non-peroxidic products were condensed at $-196^{\circ} \mathrm{C}$. This can be contrasted to the high \% recovery of pentane obtained by the simple method of expansion. The data using the expansion method are 1 isted in Table 5. 
The low recovery of pentane can occur in the condensation expeximents as a direct result of transferring the gases at too rapid a rate through the series of cold traps. Also, since several transfers of the gases were carried out in each experiment, there is probably some loss of gas at each transfer. This method of recovery does however appear to be a suitable way to trap the gases for eventual analysis, although more work must be done to increase the efficiency of the method. 


\section{DISCUSSION OF RESULTS}

The results reported here include a detailed study of the formation of peroxides as a function of time, reaction temperature and mixture composition. Product analysis for non-peroxidic compounds was carried out at each reaction temperature for various reaction times. The study of product formation was essentially a survey and no attempt was made at completeness.

One product was formed however in large enough quantities to indicate that it might have a very important role in the initial steps of the reaction mechanism. This product was crotonaldehyde. At the two low temperatures, this unsaturated aldehyde was formed under most experimental conditions, while at the two highest temperatures, some of the oxidation products of crotonaldehyde were observed.

There are two points of oxygen attack on the pentane molecule which must be considered, the hydrogen atoms on carbon atoms 2 and 3. Carbon atom 4 is equivalent to carbon atom 2, so on a statistical basis, carbon atom 2 rather than carbon atom 3 should be the position most favored for attack by the oxygen. The primary hydrogen atoms, on carbon atoms 1 and 5 are less likely to be attacked.

If carbon atom 2 is the initial point of attack on the hydrocarbon molecule, the equation group $A$ can be written to explain the observed products of the oxidation reaction. The equations 
presented produce all products observed in this and other studies on the oxidation of pentane. Other reactions can of course be written, but since the products resulting from these possible reactions have not been observed in this or other studies on pentane oxidation, they are not included. Different reaction mechanisms can also be written to explain the formation of the observed products of the oxidation reaction. These have not been considered by workers in the field and will not be considered in this discussion.

The individual reactions in the sequence will each be considered in turn and on the basis of the data obtained in this investigation, either accepted or discarded.

The first and most difficult step in the oxidation of the hydrocarbon molecule is the formation of the alkyl radical. This probably occurs by interaction of the initial reactants.

$$
\mathrm{CH}_{3} \mathrm{CH}_{2} \mathrm{CH}_{2} \mathrm{CH}_{2} \mathrm{CH}_{3}+\mathrm{O}_{2} \rightarrow \mathrm{CH}_{3} \mathrm{CHCH}_{2} \mathrm{CH}_{2} \mathrm{CH}_{3}+\cdot \mathrm{HO}_{2}
$$

This step is endothermic by approximately $45 \mathrm{kcal} . / \mathrm{mole}$ (see reference 5 , page 462).

The alkyl radical formed by reaction Al can suffer several

fates. It can decompose by

$$
\mathrm{CH}_{3} \mathrm{CHCH}_{2} \mathrm{CH}_{2} \mathrm{CH}_{3} \longrightarrow \mathrm{CH}_{3} \mathrm{CH}_{2} \mathrm{CH}=\mathrm{CH}_{2}+\mathrm{CH}_{3} \text {. }
$$

or it can readily combine with oxygen, producing a hydroperoxy radical and an alkene,

$$
\mathrm{CH}_{3} \mathrm{CHCH}_{2} \mathrm{CH}_{2} \mathrm{CH}_{3}+\mathrm{O}_{2} \longrightarrow \mathrm{CH}_{3} \mathrm{CH}=\mathrm{CHCH}_{2} \mathrm{CH}_{3}+\mathrm{HO}_{2} \cdot
$$


Equation Group A

A1 $\mathrm{CH}_{3} \mathrm{CH}_{2} \mathrm{CH}_{2} \mathrm{CH}_{2} \mathrm{CH}_{3}+\mathrm{O}_{2} \longrightarrow \mathrm{CH}_{3} \mathrm{CHCH}_{2} \mathrm{CH}_{2} \mathrm{CH}_{3}+\cdot \mathrm{HO}_{2}$

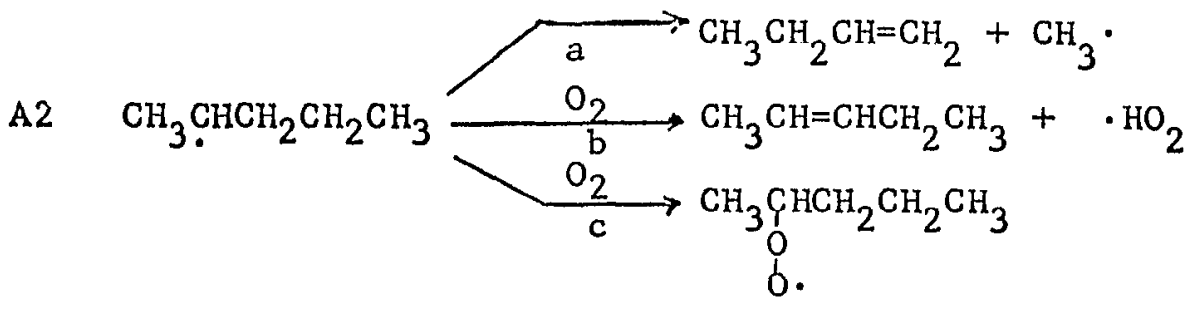

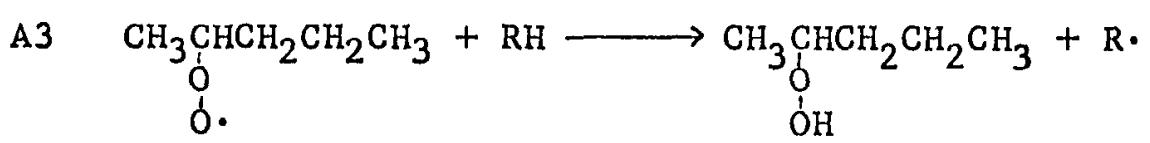

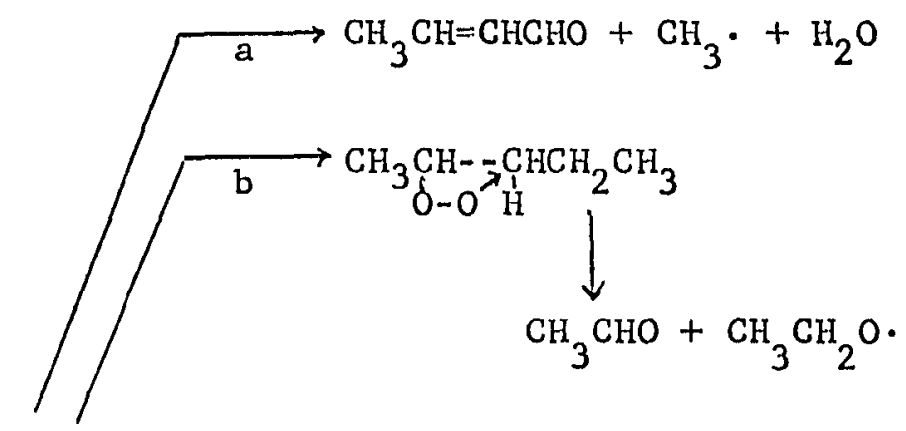

A4 $\mathrm{CH}_{3} \mathrm{CHCH}_{2} \mathrm{CH}_{2} \mathrm{CH}_{3} \longrightarrow \mathrm{c} \mathrm{CH}_{3} \mathrm{O} \cdot+\mathrm{CH}_{3} \mathrm{CH}_{2} \mathrm{CH}_{2} \mathrm{CHO}$
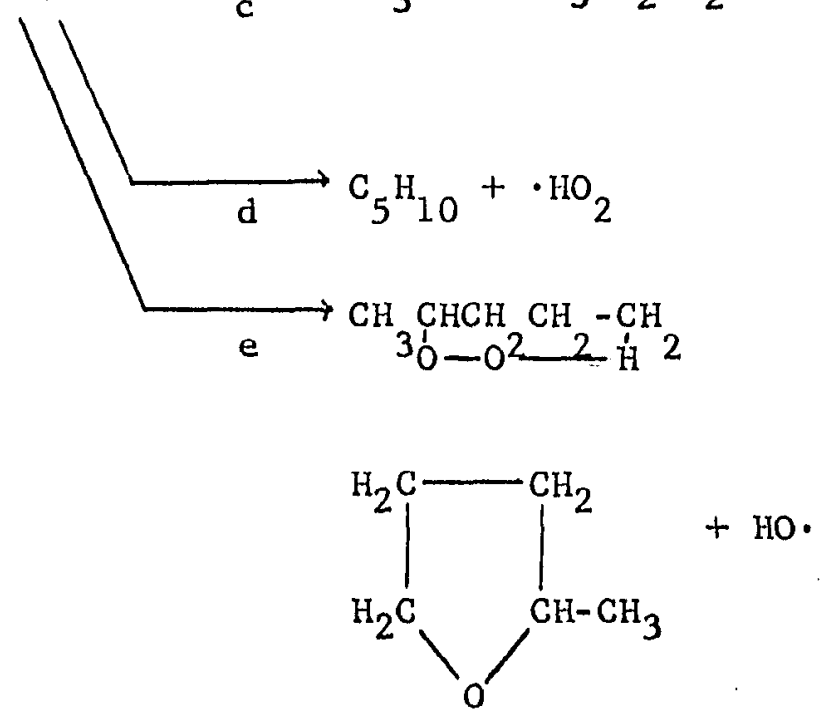
Equation Group A (contd.)

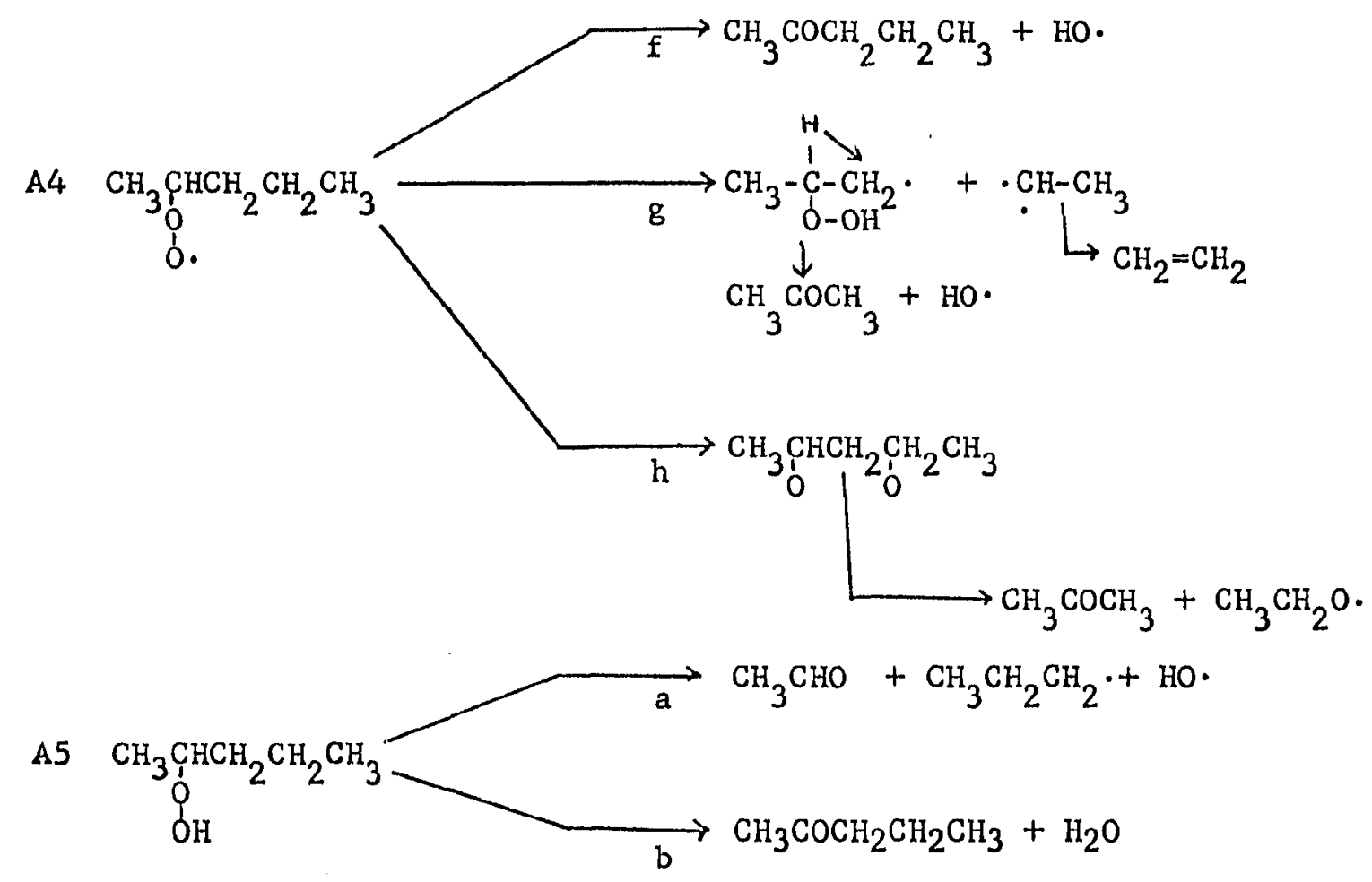

A6 $\mathrm{HO}_{2} \cdot+\mathrm{C}_{5} \mathrm{H}_{12}$

$\mathrm{H}_{2} \mathrm{O}_{2}+\mathrm{C}_{5} \mathrm{H}_{11}$.

A7 $\mathrm{HO}_{2} \cdot+\mathrm{HO}_{2} \cdot$

$\mathrm{H}_{2} \mathrm{O}_{2}+\mathrm{O}_{2}$

A $8 \mathrm{CH}_{3} \mathrm{CH}=\mathrm{CHCHO}+\mathrm{O}_{2} \longrightarrow \mathrm{CH}_{3} \mathrm{CH}=\mathrm{CHCO}+\mathrm{HO}_{2} \cdot$ 
Equation Group A (contd.)

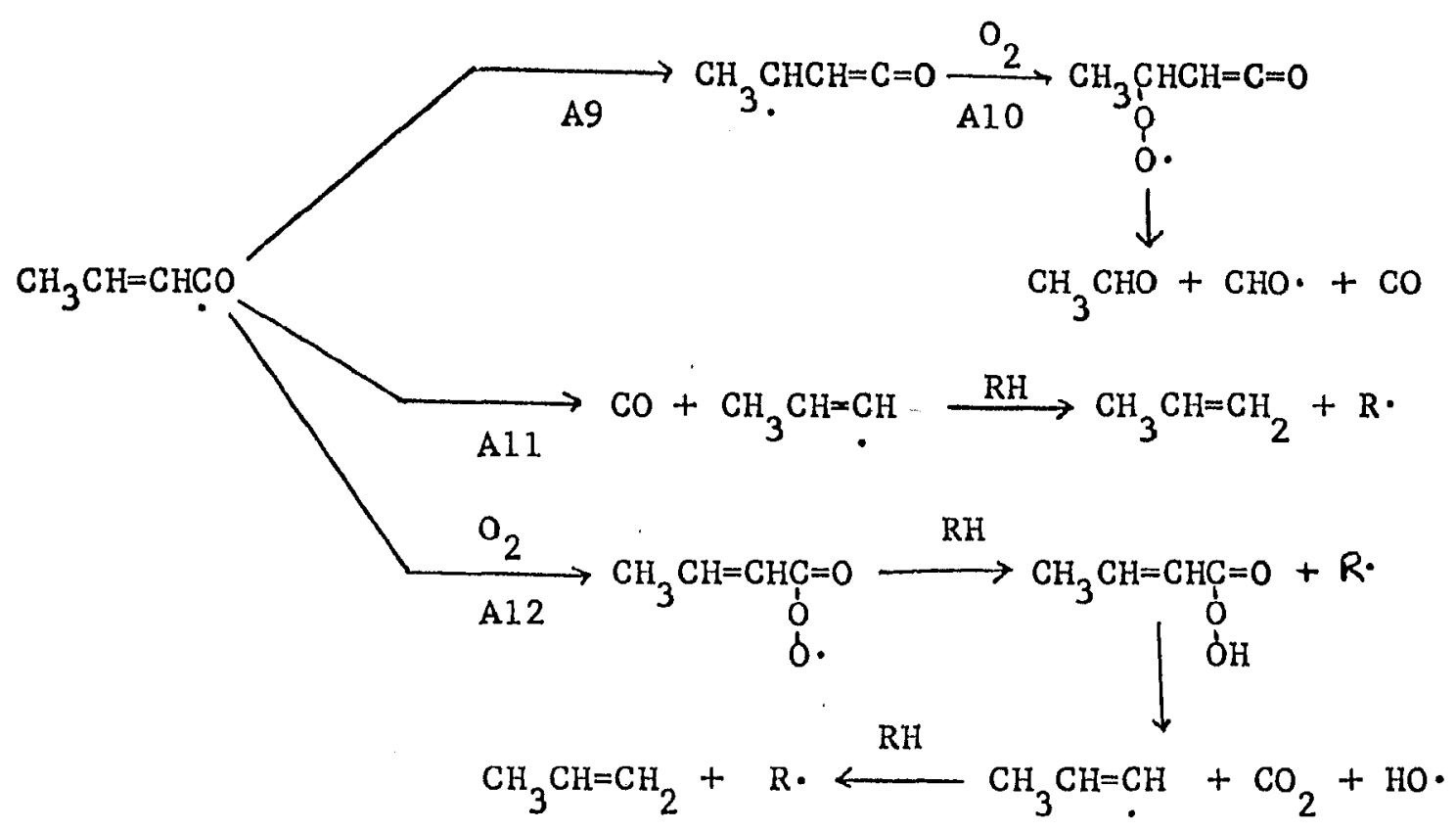

\section{$\mathrm{Al3} \mathrm{CH}_{3} \mathrm{CH}=\mathrm{CH} \longrightarrow \mathrm{CH}_{2} \mathrm{CH}=\mathrm{CH}_{2}+\mathrm{O}_{2} \longrightarrow \cdot 00 \mathrm{CH}_{2} \mathrm{CH}=\mathrm{CH}_{2}$}

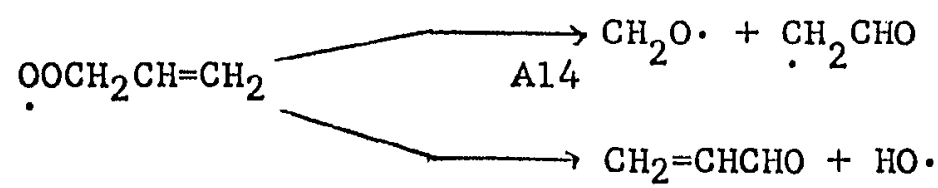

Al5 $L \mathrm{O}_{2} \rightarrow$ further products

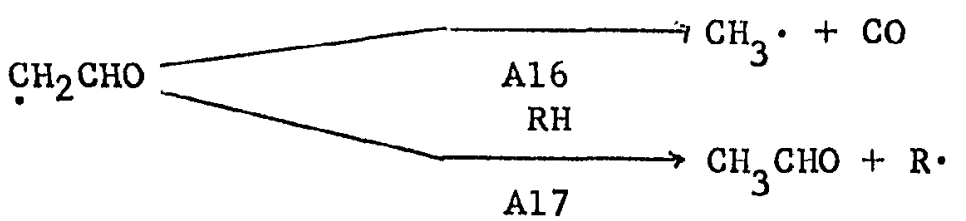


or it can form a peroxy radical

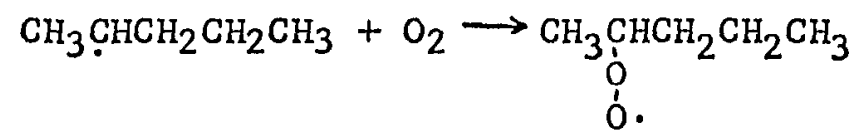

The three reactions are all likely to occur in the temperature range of this study. The products from reactions $\mathrm{A} 2 \mathrm{a}$ and $\mathrm{A} 2 \mathrm{~b}$ are not observed in this investigation. Lee, ${ }^{36}$ in his shock tube study of pentane oxidation isolated pentane as an oxidation product, while Wellman 37 in a similar study, did not.

The alkyl peroxy radical can undergo a variety of reactions and transformations. The radical can abstract a hydrogen atom from the parent hydrocarbon to form an organic hydroperoxide<smiles>[R7][S+]CCC(C)C(O)CCCC(C)O[O-]</smiles>

This reaction should have an activation energy of about $7-10 \mathrm{kcal} / \mathrm{mole}$ (see reference 5, page 462). Peroxides are observed in the oxidation reaction.

Crotonaldehyde can be formed by the following postulated sequence<smiles>C[C+]=CC=CCCCCCCC(=O)C(O)CCCCC(C)O[O-]</smiles>

From earlier studies, $16,17,18$ calculations indicate that the decomposition of the peroxy radical should have an activation energy of 
about $20 \mathrm{kcal} . / \mathrm{mole}$. This decompostition reaction would be expected to compete with the abstraction reaction $\mathrm{A} 3$ and at higher temperatures be the predominant of the two reactions. Crotonaldehyde is an observed product of the oxidation reaction.

The peroxy radical can decompose in other ways. Reaction A4b would yield the following

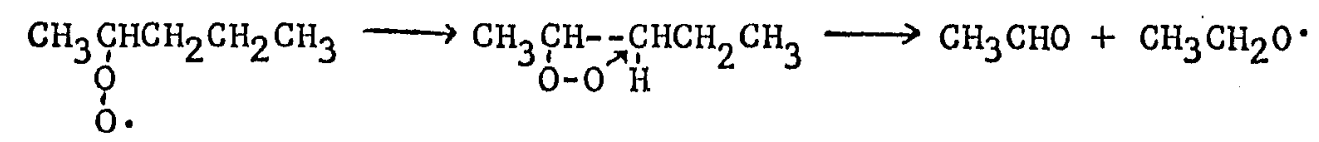

Acetaldehyde is not observed in the low temperature region of this study. If this reaction were competing with $\mathrm{A} 4 \mathrm{a}$, both acetaldehyde and crotonaldehyde would have to be observed as products during the early stages of the reaction. Reaction A4b may, however, have a higher activation energy and be preferentially formed at higher temperatures. Acetaldehyde is found at the higher temperatures but, as will be shown later, it can also be a product of the oxidation of crotonaldehyde.

Butyraldehyde can be formed by reaction $A 4 c$ as follows<smiles>C[C+]O[C-]C(C)CCCCCCC=O</smiles>

This compound is not observed as an oxidation product.

In addition to being formed by reaction steps $\mathrm{A} 2 \mathrm{a}$ and $\mathrm{A} 2 \mathrm{~b}$, pentene formation has been postulated by $\mathrm{Knox}^{15}$ to be formed by peroxy radical decomposition, with elimination of a hydroperoxy radical: 


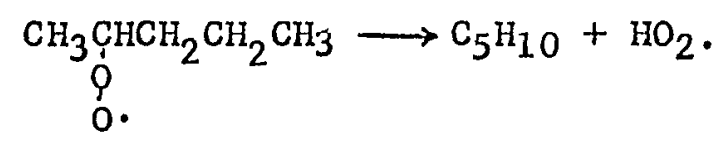

The alkene is not found in the reaction mixture as an oxidation product.

2-methyl tetrahydrofuran has been postulated to be formed by an internal $\gamma-c$ attack and elimination of a hydroxyl radical.

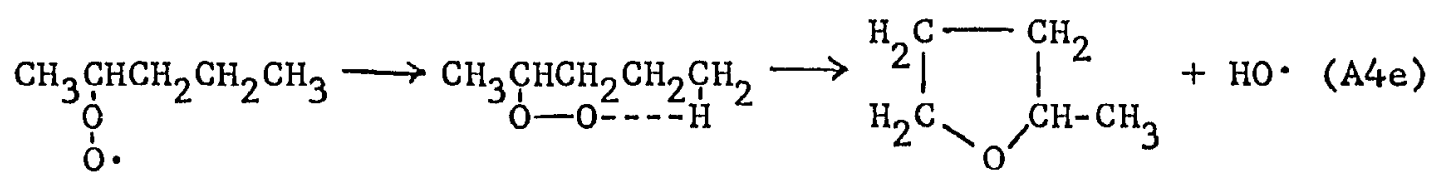

This product cannot be definitely eliminated since its existence in the reaction mixture was neither proved or disproved.

Methyl-n-propyl ketone has been found as a product in some oxidation studies and is postulated to be formed in the following manner

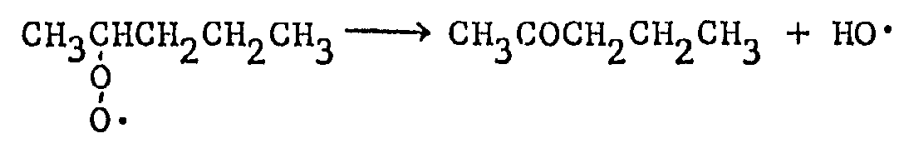

The product is not observed in the oxidation study.

The formation of acetone and ethylene can be shown in the following manner<smiles>C=CC(C)[C@@H]1CC1(OOCC)OOCCCCC(C)=O</smiles> 
Since the apparent activation energy of the formation of acetone is $38.4 \mathrm{kcal} . / \mathrm{mole}, 33$ which is similar to that reported for hydroperoxide decomposition, it may be possible that acetone could be produced as a result of the decomposition of the hydroperoxide molecule itself. In any case, acetone was not observed as an oxidation product of pentane under the conditions of the experiments reported here. The presence or absence of ethylene was not determined.

An alternate mode of acetone formation can be represented by $\beta-C$ attack and decomposition<smiles>CCCCC(CCCC(C)O[O-])C(=O)CCCC(C)[O-]</smiles>

The decomposition of the hydroperoxide has been represented by the following two reactions

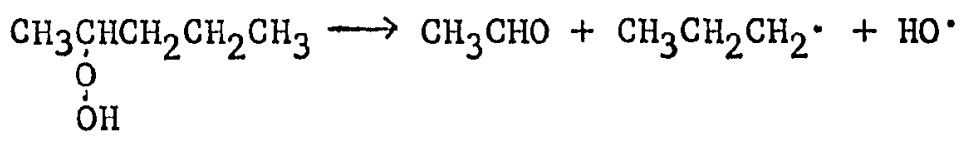

$$
\begin{aligned}
& \underset{\substack{\grave{j} \\
\text { OH }}}{\mathrm{CH}_{3} \mathrm{CHCH}_{2} \mathrm{CH}_{2} \mathrm{CH}_{3} \longrightarrow \mathrm{CH}_{3} \mathrm{COCH}_{2} \mathrm{CH}_{2} \mathrm{CH}_{3}+\mathrm{H}_{2} \mathrm{O}}
\end{aligned}
$$

The ketone is not observed and acetaldehyde is formed at the higher temperatures. Blosser ${ }^{30}$ considered the dehydration reaction $A 5 b$ as occurring at the walls of the reaction vessel. 
The fate of the hydroperoxy radical produced by reactions $A 1$, $A 2 b$, and $A 4 d$ is the subject of much speculation. Two reactions have been postulated to account for its disappearance

$$
\begin{aligned}
& \mathrm{HO}_{2} \cdot+\mathrm{C}_{5} \mathrm{H}_{12} \longrightarrow \mathrm{H}_{2} \mathrm{O}_{2}+\mathrm{C}_{5} \mathrm{H}_{11} \cdot \\
& \mathrm{HO}_{2}+\mathrm{HO}_{2} \cdot \longrightarrow \mathrm{H}_{2} \mathrm{O}_{2}+\mathrm{O}_{2}
\end{aligned}
$$

Reactions 6 and 7 effectively set up a competitive system for the disappearance of the hydroperoxy radical. If chain oxidation is to occur according to reaction $6, \mathrm{Knox}^{15}$ has shown that the ratio of the rates of reactions 7 to $6(R 7 / R 6)$ must be greater than 10 and $\mathrm{E}_{6}$ must be less than $10 \mathrm{kcal} . / \mathrm{mole}$. In any case, hydrogen peroxide is probably formed under the conditions of the experiments performed. Both modes of hydrogen peroxide formation must also be considered until further evidence is available.

The remaining reactions in sequence $A$ are concerned with the further oxidation of the crotonaldehyde produced in reaction $\mathrm{A} 2 \mathrm{~b}$. The first step probably involves the production of the crotonyl radical by abstraction of a hydrogen atom.

$$
\mathrm{CH}_{3} \mathrm{CH}=\mathrm{CHCHO}+\mathrm{O}_{2} \rightarrow \mathrm{CH}_{3} \mathrm{CH}=\mathrm{CHCO}+\mathrm{HO}_{2} \cdot
$$

The radical thus formed can undergo several types of reactions. If it rearranges by electron migration as illustrated,

$$
\mathrm{CH}_{3} \mathrm{CH}=\mathrm{CHCO} \rightarrow \mathrm{CH}_{3} \mathrm{CHCH}=\mathrm{C}=0
$$


it can be easily oxidized and decompose to the following

$$
\begin{aligned}
& \mathrm{CH}_{3} \mathrm{CHCH}=\mathrm{C}=\mathrm{O}+\mathrm{O}_{2} \rightarrow \mathrm{CH}_{3} \mathrm{CHCH}=\mathrm{C}=0 \\
& \text { o. }
\end{aligned}
$$

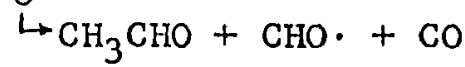

It can also decompose and the resulting radical abstract a hydrogen atom to form propylene

$$
\begin{aligned}
& \mathrm{CH}_{3} \mathrm{CH}=\mathrm{CHCO} \rightarrow \mathrm{CO}+\mathrm{CH}_{3} \mathrm{CH}=\mathrm{CH}
\end{aligned}
$$

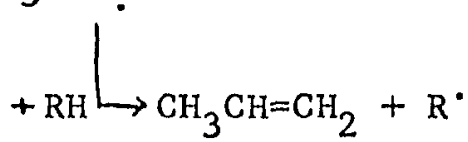

The crotonyl radical can also be oxidized in the following manner

$$
\begin{aligned}
& \mathrm{CH}_{3} \mathrm{CH}=\mathrm{CHCO}+\mathrm{O}_{2} \longrightarrow \mathrm{CH}_{3} \mathrm{CH}=\mathrm{CHC}=\mathrm{O} \\
& \text { ó } \\
& \mathrm{CH}_{3} \mathrm{CH}=\mathrm{CHC}=\underset{0}{0}+\mathrm{R} \cdot \\
& \mathrm{OH} \\
& \mathrm{CH}_{3} \mathrm{CH}=\mathrm{CH} \cdot+\mathrm{CO}_{2}+\mathrm{HO} \cdot \\
& \text { RH } \quad \mathrm{CH}_{3} \mathrm{CH}=\mathrm{CH}_{2}+\mathrm{R} \text {. }
\end{aligned}
$$

The peroxy-acid formed can be considered a stable intermediate at the lower temperatures. It has been observed by osborne and Skirrow 59

${ }^{59}$ Osborne, A. D. and Skirrow, G., J. Chem. Soc., 2750 (1960).

in their study of crotonaldehyde oxidation in a static system. At the higher temperatures it probably decarboxylates as shown in the above reaction sequence. Acetaldehyde was observed as an oxidation 
product. The formation of $\mathrm{CO}_{2}$, $\mathrm{CO}$ and propylene was not determined. No attempt was made to trap $\mathrm{CO}$ and the presence of $\mathrm{CO}_{2}$ and propylene could not be determined on the analytical column in use on the gas chromatograph.

Besides the above reactions of the propenyl radical, several other transformations are possible:

$$
\begin{aligned}
& \mathrm{CH}_{3} \mathrm{CH}=\mathrm{CH} \longrightarrow \mathrm{CH}_{2} \mathrm{CH}=\mathrm{CH}_{2}+\mathrm{O}_{2} \rightarrow \cdot \mathrm{OOCH}_{2} \mathrm{CH}=\mathrm{CH}_{2} \\
& .0 O \mathrm{CH}_{2} \mathrm{CH}=\mathrm{CH}_{2} \longrightarrow \mathrm{CH}_{2} \mathrm{O} \cdot+\cdot \mathrm{CH}_{2} \mathrm{CHO} \\
& \text {. } \mathrm{OOCH}_{2} \mathrm{CH}=\mathrm{CH}_{2} \rightarrow \mathrm{CH}_{2}=\mathrm{CHCHO}+\mathrm{HO} \text {. } \\
& +\mathrm{O}_{2} \longrightarrow \text { further products }
\end{aligned}
$$

The further oxidation of acrolein is illustrated in reaction scheme $B$ which will be presented shortly. The above reactions do illustrate the formation of formaldehyde and acrolein. Acrolein was not detected in the reaction mixture and the presence or absence of formaldehyde was not determined. These two products have been found in other studies, however.

The $\cdot \mathrm{CH}_{2} \mathrm{CHO}$ radical formed by reaction $\mathrm{Al} 4$ could disappear by two different mechanisms.

$$
\begin{aligned}
& \cdot \mathrm{CH}_{2} \mathrm{CHO} \longrightarrow \mathrm{CH}_{3}+\mathrm{CO} \\
& \cdot \mathrm{CH}_{2} \mathrm{CHO}+\mathrm{RH} \rightarrow \mathrm{CH}_{3} \mathrm{CHO}+\mathrm{R} .
\end{aligned}
$$

If attack is on carbon three, an entirely different sequence of reactions can be written as shown in equation group B. Again, as in sequence $A$, all the stable molecules shown as reaction products 


$$
\begin{aligned}
& \mathrm{O}^{2} \mathrm{H}+\varepsilon_{\mathrm{HO}} z_{\mathrm{HOOO}} z_{\mathrm{HO}} \varepsilon_{\mathrm{HO}} \stackrel{\mathrm{q}}{\longleftarrow}
\end{aligned}
$$

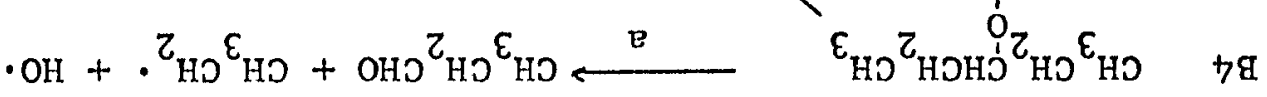

$$
\begin{aligned}
& . \mathrm{OH}+\varepsilon_{\mathrm{HO}}{ }^{2} \mathrm{HOO}^{2}{ }_{\mathrm{HO}} \varepsilon_{\mathrm{HO}} \\
& .{ }^{2} \mathrm{OH}+{ }^{O T_{H}}{ }^{5} \mathrm{O}
\end{aligned}
$$

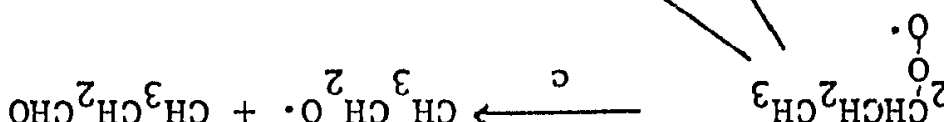

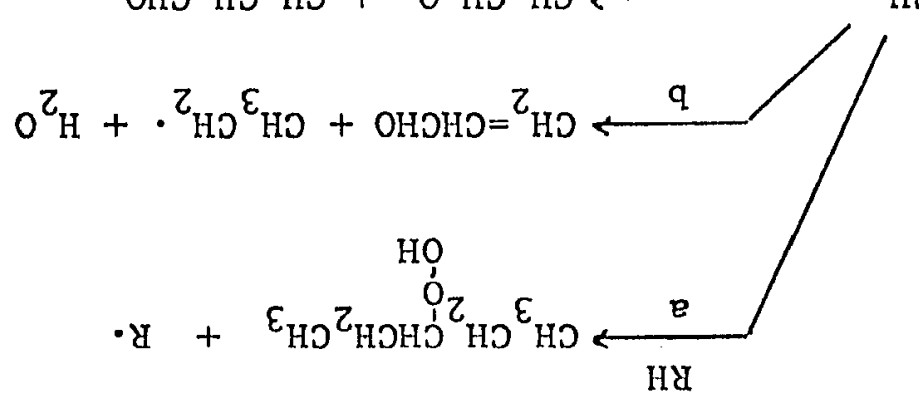

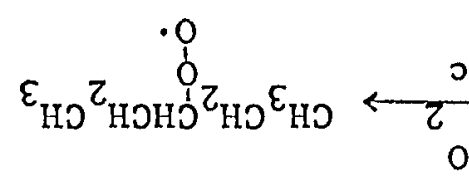

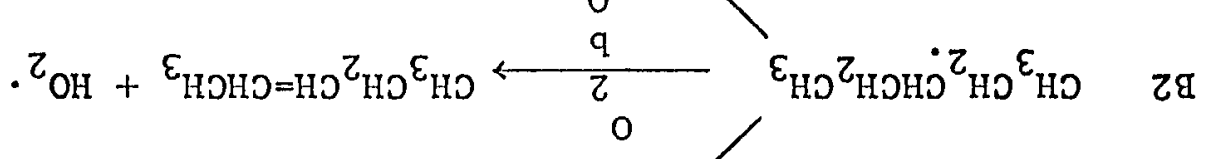

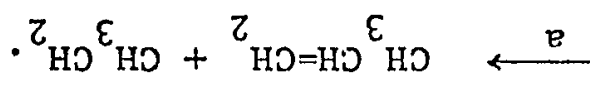

$$
\begin{aligned}
& . z_{\mathrm{OH}}+\varepsilon_{\mathrm{HO}} z_{\mathrm{HOH}} z_{\mathrm{HO}} \varepsilon_{\mathrm{HO}} \longleftarrow z_{\mathrm{O}}+\varepsilon_{\mathrm{HO}} z_{\mathrm{HO}} z_{\mathrm{HO}} \varepsilon_{\mathrm{HO}} \quad \text { Iq }
\end{aligned}
$$

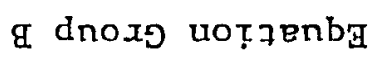


Equation Group B (contd.)

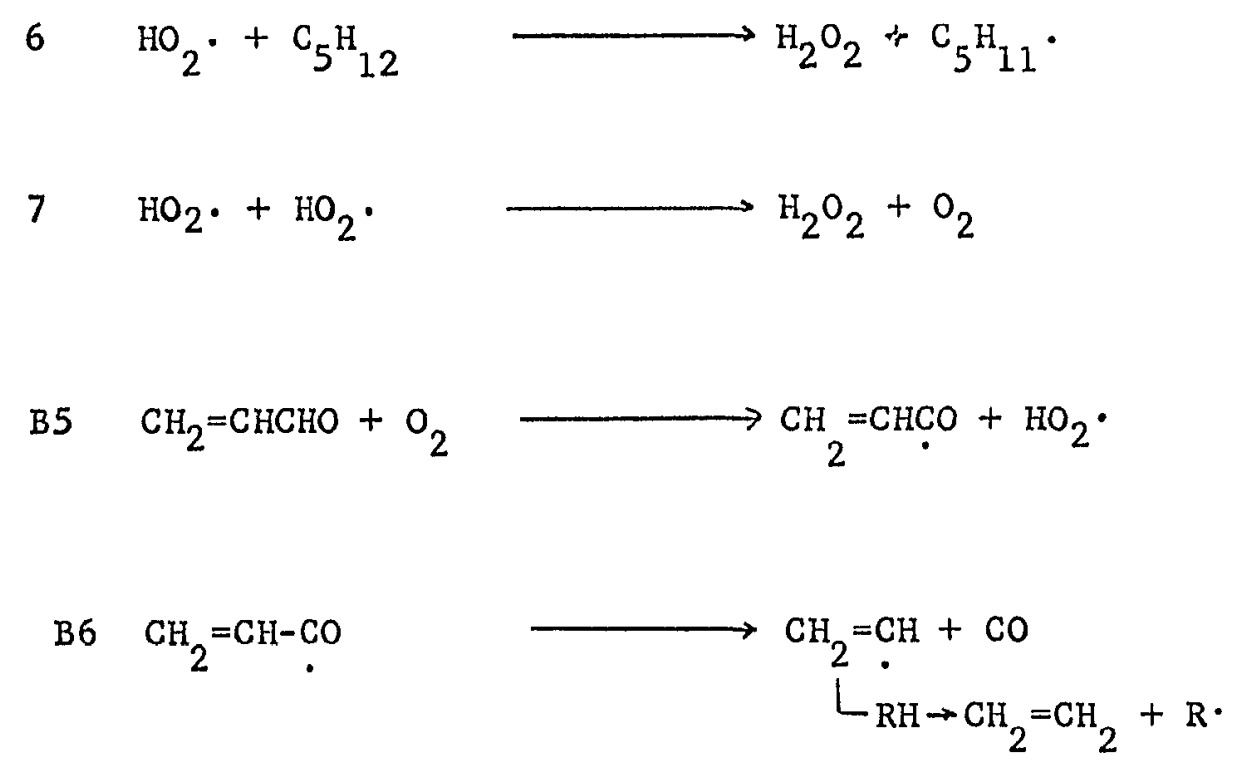

B7 $\mathrm{CH}_{2}=\mathrm{CH}-\mathrm{CO}+\mathrm{O}_{2}$

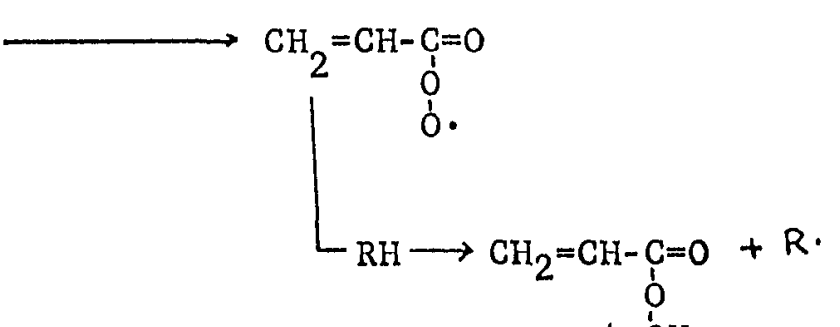

ón

$\mathrm{CH}_{2}=\mathrm{CH}_{2}+\mathrm{R} \cdot \leftarrow \mathrm{RH}-\mathrm{CH}_{2}=\mathrm{CH} \cdot+\mathrm{CO}_{2}+\mathrm{HO} \cdot$

$\downarrow \mathrm{O}_{2}$

$\mathrm{CO}, \mathrm{CO}_{2} \mathrm{H}_{2} \mathrm{O}, \mathrm{HCHO}$ 
have been observed in one or more independent studies of pentane oxidation.

Reaction $\mathrm{Bl}$ is the formation of the alkyl radical. As

$\mathrm{CH}_{3} \mathrm{CH}_{2} \mathrm{CH}_{2} \mathrm{CH}_{2} \mathrm{CH}_{3}+\mathrm{O}_{2} \rightarrow \mathrm{CH}_{3} \mathrm{CH}_{2} \mathrm{CHCH}_{2} \mathrm{CH}_{3}+\mathrm{HO}_{2}$.

in sequence $A$, this initial step is endothermic by approximately $45 \mathrm{kcal} . / \mathrm{mole}$.

The alkyl radical formed in step $B 1$ can undergo several different reactions. It can decompose by

$$
\mathrm{CH}_{3} \mathrm{CH}_{2} \mathrm{CHCH}_{2} \mathrm{CH}_{3} \rightarrow \mathrm{CH}_{3} \mathrm{CH}=\mathrm{CH}_{2}+\mathrm{CH}_{3} \mathrm{CH}_{2} \text {. }
$$

or it can react with oxygen in either of two ways

$$
\begin{aligned}
& \mathrm{CH}_{3} \mathrm{CH}_{2} \mathrm{CHCH}_{2} \mathrm{CH}_{3}+\mathrm{O}_{2} \rightarrow \mathrm{CH}_{3} \mathrm{CH}_{2} \mathrm{CH}=\mathrm{CHCH}_{3}+\mathrm{HO}_{2} \text {. }
\end{aligned}
$$

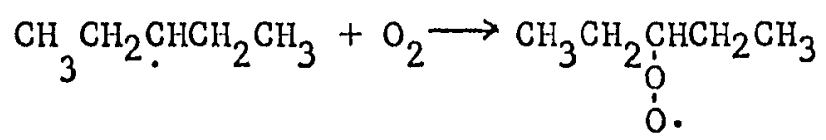

Pentene was not detected in the reaction mixture and the presence of propylene could not be determined on the analytical column in use on the gas chromatograph. Reaction B2c must still be considered, however, since the identity of the individual peroxides and hydroperoxides formed during the oxidation reaction was not established. The alkyl peroxy radical can react in a number of different ways. It can react by hydrogen abstraction to form the organic hydroperoxide

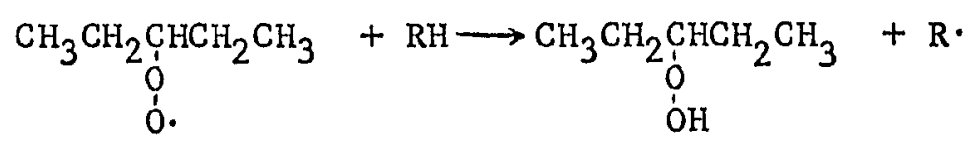


By $\beta-H$ transfer from the primary carbon atom, rearrangement and subsequent decomposition, the formation of acrolein can be illustrated as follows:

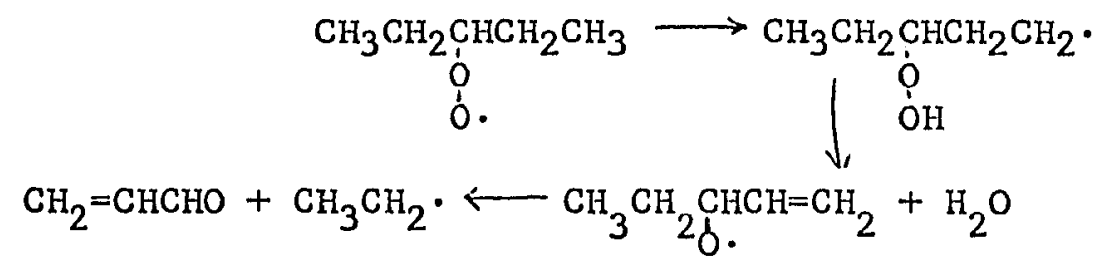

Acrolein is not observed as an oxidation product in this oxidation study.

By decomposition of the peroxy radical, several different products can be formed. Propionaldehyde formation can be illustrated by the reaction

$$
\underset{\substack{\mathrm{CH}_{3} \mathrm{CH}_{2} \mathrm{CHCH}_{2} \mathrm{CH}_{3} \\ \text { o. }}}{\rightarrow} \mathrm{CH}_{3} \mathrm{CH}_{2} \mathrm{O} \cdot+\mathrm{CH}_{3} \mathrm{CH}_{2} \mathrm{CHO}
$$

Pentene can be formed as follows

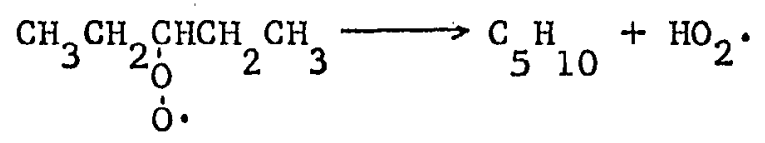

and diethyl ketone can be formed as follows

$$
\mathrm{CH}_{3} \mathrm{CH}_{2} \mathrm{CHCH}_{2} \mathrm{CH}_{3} \longrightarrow \mathrm{CH}_{3} \mathrm{CH}_{2} \mathrm{COCH}_{2} \mathrm{CH}_{3}+\mathrm{HO} \cdot
$$


Propionaldehyde, pentene and diethyl ketone were not observed as products of the reaction.

The organic hydroperoxide formed in step B3a can decompose in several ways. Propionaldehyde can be formed

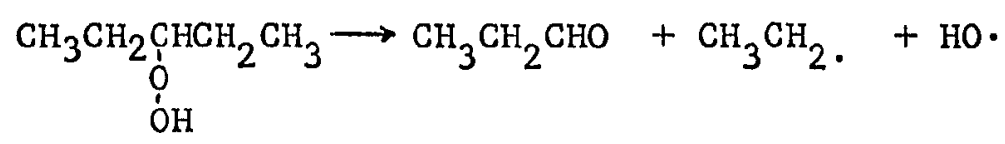

as can diethyl ketone

$$
\underset{\substack{\mathrm{O}_{3} \\ \mathrm{CH}_{3} \mathrm{CH}_{2} \mathrm{CHCH}_{2}}}{\mathrm{CH}_{3}} \longrightarrow \mathrm{CH}_{3} \mathrm{CH}_{2} \mathrm{COCH}_{2} \mathrm{CH}_{3}+\mathrm{H}_{2} \mathrm{O}
$$

The products of the above two reactions are not found in the reaction mixture. As in sequence $A$ with reaction $A 5 b$, the product of $B 4 b$, diethyl ketone, is probably formed by a wall reaction.

The fate of the hydroperoxy radical formed by reactions $B 1, B 2 b$ and $B 3 C$ is the same as that presented in reaction sequence $A$.

$$
\begin{aligned}
& \mathrm{HO}_{2} \cdot+\mathrm{C}_{5} \mathrm{H}_{12} \rightarrow \mathrm{H}_{2} \mathrm{O}_{2}+\mathrm{C}_{5} \mathrm{H}_{11} \\
& \mathrm{HO}_{2} \cdot+\mathrm{HO}_{2} \cdot \rightarrow \mathrm{H}_{2} \mathrm{O}_{2}+\mathrm{O}_{2}
\end{aligned}
$$

The comments pertinent to reactions 6 and 7 were presented with reaction sequence $A$.

The acrolein formed in reaction $\mathrm{B} 3 \mathrm{~b}$ can be further oxidized to form many products found in the oxidation of pentane. The initial 
step is probably $-.-\mathrm{CH}_{2}=\mathrm{CHCHO}+\mathrm{O}_{2} \rightarrow \mathrm{CH}_{2}=\mathrm{CHCO}+\mathrm{HO}_{2}$.

The radical thus formed can react in several ways.

$$
\begin{aligned}
\mathrm{CH}_{2}=\mathrm{CHCO} \rightarrow \mathrm{CH}_{2}=\mathrm{CH}+\mathrm{CO} \\
+\mathrm{RH}^{\longrightarrow} \underset{2}{\mathrm{CH}}=\mathrm{CH}_{2}
\end{aligned}
$$

and

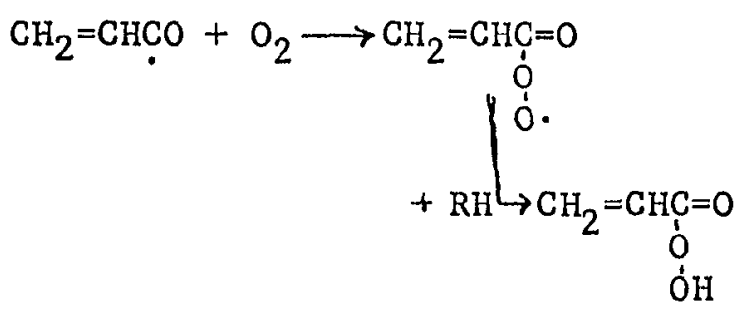

The peracid formed can decompose:

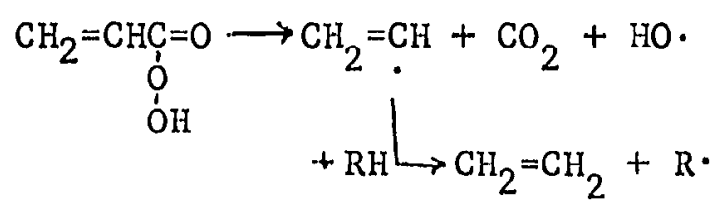

Further oxidation of the ethylene produced in this reaction step will yield $\mathrm{CO}, \mathrm{CO}_{2}, \mathrm{H}_{2} \mathrm{O}$ and $\mathrm{HCHO}$.

It is proposed here that the following mechanism will adequately explain the data obtained from this study of pentane oxidation.

The first step is the formation of the alkyl radical by hydrogen abstraction with oxygen.

$$
\mathrm{CH}_{3} \mathrm{CH}_{2} \mathrm{CH}_{2} \mathrm{CH}_{2} \mathrm{CH}_{3}+\mathrm{O}_{2} \rightarrow \mathrm{CH}_{3} \mathrm{CHCH}_{2} \mathrm{CH}_{2} \mathrm{CH}_{3}+\mathrm{HO}_{2} \text {. }
$$

Carbon two is attacked since, as a result of the product analysis, no indication of products arising from attack of the third carbon atom by oxygen is to be found. 
The second step in the proposed mechanism is the oxidation of the alkyl radical to a peroxy radical

$$
\mathrm{CH}_{3} \mathrm{CHCH}_{2} \mathrm{CH}_{2} \mathrm{CH}_{3}+\mathrm{O}_{2} \longrightarrow \mathrm{CH}_{3} \mathrm{CHCH}_{2} \mathrm{CH}_{2} \mathrm{CH}_{3}
$$

The peroxy radical thus formed can undergo transformation in two ways. It can form a hydroperoxide

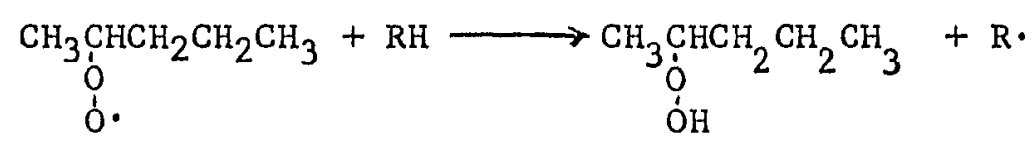

or it can form crotonaldehyde

$$
\mathrm{CH}_{3} \underset{\dot{\mathrm{C}}}{\mathrm{C}} \mathrm{HCH}_{2} \mathrm{CH}_{2} \mathrm{CH}_{3} \longrightarrow \mathrm{CH}_{3} \mathrm{CH}=\mathrm{CHCHO}+\mathrm{CH}_{3} \cdot+\mathrm{H}_{2} \mathrm{O}
$$

The radical formed in reaction $M 3$ can continue the chain reaction.

The fate of the hydroperoxy radicals formed in reaction $\mathrm{Ml}$ is open to question. There are two possible reactions

$$
\begin{aligned}
& \mathrm{HO}_{2} \cdot \mathrm{C}_{5} \mathrm{H}_{12} \longrightarrow \mathrm{H}_{2} \mathrm{O}_{2}+\mathrm{C}_{5} \mathrm{H}_{11} \cdot \\
& \mathrm{HO}_{2} \cdot+\mathrm{HO}_{2} \cdot \longrightarrow \mathrm{H}_{2} \mathrm{O}_{2}+\mathrm{O}_{2}
\end{aligned}
$$

The hydroperoxide formed by reaction $M 3$ is probably fairly stable until higher temperatures are attained. The hydroperoxide would, at the higher temperatures, probably decompose in the following manner

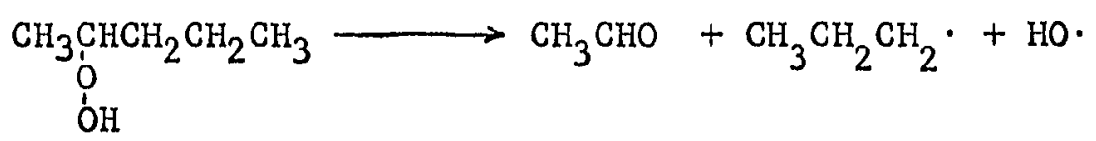


It is now proposed that the appearance of a majority of the products observed in this investigation of the oxidation of pentane arise from the further oxidation of the crotonaldehyde produced by reaction $\mathrm{M} 4$.

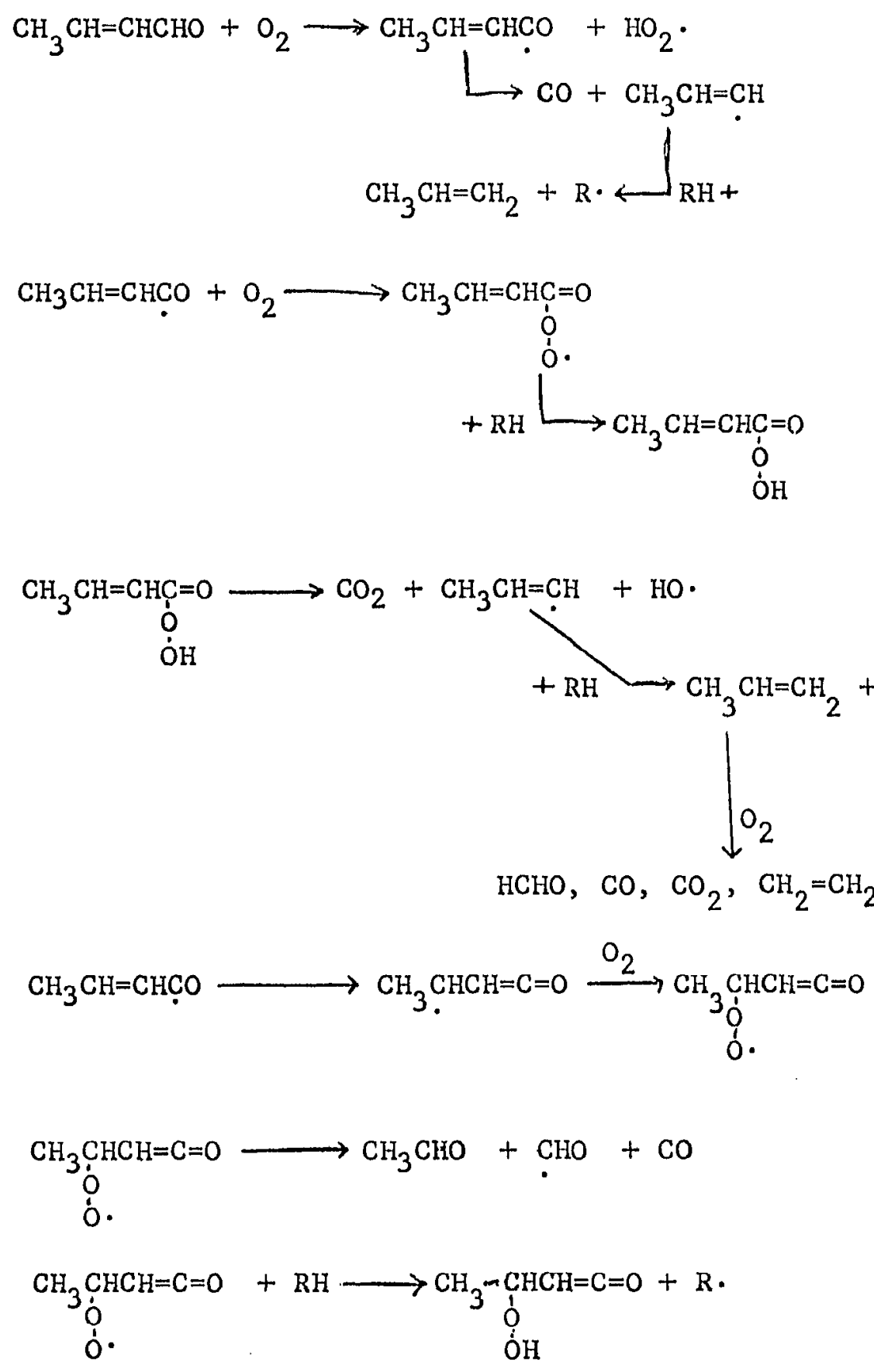


This mechanism assumes the formation of several products whose absence or presence in the reaction mixture was not determined during the course of the oxidation reaction. The analytical column in use would not separate many of the postulated products. The postulated products from reactions $\mathrm{M} 8-\mathrm{M} 13$ are known from a recent study of crotonaldehyde oxidation by osborne and Skirrow 59 in the temperature range of $150^{\circ}$ to $300^{\circ} \mathrm{C}$, percrotonic acid being the main product at the low temperatures.

The mechanism proposed assumes the formation of a hydroperoxide produced by reaction M3, hydrogen peroxide produced by either reaction M5 or M6; and the percrotonic acid produced by reaction M9. The analytical techniques used to determine peroxides during this investigation would not distinguish between the types of peroxides formed during the oxidation reaction.

of the peroxides suggested, the peracid of crotonaldehyde is probably the least stable of the three. Experimentally it has been found by osborne and Skirrow 59 in their study of crotonaldehyde oxidation that the $\mathrm{Co} / \mathrm{CO}_{2}$ ratio becomes greater than one at temperature near $200^{\circ} \mathrm{C}$. This indicates that reaction $\mathrm{M} 8$ in the postulated mechanism is becoming much more important than reactions $M 9$ or M10. The pentane hydroperoxide is probably less stable than hydrogen peroxide. Salooja 27 has demonstrated that even at the minimum ignition point of a hydrocarbon, small quantities of organic hydroperoxides remain in the reaction mixture, but that as the temperature increases to this ignition point, the amount of hydrogen peroxide increases. 
This study on formation of peroxides is quite different from other studies which have been reported. The study of Blosser 30 was carried out in a static system in a temperature range of $230^{\circ}$ to $250^{\circ} \mathrm{C}$. using a 1:1 reaction mixture and a total oxygen-pentane pressure of $230-300 \mathrm{~mm}$. The time scale was of long duration and the hydroperoxide fromed corresponded to 0.15 mole per mole of initial pentane. Salooja 27 studied the isomeric hexanes in a flow system from $250^{\circ}$ to $800^{\circ} \mathrm{C}$. and found $\mathrm{H}_{2} \mathrm{O}_{2}$ in amounts of $0.01-0.03$ moles per mole of initial fuel put into the system. The amount of organic peroxides found was initially $25-50 \%$ of the peroxide found and dropped to $10-25 \%$ in the zone of maximum cool flame activity. The organic peroxides further decreased with increase in temperature and at the ignition point of the fuel constituted only about $5 \%$ of the total peroxide found. No indication of contact time, reaction mixture composition, or total pressure is mentioned.

Sandler's $31,32,33$ studies were carried out in both flow and static systems. The temperature was varied from $270^{\circ}$ to $700^{\circ} \mathrm{C}$. and no peroxides of any type were detected in the reaction mixtures. The mixture composition varied from $1: 1$ to $8: 1$ oxygen-pentane using both oxygen and air in the reaction mixture. The initial pressure varied from 65-195 mm. Nitrogen in varying amounts was added in some mixtures. The amount varied up to $74 \%$ of the total mixture composition.

This study, in contrast to those cited, was performed under markedly different conditions. The reaction times never exceeded $3.7 \mathrm{msec}$. and the oxygen-fuel mixture was always less than about $12 \%$ of the total reaction mixture composition, the remainder consisting of helium and 
argon except when small quantities of added materials were put into the reaction mixture. The pentane in the reaction mixture amounted to about $2 \%$ of the total amount of gas in the reaction section in all experiments performed.

The total amount of peroxides found was much less than found in the study of Blosser and comperable to the total amounts of peroxide found by Salooja. The maximum amount found was about 0.01 moles per mole of initial pentane and usually much less.

The temperature range used in this investigation, $298^{\circ}-435^{\circ} \mathrm{C}$. corresponds to the other studies, the only difference being the rates of heating and cooling. In this study, the rate of heating was essentially instantaneous and the average rate of cooling was about 80-100 degrees Centigrade per millisecond. This high rate of heating and cooling was not attained in the other studies. This presented an advantage to this investigation that is usually not available in the more conventional experimental systems used for hydrocarbon oxidation studies. If intermediates were formed during the oxidation reaction which were very active, the possibility of further extensive oxidation of these intermediates is partially limited in the type of system used in this investigation and the possibility of isolation of at least a portion of these intermediates is enhanced due to the rapid rate of cooling in this system.

During this study, several oxidation products were found and many other possible oxidation products eliminated. Of the products isolated, only two could be positively identified; acetaldehyde and 
crotonaldehyde. Crotonaldehyde as an oxidation product of pentane has only been observed in a study by Malmberg and co-workers, 35 and then only as a minor product. Acetaldehyde has been found in almost every study on pentane oxidation.

Of the products that were isolated but unidentified, two appeared in many of the experiments. These are labeled as products $A$ and $B$ in Table 10. There is always speculation as to what type of compounds these might be. No good idea as to what type of compound A is, exists at the present time. Compound B might be an oxide such as ethylene or propylene oxide although it is difficult to say at the present.

The possible oxidation products under the conditions of these experiments that were definitely not found in the reaction mixture were: acetone, methanol, 2- and 3-pentanone, valeraldehyde, butyraldehyde, butanone, 1 - and 2-pentene and acrolein. In some early experiments, $\mathrm{CO}_{2}$ and $\mathrm{H}_{2} \mathrm{O}$ were found in the reaction product mixture, but their presence as oxidation products could not be definitely established. The fact that the above-mentioned compounds were not found in the reaction mixture does not completely eliminate them as oxidation products of the reaction in this investigation. As can be noticed in Table 10, the recovery of pentane was low and conceivably the unaccounted for pentane was lost during the trapping procedure. Some of the compounds listed above could have as easily not been trapped from the gas stream. 
is 1 isted in Figures 28-32 and as can be seen, the peroxide formation at each temperature goes through a maximum. The amount of peroxide formed at any time at a particular reaction temperature is an average of the experimental values at that particular reaction time. These experimental values were obtained as a function of oxygen:pentane molar ratios and, as was illustrated earlier, are independent of the molar ratios. This is in accord with the very recent work of Salooja, 27 who found, in oxidation of hexanes, that the peroxide formation was independent of the molar ratio of oxygen to fuel.

To explain these maxima and the sharp decrease of peroxides after the appearance of the maxima is rather difficult. In contrast to studies of hydrocarbon oxidation in either flow or static systems, in which a reaction parameter maximum is observed only after a significant amount of the initial fuel has reacted, the amount of pentane that reacts in this study is rather small (i.e. $<1.0 \%$ ).

It is believed that this phenomenon is due to the passage of a cool flame. As the peroxides axe being formed as a function of time by reaction $M 3$, heat is liberated since the reaction is exothermic. This liberated heat causes degenerate branching of the hydroperoxide. As more heat is liberated, more degenerate branching results and finally, enough heat is liberated to cause the passage of a cool flame and also a rapid decrease in the amount of hydroperoxide in the reaction mixture. The rapid decrease in the concentration of the hydroperoxides present in the reaction mixture results from the increased rate of degenerate branching which is caused as a result of the amount of heat liberated at the time of passage of the cool 
flame. This statement can be immediately criticized for several reasons and they will now be discussed with evidence disputing the criticisms.

Pease, 60 while studying propane oxidation under flow

60 Pease, R. N., J. Am. Chem. Soc., 51, 1839 (1929).

conditions, found that the treatment of the walls of the reaction tube with potassium chloride, which caused the complete disappearance of organic peroxides from the reaction products, had little effect on the rate of the oxidation process. This gave the basis for concluding that the role of the organic peroxides in the overall course of hydrocarbon oxidation was insignificant. Newitt and Thornes ${ }^{61}$ refer to the experiments by Pease and repeated them with

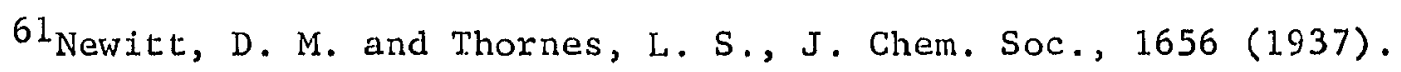
the same result. In these it was possible to show that cool flames can arise and propagate even if at the moment of appearance of cool flames in the mixture there are only traces of peroxides.

As a result of this, Newitt and Thornes proposed that coolflame ignition is the accumulation up to a certain concentration not of organic peroxides, but of higher aldehydes. The fundamental confirmation of this, in the authors' opinion, is the fact that they established that during the cool flame oxidation of propane, the times of attainment of the maximum quantities of higher aldehydes coincided 
with the times of appearance of cool flames. They propose too that, during the propagation of the cool flame, higher aldehydes undergo subsequent oxidation with the probable formation of acylperoxides and finally formaldehyde.

The above is a rather imposing argument against the role of peroxides in cool flame oxidation. The possibility that aldehydes are responsible for the cool flame phenomenon observed in this study seems unlikely. In the first place, the only aldehyde found at the two low temperatures in this study was crotonaldehyde and its formation increased in a linear fashion as a function of time. If the aldehyde must react during the passage of the cool flame, one would expect that the aldehyde formation curve as a function of time would be similar to the curves corresponding to peroxide formation as a function of time at any temperature (Figures 28-32). This is not what is observed in this investigation.

The other argument against the aldehyde theory is found in some recent work of Salooja. ${ }^{28}$ He found, when the walls of the reaction vessel were coated with potassium chloride, that the hydrogen peroxide formation was minimized, but that the organic peroxides were still present. These facts were obtained during a study of pentane oxidation and seem completely to contradict the works of both Pease and Newitt and Thornes. Another study by Salooja 27 on the oxidation of hexanes demonstrated that the organic peroxides formed increased as a function of temperature until the temperature zone of maximum cool flame activity was attained. The concentration of the peroxides 
then dropped markedly and further decreased with increasing temperature.

The other argument against the hypothesis of the passage of cool flames in the present work concerns the increase in temperature at the time in which the cool flame passes. Other work shows that the temperature rise at the cool flame can be as much as $150^{\circ} \mathrm{C}$. above the temperature of initiation, but is sometimes much less (e.g. $28^{\circ}$ with $2,2^{\prime}$-dimethylbutane ${ }^{62}$ ), and only a small proportion

${ }^{62}$ Oberdorfer, P. E., Dissert. Abst., 20, 2020 (1959).

of the reactants is consumed. A temperature increase of this magnitude should be observed on the oscilloscope trace obtained from the experiment. It is not. On the other hand, the temperature increase may be insignificant, as indicated by the data of Bardwell and Hinshelwood. ${ }^{63}$ These authors studied the cool flame oxidation of

63 Bardwe11, J. and Hinshe1wood, C. N., Proc. Roy. Soc. (London), A205, 375 (1951).

methyl ethyl ketone. Of significance in the study was the effect of addition of inert gas to the reaction mixture. In their study, the inert gas was nitrogen. They doubled the total pressure of the reaction mixture in the system by adding nitrogen and the only observable effect was to decrease the time between successive cool flames by only $14 \%$. 
Thus, it appears that the inert gas addition does not prevent cool flame formation but in fact increases the frequency of passage of the cool flame. It also appears that if enough inert gas was added to the reaction mixture, the cool flame would still pass through the reaction mixture, but that there may not be an observable rise in temperature.

An alternative explanation for the appearance of these maxima is to consider the following sequence of reactions $\left(\mathrm{R}=\mathrm{C}_{5} \mathrm{H}_{11}{ }^{\circ}\right)$ :

$$
\begin{aligned}
& \mathrm{RO}_{2} \cdot \mathrm{RH} \stackrel{\mathrm{k}_{1}}{\longrightarrow} \mathrm{ROOH}+\mathrm{R} \cdot \quad \mathrm{FI} \\
& \mathrm{ROOH} \stackrel{\mathrm{k}_{2}}{\longrightarrow} \mathrm{C} \cdot+\mathrm{D} . \quad \mathrm{F} 2 \\
& \mathrm{ROOH}+\mathrm{C} \cdot \stackrel{\mathrm{k}_{3}}{\longrightarrow} \text { Products F3 } \\
& \mathrm{RO}_{2} \stackrel{\mathrm{k}_{4}}{\longrightarrow} \mathrm{C} \cdot+\mathrm{E} \quad \mathrm{F4}
\end{aligned}
$$

where $C \cdot$ and $D \cdot$ are unspecified radicals. The substance $E$ may or may not be a radical. By varying the relative values of $k_{1}, k_{2}, k_{3}$, and $k_{4}$ the peroxide formation curves (Figures 28-32) can be reasonably reproduced, the general criteria being that $k_{4} / k_{1}>1$. The greater this ratio, the sharper the maximum on the peroxide formation-time curve becomes.

From Figure 35, which is a loarithmic plot of the time required for the peroxide concentration to reach a maximum as a function of reciprocal Kelvin degrees, and apparent activation energy of 2.9 kcal./mole was obtained. This value can be compared to activation energies obtained from other cool flame studies (see reference 3, pp. 205-207). Values by others vary from 39-73 kcal./mole. The 
dependent variable is generally the frequency of passage of the cool flame.

Of significance is that the value obtained in this study is positive and that the time to reach the maximum peroxide concentration decreases with an increase in reaction temperature. It is not obvious at this time that additional valid conclusions can be reached by consideration of the value of this apparent activation energy. The test of the proposed mechanism, as outlined earlier, will depend ultimately upon a much more complete analysis of the oxidation products. Of particular interest would be the definite identification of $C O$ as an early oxidation product as postulated in reaction $\mathrm{M} 8$ and the effect of temperature on the $\mathrm{Co} / \mathrm{CO}_{2}$ ratio. These data would enable one more clearly to determine the fate of the crotonyl radical (i.e. its tendency to decompose as postrlated in $M 8$ or its tendency to peroxidize and subsequently decarboxylate as postulated in $\mathrm{M} 9$ and $\mathrm{M} 10$ ) in the overall oxidation scheme. Another product formed early in the reaction according to the postulated mechanism is propylene. In the work reported here its existence in the reaction mixture could not be ascertained. Discovery of its presence in the reaction mixture would greatly enhance the validity of the postulated mechanism.

At long reaction times, times which correspond to a decrease in peroxide concentration, there were other products found in the reaction mixture, but they could not be identified. The positive identification of these compounds would be of great value since it might 
give an indication of what type of peroxide decomposition occurs as a result of the passage of the cool flame through the reaction mixture.

Acetaldehyde is known to act as a branching agent in certain oxidation systems. In order to see if acetaldehyde would act as a branching agent in the system being investigated, measured amounts of acetaldehyde were added to the reaction mixture prior to the oxidation. The amounts added varied from 5 to $40 \mu$ moles. This amounted to $0.6-4.0 \%$ of the pentane initially placed in the shock tube.

Al1 acetaldehyde addition experiments were carried out at $327^{\circ}$ C. under various conditions. Product analyses were made and total peroxides determined. The total peroxides were determined as a function of time and reaction mixture composition for various amounts of acetaldehyde, while the non-peroxidic products were determined only as a function of time, maintaining an essentially constant reaction mixture composition. In the peroxide data, some rather different results were obtained. They are illustrated in Figures 36-38. Two features common to all of the peroxide data were noticed. It was found that the amount of peroxide formed was reduced steadily with the increase in the quantity of acetaldehyde added. It was not a large reduction. The othex feature was that the peroxides formed in the presence of added acetaldehyde demonstrated an oxygen dependence. This oxygen dependence was not observed in experiments in which there was no added acetaldehyde.

In the experiments in which the formation of the non-peroxidic 
products was determined, one feature observed was that at the fast reaction times 1.6 and $1.9 \mathrm{msec}$, the formation of crotonaldehyde was inhibited, while at a reaction time of $2.5 \mathrm{msec}$, crotonaldehyde is found as an oxidation product.

Many reactions have been postulated in an attempt to discover the basis of the mechanism of the chain branching process. It is believed that the explanation of the data obtained from the addition experiments of this study requires the determining feature to be the competition between the routes of further transformation, not of the aldehyde, but of the peroxide radical $\mathrm{ROO} \cdot$. The following reactions are considered $\left(\mathrm{R}=\mathrm{C}_{5} \mathrm{H}_{11}\right)$ :

$$
\begin{array}{lll}
\mathrm{R}+\mathrm{O}_{2} & \mathrm{C} 1 \\
\mathrm{ROO} \cdot+\mathrm{CH}_{3} \mathrm{CHO} \longrightarrow \mathrm{ROO} \cdot & \mathrm{C} 2 \\
\mathrm{ROO} \cdot \mathrm{RH}\left(\mathrm{CH}_{3} \mathrm{CHO}\right) \longrightarrow \mathrm{RO}+\cdot \mathrm{OH}+\mathrm{CH}_{3} \mathrm{CO} & \mathrm{C} 3 \\
\mathrm{ROO} \cdot & \mathrm{ROOH}+\cdot \mathrm{R}_{\left(\mathrm{CH}_{3} \mathrm{CO}\right)}
\end{array}
$$

At the temperature studied, $327^{\circ} \mathrm{C}$. , the majority of the radicals R00. will probably react according to reactions $\mathrm{C} 2$ and $\mathrm{C} 3$, since $\mathrm{C} 4$ has an apparently higher activation energy. Also at this temperature the oxidation rate is probably determined by the reaction of the formation of the $\mathrm{ROO}$. radical, since it has a small activation energy. Since more peroxide is formed at higher oxygen concentrations, it appears that reaction $\mathrm{C} 3$ is more important than reaction $\mathrm{C} 2$ under these conditions. At the lower oxygen concentrations, less peroxide is formed in the presence of acetaldehyde. It appears that reaction 
$\mathrm{C} 2$ is more important under these conditions than reaction $\mathrm{C} 3$. It is not readily apparent why this oxygen dependency exists or how it can be simply explained.

At long enough reaction times, reaction $\mathrm{C} 4$ can also participate in the sequence of events. As postulated in the oxidation mechanism, crotonaldehyde is a product coming from decomposition of the peroxy radical $\mathrm{ROO} \cdot$.

The results of the acetaldehyde addition experiments indicate that under the reaction conditions studied in this investigation, acetaldehyde does induce some branching. It is believed, on the basis of the results however, that acetaldehyde is not a very improtant branching agent.

In order to determine the effect of radicals on the oxidation of pentane, small amounts of tertiary butylhydroperoxide were added to the reaction mixture in several experiments at $327^{\circ} \mathrm{C}$. The amount was of the order of $15 \mu$ moles in each experiment and was about $1.1 \%$ of the reaction mixture based upon the initial amount of pentane in the mixture.

In the experiments in which the peroxides were determined, about $50 \%$ of the tertiary butylhydroperoxide was recovered as unreacted compound. This figure is based upon the assumption that the addition of the tertiary butylhydroperoxide did not affect the normal hydroperoxide production in the oxidation and that the tertiary butylhydroperoxide that was not recovered was thermally decomposed into its normal decomposition products. 
In the product analysis experiments, acetone was found as was crotonaldehyde. The crotonaldehyde was found in greater quantity than in the experiments in which no tertiary butylhydroperoxide was added to the reaction mixture. No methanol was detected in the reaction product mixture.

The thermal decomposition of tertiary butylhydroperoxide can be represented by:

$$
\begin{array}{ll}
\left(\mathrm{CH}_{3}\right)_{3} \mathrm{COOH} \longrightarrow\left(\mathrm{CH}_{3}\right)_{3} \mathrm{CO}+\cdot \mathrm{OH} & \mathrm{D} 2 \\
\left(\mathrm{CH}_{3}\right)_{3} \mathrm{COO} \longrightarrow \mathrm{CH}_{3} \mathrm{COCH}_{3}+\cdot \mathrm{CH}_{3} & \text { D2 } \\
\cdot \mathrm{CH}_{3}+. \mathrm{OH} \longrightarrow \mathrm{CH}_{3} \mathrm{OH} & \text { D3 }
\end{array}
$$

Since no methanol is formed under the conditions of this investigation, reaction D3 can probably be disregarded. The question then concerns the fate of the methyl radical and the increase in the amount of crotonaldehyde in the reaction mixture.

It is believed that on the basis of the limited data obtained from these experiments the following sequence of reactions occur:

$$
\begin{aligned}
& \cdot \mathrm{CH}_{3}+\mathrm{C}_{5} \mathrm{H}_{12} \longrightarrow \mathrm{CH}_{4}+\mathrm{C}_{5} \mathrm{H}_{11} \cdot \\
& \mathrm{C}_{5} \mathrm{H}_{11} \cdot+\mathrm{O}_{2} \longrightarrow \mathrm{C}_{5} \mathrm{H}_{11} \mathrm{OO} \cdot \\
& \mathrm{C}_{5} \mathrm{H}_{11} \mathrm{OO} \cdot \longrightarrow \mathrm{CH}_{3} \mathrm{CH}=\mathrm{CHCHO}+\cdot \mathrm{CH}_{3}+\mathrm{H}_{2} \mathrm{O}
\end{aligned}
$$

No definite arguments for this tentative mechanism can be set forth. It is only an attempt to explain observed results. One conclusion can be drawn however and that is that in the presence of tertiary butylhydroperoxide, the radicals produced from its thermal decomposition cause an increase in the amount of crotonaldehyde found in the reaction mixture. 
In this investigation, data have been gathered on both total peroxide formation and non-peroxidic compound formation under a variety of reaction conditions. The results indicate that the predominant feature of this investigation is that the peroxy radical ROO - undergoes two simultaneous reactions: (1) formation of a hydroperoxide by means of a bimoecular hydrogen abstraction reaction, and (2) a thermal decomposition to crotonaldehyde, $\cdot \mathrm{CH}_{3}$ and $\mathrm{H}_{2} \mathrm{O}$. Since the non-peroxidic product determination experiments were limited in scope, it is difficult to say anything of definite consequence concerning the magnitude of these two reaction paths and which one predominates. Qualitatively the peroxide path is more important, particularly at the two lowest temperatures. At the two highest temperatures, it is much more difficult to state a preference. The conclusions drawn above agree with those reported by other workers. ${ }^{16-21}$ They favor the two simultaneous reaction modes of the Roo radical. In order to determine in a more quantitative manner the importance of the ROO radical, much more data, particularily on the formation of the non-peroxidic compounds, will have to be obtained. The formation of these compounds will also have to be determined under a wider variety of reaction conditions. With this in mind, and with the insight gained into the early reaction steps in the oxidation of pentane obtained from this study, ultimately a more complete reaction scheme for hydrocarbon oxidation, and in particular pentane, will be forthcoming. 


\section{SUGGESTIONS FOR FURTHER WOR.K}

\section{Analytical Methods}

At the present time, very little work has been done on positive identification of peroxidic compounds resulting from hydrocarbon oxidation. The possible occurrence of peroxides, other than the three suggested in this study, should be examined. The three suggested in this study: 2-pentane hydroperoxide, hydrogen peroxide and percrotonic acid, should be positively identified. Perhaps the method which would best succeed in attaining this objective is the tool of paper chromatography. 22 The use of gas chromatography 23 to isolate peroxides has been employed, but the method is very tedious. Further investigation into this potentially promising method might yield fruitful results. The use of polarographic techniques has met with little success (see reference $30, \mathrm{pp} .42 \mathrm{ff.}$ ). It is very useful in distinguishing between hydrogen peroxide and the organic hydroperoxides. Other than this use, it does little to help unravel the complex mixture of peroxides formed during the oxidation reaction.

Because of the very small amounts of products formed in an investigation of this type, more exacting techniques of gas analysis must be employed. One method which would partially alleviate the situation would be the use of a gas chromatograph equipped with a flame ionization detector. The actual method of removing gases from the reaction section of the shock tube should be redesigned so 
as to improve the recovery of the gases. In order to improve the recovery of the gases, a throttling device or flow restrictor should be placed between the end plate valve of the shock tube and the trapping system. A more complete analysis should be employed also. This would entail constructing a trapping system that would effectively remove non-condensable reaction products from the gaseous stream. In addition, formaldehyde analytical data should be obtained. To further improve the scope of analysis, a study of different analytical columns to use with the gas chromatograph should be instituted. The positive identification of reaction products will always be a problem since usually such small quantities are formed that conventional chemical techniques of identification are of little use. The use of a mass spectrometer in conjunction with the gas chromatograph may be of assistance in the problem of product identification. Another potentially useful method, infra-red, should be investigated.

II. Variation of Reaction Mixture Composition

Throughout this entire study, only the formation of total peroxides was investigated as a function of oxygen: pentane molar ratios. Product analysis was determined only on reaction mixtures with an essentially constant molar ratio. The formation of oxidation products should be investigated over the entire range of oxygen:pentane molar ratios. If the individual peroxides formed during the reaction could be successfully identified, then their individual rates of formation should also be investigated as a function of mixture composition. 
III. Effect of Added Substances on the Oxidation Reaction

The effect of added acetaldehyde is not at all clear. The few expeximents reported here indicate that under certain experimental conditions, the added acetaldehyde acted as an accelerator with respect to peroxide formation. The results also indicate an oxygen dependence which at the present is most difficult to explain.

During experiments in which the non-peroxidic products were determined, crotonaldehyde formation was inhibited under some of the reaction conditions. The reasons set forth for this observation are tentative and not entirely satisfactory.

The effect of the added acetaldehyde on the oxidation reaction must be studied as a function of temperature, and the non-peroxidic products formed should be studied over a range of oxygen: pentane molar ratios.

Tertiary butylhydroperoxide was added to the reaction mixture in a few experiments. Acetone was observed as was also an increase in crotonaldehyde. No methanol was found. These data, though 1 imited in scope, suggest that radical attack on the pentane may be important. More data should be gathered over a wider range of experimental conditions.

The accurate determination of the ratio of crotonaldehyde found with and without added tertiary butylhydroperoxide as a function of temperature and reaction mixture composition might give an indication of the importance of the radical attack on the pentane relative to the importance of the oxidation. 
IV. Hydrocarbon Reactivity

Since in pentane oxidation, crotonaldehyde is an early product, there is a possibility that acrolein might be an important intermediate in the oxidation of butane and perhaps ketene could be an intermediate oxidation product of propane. If this were the situation, interesting competitive oxidation experiments could be derigned using the shock tube in which the relative reactivities of these hydrocarbons, with respect to oxidation, could be measured. This would entail measuring the relative amounts of unsaturated aldehyde formed from each hydrocarbon. 


\section{APPENDIX}

\section{Sample Calculations for Experiment 166}

iuis experiment which was an acetaldehyde addition experiment, illustrates all the types of calculations used throughout this investigation. The experimental details have been outlined earlier.

In this experiment acetaldehyde is added to a sample septum bulb with a volume of $14.04 \mathrm{cc}$. and simultaneously to a sample bulb with a volume of $17.86 \mathrm{cc}$. to an approximate pressure of $10-11 \mathrm{~mm}$. at room temperature $\left(31.1^{\circ} \mathrm{C}.\right)$. The stopcocks to both bulbs are closed and the system evacuated. A He-Ar mixture is then admitted to the sample septum bulb to a pressure of $720 \mathrm{~mm}$, and the bulb removed from the vacuum system and placed on the mercury-leveling device. The pressure inside the bulb is then adjusted to atmospheric pressure which was $753.4 \mathrm{~mm}$. Samples were then analyzed on the gas chromatograph using a sample size of 0.10 cc. Upon comparing the peak heights obtained with the standard curve of acetaldehyde concentration vs. peak height it was found that $0.01 \mathrm{cc}$. of this acetaldehyde sample corresponded to $0.072 \mu$ moles. With this information the calculation can be completed.

The volume of the sample in the septum bulb after adjusting to atmospheric pressure is

$$
V=\left(\frac{720 \mathrm{~mm} .}{753.4 \mathrm{~mm} .}\right)(14.04 \mathrm{cc} .)=13.41 \mathrm{cc} .
$$


The total number of moles in $13.41 \mathrm{cc}$. is

$$
\mathrm{n}=\left(\frac{13.41 \mathrm{cc}}{0.10 \mathrm{cc} \cdot}\right)(0.072 \mu \mathrm{moles})=8.7048 \mu \text { moles }
$$

This is also the number of moles in $14.04 \mathrm{cc}$. at the original acetaldehyde pressure.

The pressure of acetaldehyde in the $14.04 \mathrm{cc}$. septum bulb is

$$
P=\frac{n R T}{V}=\frac{\left(8.71 \times 10^{-6}\right)(0.08205)(304.2)}{\left(14.04 \times 10^{-3}\right)}
$$

$$
\mathrm{P}=15.475 \times 10^{-3} \mathrm{~atm} .=11.76 \mathrm{~mm} .
$$

This is the pressure in the sample bulb of volume $17.86 \mathrm{cc}$.

Upon expansion of the sample bulb into the vacuum system and reaction section of the shock tube the dilution factor is

$$
\frac{17.86 \mathrm{cc} .}{2540.76 \mathrm{cc}}
$$

and the pressure becomes

$$
\mathrm{P}=\left(\frac{17.86 \text { cc. }}{2540.76 \mathrm{cc} .}\right)(11.76 \mathrm{~mm} .)=0.083 \mathrm{~mm} .
$$

and the quantity in the reaction section which has a volume of 2020.5 cc is

$$
\mathrm{n}=\frac{\mathrm{PV}}{\mathrm{RT}}=\frac{\left(\frac{0.083 \mathrm{~mm}}{760 \mathrm{~mm}}\right)(2.02051 .)}{(0.08205)(304.2 \mathrm{deg})}=8.85 \mu \mathrm{moles}
$$

A pentane-oxygen mixture is now admitted to the sample septum bulb and the reaction section of the shock tube to a measured pressure of $28 \mathrm{~mm}$, and the appropriate valves and stopcocks closed 
and the system evacuated. A He-Ar mixture is admitted to the sample septum bulb to a pressure of $726 \mathrm{~mm}$. and the bulb removed from the system and placed on the mercury-leveling device and the pressure inside the bulb adjusted to the pressure of the atmosphere which was $753.4 \mathrm{~mm}$. Samples, $1.0 \mathrm{cc}$. in size, were injected into the chromatograph and the amount of pentane determined. A 1.0 cc. sample contained $0.60 \mu$ moles of pentane.

The volume of the septum bulb after adjusting to atmospheric pressure is

$$
V=\left(\frac{726 \mathrm{~mm} .}{753.4 \mathrm{~mm} .}\right)(14.04 \mathrm{cc} .)=13.53 \mathrm{cc}
$$

The total number of moles of pentane in this volume is

$$
\mathrm{n}=\left(\frac{13.53 \mathrm{cc} .}{1.0 \mathrm{cc} .}\right)(0.60 \mu \mathrm{moles})=8.12 \mu \text { moles }
$$

This is also the number of moles in $14.04 \mathrm{cc}$. initially.

The number of moles of pentane in the reaction section of the shock tube is

$$
\mathrm{n}=\left(\frac{2020.5 \mathrm{cc} .}{14.04 \mathrm{cc} .}\right)(8.12 \mu \text { moles })=1168 \mu \text { moles and the pressure }
$$
of pentane in the shock tube is

$$
\begin{gathered}
\mathrm{P}=\frac{\mathrm{nRT}}{\mathrm{V}}=\frac{\left(1168 \times 10^{-6}\right)(0.08205)(304.2)}{(2.0205)} \\
P=0.014389 \mathrm{~atm} .=10.94 \mathrm{~mm} . \text { and the pressure of the } O_{2} \text { in the }
\end{gathered}
$$


shock tube is

$$
\mathrm{P}_{\mathrm{O}_{2}}=28 \mathrm{~mm} .-10.94 \mathrm{~mm} .=17.06 \mathrm{~mm} .
$$

The other quantities can now be evaluated.

$$
\frac{\mathrm{O}_{2}}{\mathrm{C}_{5} \mathrm{H}_{12}}=\frac{17.07}{10.94}=1.56 ; \quad \frac{\mathrm{CH}_{3} \mathrm{CHO}}{\mathrm{C}_{5} \mathrm{H}}=0.0071
$$

The peroxides removed from the shock tube in this experiment required $1.11 \mathrm{cc}$. of $0.01 \mathrm{~N} \mathrm{~S}_{2} \mathrm{O}_{3}^{--}$to reach the equivalence point. Since one equivalent of peroxide yields one equivalent of iodine which needs two equivalents of thiosulfate for stoichiometric reaction, the number of

$$
\begin{array}{ll}
\mathrm{ROOH}+2 \mathrm{I}^{-}+2 \mathrm{H}^{+} & \longrightarrow \mathrm{ROH}+\mathrm{H}_{2} \mathrm{O}+\mathrm{I}_{2} \\
\mathrm{I}_{2}+2 \mathrm{~S}_{2} \mathrm{O}_{3}^{--} & \longrightarrow 2 \mathrm{I}^{-}+\mathrm{S}_{4} \mathrm{O}_{6}^{--}
\end{array}
$$

moles of peroxide formed was $5.55 \mu$ moles. The moles of peroxide out per mole of pentane in is

$$
\frac{5.55 \text { moles }}{1168 \text { moles }}=4.75 \times 10^{-3}
$$

To calculate the reaction temperature the heights of the pressure jumps on the oscilloscope trace photographs are measured. They were found to be 1.20 and $2.10 \mathrm{~cm}$. respectively. When these are converted to pressure units, $\mathrm{P}_{2_{1}}$ and $\mathrm{P}_{52}$ can be calculated and hence the reaction temperature can be calculated.

We have in the electronic circuitry the following conversions: 


$$
\frac{4 \mathrm{pcb} .}{1 \mathrm{psi} \cdot} \times \frac{20 \mathrm{mv} .}{1 \mathrm{pcb} \cdot} \times \frac{14.696 \mathrm{psi}}{1 \mathrm{~atm} .} \times \frac{1 \mathrm{v} .}{1000 \mathrm{mv} \cdot}=\frac{1.176 \mathrm{v} .}{1 \mathrm{~atm} .}
$$

The oscilloscope deflection which is calibrated to be $1 \mathrm{~cm}$. deflection per volt is used to convert the measured deflection on the oscilloscope trace into $\mathrm{mm}$. of pressure. Therefore, $1.20 \mathrm{~cm}$. becomes

$\frac{1 \mathrm{~atm} .}{1.176 \mathrm{ve}_{0}} \times \frac{1 \mathrm{v} \cdot}{1 \mathrm{~cm} \cdot} \times(1.20 \mathrm{~cm})=.1.0204 \mathrm{~atm} .=776 \mathrm{~mm}$.

and since $\mathrm{P}_{1}=719 \mathrm{~mm}, \mathrm{P}_{2}=719 \mathrm{~mm}$. $+776 \mathrm{~mm} .=1495 \mathrm{~mm}$. and $\mathrm{P}_{21}=$ 2.079. In a similar manner $2.10 \mathrm{~cm}$. becomes $1360 \mathrm{~mm}$. and $P_{5}=1495$ mm. $+1360 \mathrm{~mm} \cdot=2855 \mathrm{~mm}$. and $P_{52}=1.9096$.

Using Equation (4)

$$
\begin{aligned}
& \mathrm{T}_{21}=\frac{\mathrm{P}_{21}\left(\alpha_{1}+\mathrm{P}_{21}\right)}{1+\sigma_{1} \mathrm{P}_{21}}=\frac{(2.079)(4+2.079)}{1+4(2.079)}=1.5324 \\
& \mathrm{~T}_{2}=(1.5324)\left(304.2^{\circ} \mathrm{K}_{.}\right)=466.2^{\circ} \mathrm{K}_{.}=193.0^{\circ} \mathrm{C} .
\end{aligned}
$$

Using Equation (10)

$$
P_{52}=\frac{\alpha_{1}+2-P_{12}}{1+\alpha_{1} P_{12}}=\frac{4+2-0.481}{1+4(0.481)}=1.8874
$$

Using Equation (11)

$$
\begin{aligned}
& \mathrm{T}_{52}=\frac{\mathrm{P}_{52}\left(\alpha_{1}+\mathrm{P}_{52}\right)}{1+\alpha_{1} \mathrm{P}_{52}}=\frac{1.8874(4+1.8874)}{1+4(1.8874)}=1.299 \\
& \mathrm{~T}_{5}=\left(466.2^{\circ} \mathrm{K}_{0}\right)(1.299)=605.6^{\circ} \mathrm{K} .=332.3^{\circ} \mathrm{C} .
\end{aligned}
$$

II. Chromatographic Analysis

In the portion of this investigation which was concerned with 
analysis of products other than peroxides, the gas chromatograph was the instrument used for analysis. The procedure followed was to initially cool the columns to $-20^{\circ} \mathrm{C}$. or lower with liquid nitrogen and allow the columns to warm back to this temperature. The gas sample to be analyzed was then injected. After the elution of the pentane peak, the columns were temperature programmed at the rate of $3^{\circ} / \mathrm{min}$. to $30^{\circ} \mathrm{C}$.

The other conditions which were generally used for analysis are the following: helium head pressure was maintained at 50 psig, the temperature of the injector was $65^{\circ} \mathrm{C}$., the detector temperature was $145^{\circ} \mathrm{C}$., the DC filament bridge was set at $220 \mathrm{ma}$, and the flow rate of helium gas through the columns was $50 \mathrm{cc} . / \mathrm{min}$.

In Table 11 is tabulated the elution times of the various compounds used in this study. Ones that are not mentioned that have been listed earlier in the text were never determined. Their use was only in syringe addition injections to determine whether or not the compound in question was the added compound. Details concerning this technique have been described on pages 60 and 61 .

The composite chromatogram illustrated in Figure 39 identifies the elution times of the various compounds found during this investigation. The ones that were able to be identified are labeled as such and the unidentified ones are labeled as A, B, C, etc. This lettering corresponds to that in Table 10 under the column headed "comments". 
TABLE 11

RETENTION TIMES OF KNOWN

COMPOUNDS AND PRODUCTS

IN ORDER OF ELUTION

\begin{tabular}{lcc}
\hline Average & $\begin{array}{c}\text { Relative } \\
\text { Retention Time } \\
\text { (min) }\end{array}$ & $\begin{array}{c}\text { Retention Time } \\
\left.\text { (n- }-\mathrm{C}_{512}=1.00\right)\end{array}$ \\
n-pentane & $1: 04$ & 1.00 \\
2-pentene & Unknown & 1.10 \\
Acetaldehyde & $1: 42$ & 1.60 \\
C & $2: 05$ & 1.80 \\
B & $2: 15$ & 1.95 \\
D & $2: 40$ & 2.30 \\
Propanal & $4: 05$ & 3.80 \\
Acetone & $5: 10$ & 4.90 \\
Butanone & $7: 50$ & 7.30 \\
Butana1 & $8: 15$ & 7.70 \\
A & $11: 40$ & 11.00 \\
3-pentanone & $11: 50$ & 11.10 \\
2-pentanone & $12: 30$ & 11.70 \\
Pentanal & $13: 00$ & 12.20 \\
Crotonaldehyde & $12: 50$ & 13.00 \\
& & \\
\hline
\end{tabular}

* In run P-18 when both $\mathrm{A}$ and crotonaldehyde were present, 3-pentanone was added. 3-pentanone eluted 40 seconds after A, and crotona1dehyde 2:20 min. after A. 


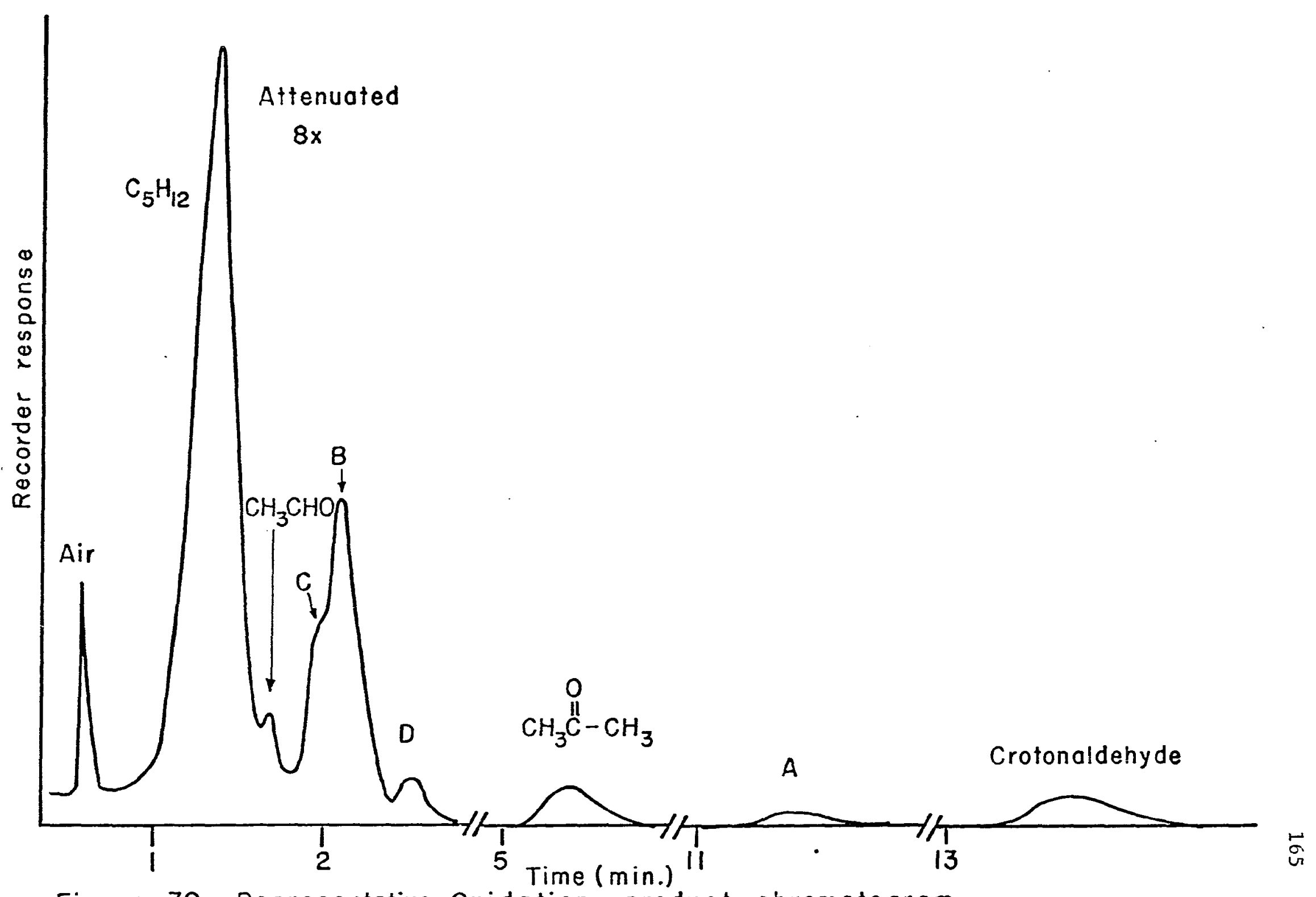

Figure 39. Representative Oxidation product chromatogram. 
C. Tertiary Butylhydroperoxide Addition Experiments

As mentioned in an earlier section, in the tertiary butylhydroperoxide addition experiments approximately $50 \%$ of this peroxide was recovered as unreacted peroxide assuming that it did not interfere with the normal peroxide producing mechanism in the oxidation reaction. The portion that reacted was assumed to have been thermally decomposed into its decomposition products.

The data from the two experiments are shown below in Table 12 . The amount of peroxide produced by the oxidation reaction is calculated using the figure 10.70 moles per mole of pentane, which is the average peroxide production found in the non-addition experiments at $327^{\circ} \mathrm{C}$. and a reaction time of $1.9 \mathrm{msec}$.

\section{Table 12}

Peroxide Formation in Tertiary Butylhydroperoxide Addition Experiments at $327^{\circ} \mathrm{C}$. and a Reaction Time of $1.9 \mathrm{msec}$.

\begin{tabular}{|c|c|c|c|c|c|c|}
\hline \multirow{2}{*}{$\begin{array}{l}\text { Exp. } \\
\text { No. }\end{array}$} & \multirow{2}{*}{$\begin{array}{l}\mathrm{RH} \text { in } \\
\mu \text { moles }\end{array}$} & \multirow{2}{*}{$\begin{array}{l}\text { TEH in } \\
\mu \text { moles }\end{array}$} & \multicolumn{3}{|c|}{ Peroxides out (Mmoles) } & \multirow{2}{*}{$\begin{array}{c}\text { TBH } \\
\% \text { unreacted }\end{array}$} \\
\hline & & & Total & Non-TBH & $\mathrm{TBH}$ & \\
\hline 190 & 1070 & 17.7 & 18.15 & 11.45 & 6.70 & 37.9 \\
\hline 192 & 1168 & 7.75 & 17.30 & 12.49 & 4.81 & 62.1 \\
\hline
\end{tabular}

RH, Pentane; TBH, Tertiary Butylhydroperoxide 


\section{BIBLIOGRAPHY}

10) Backstrom, H. L. J., J. Am. Chem. Soc., 49, 1460 (1927)

63) Bardwe11, J. and Hinshelwood, C. N., Proc. Roy. Soc. (London), A205, 375 (1951)

30) Blosser, P. M., "The Kinetics of the Low-temperature GasPhase Oxidation of n-Pentane in a Static System," Ph. D. dissertation, The Ohio State University (1955)

20) Blyumberg, E. A. and Norikov, Yu. D., Isv. Akad. Nauk S.S.S.R. o. Kh. N. No. $\underline{8}, 1357$ (1962)

11) Bone, W. A., Proc. Roy. Soc. (London), Al37, 243 (1932)

41) Bradley, J. N., Shock Waves in Chemistry and Physics, John Wiley \& Sons, Inc., New York, 1962

42) Bradley, J. N., The Royal Institute of Chemistry (London), Lecture Series 1963, No. 6, "Chemical Applications of the Shock Tube."

40) Carrington, T. and Davidson, N., J. Phys. Chem., 57, 418 (1953)

22) Cartlidge, J. and Tipper, C. F. H., Anal. Chim. Acta., 22, 106 (1960)

26) Cartiledge, J. and Tipper, C. F. H., Proc Roy. Soc. (London), A261, 388 (1961)

32) Chung, Y. H. and Sandler, S., Combustion and Flame, 6295 (1962)

33) Chung, Y, H. and Sandler, S., Combustion and Flame, $\underline{7}$, 339 (1963)

23) Cullis, C. F. and Fersht, E., Combustion and Flame, I, 185 (1963)

24) Davies, A. G., Organic Peroxides, Butterworths, London, 1961

43) Ferri, A., Ed., Fundamental Data Obtain ed from Shock Tube Experiments, Agardograph No. 41, Pergamon Press, New York 1961 
1) Fish, A, Quart. Revs. (London), 18, 243 (1964)

17) Fok, N. V., Bereslavskii, B. B., Nalbandyan, A. B. and Shtern, V. Ya., Dokl. Akad. Nauk SSSR, 67, 499 (1949)

18) Fok, N. V. and Nalbandyan, A. B., Dok1. Akad. Nauk SSSR, 85, 1093 (1952)

16) Fok, N. V. and Nalbandyan, A. B., Dokl. Akad. Nauk SSSR, 89, 125 (1953)

50) Fristrom, R. M., Chem. \& Eng. News, Oct. 14, 1963, pp. 150-160

44) Gaydon, A. G. and Hurle, I. R., The Shock Tube in High Temperature Chemical Physics, Reinhold Publ. Corp., New York, 1963

45) Glass, I. I. and Hall, J. G., Navord Report 1488 (Vol. 6), Handbook of Supersonic Aerodynamics, Section 18, Shock Tubes, U.S. Govt. Printing Office, Washington, 1959

51) Glick, H. S., Squire, W. and Hertzberg, A., Fifth International Symposium on Combustion, Reinhold, New York, 1955, p. 393

53) Glick, H. S., Squire, W. and Klein, J. J., J. Chem. Phys., 27, 850 (1957)

46) Greene, E. F. and Toennies, J. P., Chemical Reactions in Shock Waves, E. Arnold Ltd., London, 1964

25) Hawkins, E. G. E., Organic Peroxides, E. and F. F. Spon Ltd., London, 1961

8) Hinshelwood, C. N., Disc. Faraday Soc., 2, 117 (1947)

15) Knox, J. H., Combustion and Flame, 9, 297 (1965).

57) Kokatnur, V. K. and Jelling, M., J. Am. Chem. Soc., 63, 1432 (1941)

36) Lee, W. E., "A Study of Free Radical Processes in the Chemical Shock Tube," Ph. D. dissertation, The Ohio State University (1959)

35) Malmberg, E. W., Smith, M. L., Bigler, J. E. and Bobbit, J. A., Fifth Internationa1 Symposium on Combustion, Reinhold, New York, 1958, p. 385

52) Mark, H., "On the Interaction of a Reflected Shock Wave with the Boundary Layer in a Shock Tube," Ph. D. dissertation, Cornell University (1957) 
2) Medley, H. D. and Cooley, S. D., "Hydrocarbon Oxidation," in J. J. McKetta, Jr., Ed., Advances in Petroleum Chemistry and Refining, Vol. III, Interscience Publishers, Inc., New York 1960, pp. 309-376

3) Minkhoff, G. J. and Tipper, C. F. H., Chemistry of Combustion Reactions, Butterworths, London, 1960

21) Nalbandyan, A. B. and Kleimenov, N. A., Dok1. Akad. Nauk SSSR, 124, 119 (1959)

61) Newitt, D. M. and Thornes, L. S., J. Chem. Soc., 1656 (1937)

12) Norrish, R. G.W., Proc. Roy. Soc. (London), Al50, 36 (1935)

13) Norrish, R. G. W., Proc. Roy. Soc. (London), A221, 151 (1954)

55) Nozaki, K., Ind. Chem., Anal. Ed., 18, 583 (1946)

62) Oberdorfer, P. E., Dissert. Abst., 20, 2026 (1959)

59) Osborne, A. D. and Skirrow, G., J. Chem. Soc., 2750 (1960)

47) Palmer, H. B., J. Inst. Fuel (London), 34, 359 (1961)

39) Payman, W. and Shepherd, W. C. F., Proc. Roy. Soc. (London), A186, 293 (1946)

60) Pease, R. N., J. Am. Chem. Soc., 51, 1839 (1929)

58) Petry, R. C., "The Products of the Reaction Between Oxygen and Trimethylborane Below the Explosion Limits," Ph. D. dissertation, The Ohio State University (1958)

14) Pope, J. C., Dykstra, E. J. and Edgar, G., J. Am. Chem. Soc., 51, 1875,2203 (1929)

19) Porikova, A. I., Voyevodskii, V. V. and Nalbandyan, A. B., Zh. fiz. Khim,, 33, 1336 (1959)

48) Pritchard, H. 0., Quart. Revs. (London), 14, 46 (1960)

4) Ridge, M. J., Revs. Pure and Appl. Chem. (Australia), $\underline{6}$, 121 (1956)

34) Salooja, K. C., Combustion and Flame, 9, 33 (1965)

27) Salooja, K. C., Combustion and Flame, 9, 219 (1965) 
28) Salooja, K. C., Combustion and Flame, 10, 45 (1966)

31) Sandler, S. and Beech, J. A., Can. J. Chem., 38, 1455 (1960)

29) Seakins, M., Proc. Roy. Soc. (London), A261, 281 (1961)

5) Shtern, V., Ya., The Gas-Phase Oxidation of Hydrocarbons, The Macmillan Company, New York, 1964

54) Strehlow, R. A. and Cohen, A., J. Chem. Phys., 28, 983 (1958)

6) Tipper, C. F. H., Quart. Revs. (London), 11, 313 (1957)

7) Ubbelohde, A. R., Proc Roy. Soc. (London), A152, 354 (1935)

38) Vielle, P., Comp. Rend., 129, 1228 (1899)

9) Walsh, A. D., Trans, Faraday Soc., 42, 269 (1946)

37) Wellman, W. E., "High Temperature Oxidation of Hydrocarbons in the Chemical Shock Tube," Ph. D. dissertation, The Ohio State University (1960)

56) Winter, Paul K., General Motors Corporation, Private Communication, 1942

49) Wright, J. K., Shock Tubes, John Wiley \& Sons, Inc., New York, 1961 